\title{
Vision restoration in photoreceptor-degenerated mice and macaque monkeys using nanowires
}

\section{Ruyi Yang}

Fudan University

\section{Peng Zhao}

Fudan University

\section{Liyang Wang}

Fudan University

Chenli Feng

Fudan University

Chen Peng

Fudan University

\section{Zhexuan Wang}

Fudan University

\section{Yingying Zhang}

East China Normal University

Minqian Shen

Fudan University

Kaiwen Shi

Fudan University

Shi-Jun Weng

Fudan University

\section{Chunqiong Dong}

Fudan University

\section{Yuqing Chen}

Fudan University

\section{Fu Zeng}

Fudan University

Tianyun Zhang

Fudan University

\section{Luoyin Fu}

Fudan University

\section{Ruoxi Ma}

Fudan University 
Huashan Hospital

\section{Su Jiang}

Fudan University

\section{Wendong Xu}

Fudan University

\section{Gang Wang}

Beijing Institute of Basic Medical Sciences

\section{Gengfeng Zheng}

Fudan University https://orcid.org/0000-0002-1803-6955

\section{Aihua Chen}

East China Normal University

\section{Fei Yuan}

Fudan University

\section{Yuanzhi Yuan}

Fudan University

\section{Biao Yan}

Fudan University https://orcid.org/0000-0003-3252-2965

Jiayi Zhang ( $\nabla_{\text {jiayizhang@fudan.edu.cn })}$

Fudan University https://orcid.org/0000-0002-1575-0723

\section{Article}

Keywords:

Posted Date: March 1st, 2022

DOl: https://doi.org/10.21203/rs.3.rs-492941/v2

License: (c) (i) This work is licensed under a Creative Commons Attribution 4.0 International License. Read Full License 
[Submitted as an Article to the editor of Nature Biomedical Engineering]

\section{Vision restoration in photoreceptor-degenerated mice and macaque monkeys using} nanowires

Ruyi Yang ${ }^{l}$, Peng Zhao ${ }^{1}$, Liyang Wangl, Chenli Feng ${ }^{l}$, Chen Peng ${ }^{2}$, Zhexuan Wang ${ }^{l}$, Yingying Zhang ${ }^{3}$, Minqian Shen ${ }^{1}$, Kaiwen Shi', Shijun Weng', Chunqiong Dongl, Yuqing Chen ${ }^{1}$, Fu Zeng', Tianyun Zhang ${ }^{l}$, Luoyin $\mathrm{Fu}^{1}$, Ruoxi $\mathrm{Ma}^{1}$, Fei Wang ${ }^{4}$, Su Jiang', Wendong $\mathrm{Xu}^{4}$, Gang Wang , Gengfeng Zheng', Aihua Chen ${ }^{3}$, Fei Yuan ${ }^{1}$, Yuanzhi Yuan ${ }^{1, *}$, Biao Yan ${ }^{1, *}$, Jiayi Zhang ${ }^{1, *}$

${ }^{1}$ State Key Laboratory of Medical Neurobiology, MOE Frontiers Center for Brain Science, Institutes of Brain Science, Department of Ophthalmology, Zhongshan Hospital, Shanghai Medical College, Fudan University, Shanghai 200032, China.

${ }^{2}$ Laboratory of Advanced Materials, Department of Chemistry, Faculty of Chemistry and Materials Science, Fudan University, Shanghai 200240, China.

${ }^{3}$ Key Laboratory of Brain Functional Genomics (Ministry of Education), East China Normal University, Shanghai 200062, China

${ }^{4}$ Department of Hand Surgery, National Clinical Research Center for Aging and Medicine, Huashan Hospital, Institute of engineering and application technology, Fudan University, Department of Hand and Upper Extremity Surgery, Jing'an District Center Hospital, Shanghai Clinical Medical Center for Limb Function Reconstruction, Shanghai 200040, China.

${ }^{5}$ Center of Brain Sciences, Beijing Institute of Basic Medical Sciences, Beijing 100850, China

The first four authors contributed equally to this work.

*Corresponding authors: Jiayi Zhang, Biao Yan and Yuanzhi Yuan; E-mail addresses: jiayizhang@fudan.edu.cn,biaoyan@fudan.edu.cn, andyuan.yuanzhi@zs-hospital.sh.cn.

\section{Abstract}

Photoreceptor degeneration diseases, such as retinitis pigmentosa and age-related macular degeneration, are major causes of blindness. Photovoltaic devices or materials activates retinal cells in response to light, hence are promising retinal prosthesis in treating blind patients. The restoration of image-forming vision with high sensitivity is the key. Here we demonstrated that Au nanoparticle- 
coated titania $\left(\mathrm{TiO}_{2-\mathrm{x}}\right)$ nanowire $(\mathrm{NW})$ arrays can restore vision in blind mice and non-human primates with photoreceptor degeneration. We first showed that blind mice with subretinal implant of NW arrays were capable of detecting static, moving and flashing objects with low light intensity threshold for 22 months, having a visual acuity of $0.3 \mathrm{cpd}(0.4 \mathrm{cpd}$ in normal mice). Results in chronic in vivo calcium imaging in primary visual cortex (V1) collectively suggested the plastic change in V1 neurons as well as the improvement in visual information encoding for natural images after NW implant. What's more, macaque monkeys with subretinal implant of NW arrays were capable of detecting an LED of $0.5^{\circ}$ in diameter at $10 \mu \mathrm{W} \cdot \mathrm{mm}^{-2}$ in visually-guided saccade experiments. Our findings opened up the possibility to utilize nanomaterials as artificial photoreceptors to ameliorate visual deficits of patients with photoreceptor degeneration.

\section{Introduction}

Photoreceptor degeneration caused by retinitis pigmentosa (RP) or age-related macular degeneration (AMD) has long been a major cause of blindness. Despite the loss of photoreceptors in the retina, the remaining retinal cells as well as their projections to the brain are preserved from the disease. In the past decade, success in treating Leber congenital amaurosis (LCA) using AAVbased treatment has opened up opportunities in gene therapy ${ }^{1,2}$. Recent studies using genetic and stem-cell based strategies have made great progress in providing proof-of-principle evidences to restore light sensitivity in photoreceptor-degenerated mice ${ }^{3-7}$. One clinical study demonstrated that with the help of engineered googles, an RP patient exhibited partial restoration of vision with retinal expression of optogenetic proteins ${ }^{8}$. Challenges are in the restoration of image-forming vision with high sensitivity, as well as biosafety issues ${ }^{9}$.

The multielectrode stimulation devices turn light signals in the external world into patterned electrical currents and stimulate the remaining retinal cells to establish visual perception in blind patients with late-stage photoreceptor-degenerating diseases ${ }^{10}$. Argus II, a device with 60 pixels, received market approval in both Europe and the United States. The epiretinal implant of Argus II enabled blind patients to not only perceive light but also perform certain visual tasks ${ }^{11-13}$, despite issues of limited visual acuity and safety profile in multicenter studies ${ }^{14}$. Similar issues occurred to subretinal implant Alpha AMS 15,16. These early efforts in retinal prosthesis were followed by 
subretinal implant IRIS II with 378-pixel electrical stimulation (each pixel is $100 \mu \mathrm{m}$ in diameter) in the retina ${ }^{17,18}$. With the assistance of video glasses that turns visible light into pulsed near-infrared light, patients achieved better visual acuity than those implanted with Argus II ${ }^{19}$. Neuroprosthesis with multichannel electrical stimulation device implanted intracranially into V1 also enabled form vision in both monkey and human ${ }^{20,21}$, despite a more invasive surgical procedure comparing to retinal prosthesis. Novel materials including organic photovoltaic and injectable nanoparticles provided proof-of-principle evidence for light perception in blind mice and shed light onto the next generation retinal prosthesis with improved surgical procedure and spatial resolution ${ }^{22-25}$. However, unlike semiconductor devices with tunable stimulation current, photoactive materials often exhibit limited light sensitivity.

We previously developed $\mathrm{Au}$ nanoparticle-decorated titania nanowire arrays $\left(\mathrm{Au}-\mathrm{TiO}_{2} \mathrm{NW}\right.$ array), in which each NW was roughly $100 \mathrm{~nm}$ in diameter and $2 \mu \mathrm{m}$ in length, with a similar physical size to photoreceptors. NW array converts UV, blue and green light into photocurrent to activate retinal ganglion cells in retinal degenerated 1 knockout $\left(r d 1^{-/-}\right) /$cone diphtheria toxin subunit-A ( $c D T A)$ blind mice, with light intensity threshold as low as $10 \mu \mathrm{W} \cdot \mathrm{mm}^{-2}$ and a spatial resolution of $100 \mu \mathrm{m}$ in vitro ${ }^{26}$. The performance of the NW array in restoring image-forming vision in vivo, and more importantly, the potential for clinical application, is yet to be evaluated.

In this study, we developed $\mathrm{Au} @ \mathrm{TiO}_{2-\mathrm{x}} \mathrm{NW}$ arrays (referred to as NW array below) with an enhanced UV-visible absorbance profile compared to $\mathrm{Au}-\mathrm{TiO}_{2} \mathrm{NW}$ array. We showed NWimplanted blind mice had a visual acuity of $0.3 \mathrm{cpd}$ and recognized static, moving and flashing objects in the two-choice box, respectively. One important question rarely addressed is the coding of visual information in animals with retinal prosthesis. Interestingly, we found that the number of light-responsive V1 neurons peaked at 1 week post implant surgery, and these light-responsive V1 neurons responded to natural images in a similar way to those in normal mice. These evidence collectively indicate that image-forming vision was restored. Finally, we implanted NW arrays into the subretinal space of macaque monkey and showed that NW arrays have good biocompatibility. Visually-guided saccade to the NW-implanted area suggested the perception of an LED of $0.5^{\circ}$ in diameter at a light intensity as low as $10 \mu \mathrm{W} \cdot \mathrm{mm}^{-2}$. Our study provided evidence for a novel retinal prosthesis material with high sensitivity. 


\section{Results}

\section{Improved photocurrent of $\mathrm{Au} @ \mathrm{TiO}_{2-\mathrm{x}} \mathrm{NW}$ arrays}

The $\mathrm{TiO}_{2-\mathrm{x}} \mathrm{NW}$ arrays were prepared by hydrothermal growth and subsequent thermal annealing in $\mathrm{H}_{2} /$ Ar to create oxygen vacancies. Au nanoparticles were then in situ reduced and deposited on the NW surface to obtained $\mathrm{Au} @ \mathrm{TiO}_{2-\mathrm{x}} \mathrm{NW}$ arrays. The X-ray diffraction (XRD, Extended Data Fig.1a) patten presented two peaks at 36.3 degrees and 63.1 degrees that matched well with rutile $\mathrm{TiO}_{2}(101)$ and (002) planes. The NW arrays were composed of highly-dense single NW arrays with average lengths of $\sim 2.5 \mu \mathrm{m}$ and diameters of $\sim 100 \mathrm{~nm}$ (Extended Data Fig.1b, c). High-resolution transmission electron microscopy (HRTEM) images showed the lattice spacing of the dark nanoparticles and NW arrays were 0.235 and $0.246 \mathrm{~nm}$ (Extended Data Fig.1c and inset), corresponding to cubic-phase $\mathrm{Au}$ (111) planes (JCPDS\# 00-001-1172) and rutile-phase $\mathrm{TiO}_{2}(101)$ planes (JCPDS\# 01-088-1175), respectively. The spherical aberration-corrected HAADF-STEM image (Extended Data Fig.1d) showed the array of bright Ti (highlighted by blue spheres) and dark $\mathrm{O}$ (highlighted by red spheres) contrast on rutile $\mathrm{TiO}_{2}(101)$ planes. The extracted intensity from the yellow dashed line of the fourth O atom greatly decreased (Extended Data Fig.1e), indicating the oxygen vacancies ${ }^{27}$. The existence of oxygen vacancies was further confirmed by $\mathrm{X}$-ray photoelectron spectroscopy (XPS, Extended Data Fig.1f), in which the modified $\mathrm{Au} @ \mathrm{TiO}_{2-\mathrm{x}}$ presented an additional shoulder peak centered at $\sim 532.5 \mathrm{eV}^{28}$.

When illuminated by UV $\left(375 / 28 \mathrm{~nm}, 292.99 \mu \mathrm{W} \cdot \mathrm{mm}^{-2}\right)$, blue $\left(470 / 20 \mathrm{~nm}, 318.47 \mu \mathrm{W} \cdot \mathrm{mm}^{-2}\right)$, green $\left(546 / 12 \mathrm{~nm}, 420.38 \mu \mathrm{W} \cdot \mathrm{mm}^{-2}\right)$ or red $\left(697 / 30 \mathrm{~nm}, 331.21 \mu \mathrm{W} \cdot \mathrm{mm}^{-2}\right)$ light, the average photocurrents of the newly fabricated NW arrays were about 13000, 1300, 1100 and $30 \mathrm{pA}$, respectively (Extended Data Fig.2a-b), which is consistent with its adsorption spectrum (Extended Data Fig.2c). The photocurrents under UV, blue and green light increased by $5 \sim 7$ times compared to those reported in our previous study ${ }^{26}$ (Extended Data Fig.2d).

To confirm that NW arrays elicit light-evoked responses to function as artificial photoreceptors, we utilized $r d 1^{-\digamma} / c D T A$ mice (referred to as blind mice below) whose rod and cone photoreceptors were completely gone by P50 ${ }^{26}$ (referred to as blind mice, Extended Data Fig.2e). Retinal ganglion cells (RGCs) of blind mice retina did not respond to UV, blue or green light. When NW arrays were attached to the blind retina, the RGCs of blind mice were activated by UV, blue or green light, 


\section{Localization of light source in NW-implanted blind mice}

Inspired by multiple visual tests used in human clinical trials with retinal prostheses implant ${ }^{15}$,

30,31, in which patients were asked to recognize various objects in blank background, we designed choice-box-based experiments to assess visual functions in mice. In our choice-box experiments, visual stimuli were delivered as it would naturally occur under natural circumstances.

In a rectangular box, two visual stimuli were projected onto one side of the box, and the opposite side was installed with one water port (Fig.1a). The behavior experiments were consisted of training and testing trials (Fig. 1b). During the training trials, $2 \sim 3$ seconds of random after tone 1 (a preparation cue), visual stimuli were turned on for $20 \mathrm{sec}$ (defined as reaction time). If the mice touched the target area corresponding to the pre-selected visual stimulus (defined in each of the following experiments) within $20 \mathrm{sec}$, the trial was defined as "correct". Tone 2 (a cue for water reward) was provided and the mice received a water reward. If mice did not touch the screen (miss) or touch areas outside the target area (wrong), they would not get a water reward. When the miss rate (percentage of "miss" trials across all trials) becomes less than 50\% for more than 3 days, the behavior paradigm was switched to testing trials, in which reaction time was $10 \mathrm{sec}$ (Fig. 1b). Correct tests $^{26}$. Light localization test was conducted in human subjects implanted with Argus II or AMS alpha. $96 \%$ of patients with Argus II implant and 78\% patients with AMS alpha implant performed statistically better with the device switched on ${ }^{12,31}$. In the choice-box, LEDs with near UV, green or blue light emissions were used as visual stimuli, respectively (Fig.1c). In each trial, one of the two LEDs were turned on. If mice touched the target area $(6 \mathrm{~cm}$ in diameter centered at the on-LED) corresponding to the ON LED, they would receive a water reward (correct) (Extended Data Movie 1). All mice used in the light localization test were over 3 months old. for UV, green and blue light, respectively. The correct rate of blind mice implanted with glass was less than $25 \%$ for all three colors. For blind mice with NW arrays implant, the correct rate was 
significant difference in the correct rate between NW-implanted mice and normal mice when light intensities were above $3.31 \mu \mathrm{W} \cdot \mathrm{mm}^{-2}$ for blue light and $6.75 \mu \mathrm{W} \cdot \mathrm{mm}^{-2}$ for green light (Fig. 1e, f). Interestingly, blind mice with NW arrays implanted for 4 weeks tended to learn faster than those with NW arrays implanted for 1 weeks in the light source localization test (Extended Data Fig.3ad). These data suggested that NW-implanted blind mice were capable of recognizing locations of light sources. Moreover, NW-implanted blind mice were capable of detecting static light that was on for up to $10 \mathrm{sec}$, confirming that image fading was less of a concern in our experiments.

Recent study reported melanopsin-expressing in ipRGC cells contribute to visual responses ${ }^{32}$. We found that the blind mice with glass implanted, in which ipRGCs were presumably functional, had a very low correct rate $(<25 \%)$, suggesting that melanopsin-expressing ipRGCs may not contribute to the localization of light under the light intensities we used in these experiments.

\section{Perception of moving objects in NW-implanted blind mice}

Clinical studies reported that $57 \%$ of patients with Argus II implant and $56 \%$ of patients with AMS alpha implant could detect the motion direction correctly, suggesting that detecting motion is more difficult than localizing light for patients with retinal prosthesis ${ }^{33,34}$. Moving light bars $(9.60$ degrees in width, 6.85 degrees/sec) elicited transient spikes in the RGCs of blind mice retina attached to NW arrays in vitro, but not in the RGCs of blind mice (Fig.2a-f). Interestingly, light bars of 3.84 degree in width elicited the strongest responses in the RGCs of blind mice with NW arrays attached (Fig.2e, f).

We then examined the performance of NW-implanted blind mice in discriminating moving from static light bars in a choice-box-based behavioral test. After finishing light localization test in Fig. 1, mice were trained to touch the target area associated with a moving light bar to be rewarded (Fig.2g, Extended Movie 2). The correct rates of both normal and NW-implanted blind mice were $84.79 \%$ in detecting moving light bars of 5.25 degree wide and 7.85 degrees/sec (Fig. 2h-i, Extended Data Fig.3e), slightly lower than that in light localization test. Similar to normal mice, mice implanted with NW-array were good at detecting moving light bars of $\sim 5$ degree wide (Fig.2i).

In Figure 2d, RGCs of blind mice with NW arrays attached responded to moving light bars with transient spiking activities, indicating that mice are capable of detecting moving objects with fast speed. Indeed, when presented with moving bars between 6.54 degrees/sec and 10.47 
degrees/sec (5.25 degree in width), NW-implanted blind mice showed similar performance with normal mice (Fig.2j). Interestingly, NW-implanted blind mice failed to detect moving bars when the speed was below 6.54 degrees/sec (Fig.2j). These results suggested that NW-implanted blind mice can discriminate moving objects from static ones.

\section{Perception of flashing light in NW-implanted blind mice}

The patients with PRIMA implant reported persistent perception of flickering when stimulation frequencies were from 3 to $10 \mathrm{~Hz}$, and flickering disappeared when the frequency was larger than $60 \mathrm{~Hz}^{19}$. As reported in our previous study ${ }^{26}, \sim 30 \% \mathrm{RGCs}$ exhibited sustained firing in response to 1-sec light stimulation and $\sim 70 \%$ RGCs responded transiently to light stimuli, indicating that RGCs exhibited diverse temporal features in response to light ${ }^{26}$. In this study, we first examined the temporal resolution in RGCs of blind mice retina attached to NW arrays (Fig.3a). RGCs of both normal retina and NW arrays-attached blind retina responded to each flash faithfully at $1.25 \mathrm{~Hz}$ (Fig.3b-d). When stimulated by flashlight of $0.5 \mathrm{~Hz} \sim 5 \mathrm{~Hz}$, at the firing rate and fraction of responses were similar between RGCs in normal and NW arrays-attached blind retina (Fig.3e, f).

To evaluate the temporal resolution of NW-implanted blind mice, mice were trained to touch the target area associated with flashing light (Fig.3g, Extended Data Fig.3f, Extended Movie 3). All mice were used in the light localization and moving object detection tests. Blind mice with NWimplant showed similar performance as normal mice at 2 to $3.3 \mathrm{~Hz}$ (Fig. $3 \mathrm{~h}-\mathrm{i}$ ). When the frequency of flash stimulation was either larger than $5 \mathrm{~Hz}$ or smaller than $1 \mathrm{~Hz}$, the correct rate of NWimplanted blind mice was slightly smaller than that of normal mice, but still significantly higher than that of blind mice (Fig.3i).

After mice finished light localization, moving object and flashing light detection tests $(22$ months after implant), we examined the histology of their retinae by immunostaining the retinal cells at the implant site. The retinal ganglion cells (labeled by Brn3a), bipolar cells (labeled by PKC$\alpha$ ) and amacrine cells (labeled by HPC) did not exhibit differences from those in normal (Fig.3j). In addition, microglia cells (labeled by Iba1) were not activated. These data suggested NW arrays exhibited favorable biocompatibility in mice. 
Visual acuity and contrast sensitivity are the gold standards for clinical assessment of visual functions. Visual acuity is associated with the ability to resolve fine details and critical to pattern recognition, while contrast sensitivity is associated with the ability to distinguish subjects from background ${ }^{35}$. Previous clinical studies used Landolt C-rings to measure visual acuity in patients with retinal prostheses implant, and the best recorded visual acuity was 20/1260, 20/546 and 20/460 by Argus II, AMS alpha and PRIMA, respectively ${ }^{19,33,34}$. To our knowledge, contrast sensitivity was not measured in any of the retinal prosthesis in clinical trials. In recent studies, the researchers used reprogramming techniques to recover youthful epigenetic information to restore the function of RGCs in the mice with glaucoma and the visual acuity increased from 0.20 to $0.27 \mathrm{cpd}^{6}$.

To examine visual acuity and contrast sensitivity in NW arrays-implanted blind mice, we conducted an optomotor test (Fig.4a, Extended Movie 4). All mice used in visual acuity and contrast sensitivity test were over 11 months old. NW arrays were implanted into blind mice for more than 9 months. In normal mice, the peak of contrast sensitivity was $0.1 \mathrm{cpd}$, and the average observed contrast sensitivity was 30 (or $3.3 \%$ contrast) (Fig.4b, c). The visual acuity of normal mice was $0.424 \pm 0.012 \mathrm{cpd}$, which was consistent with previous reports ${ }^{36,37}$. We did not observe any optomotor response in blind mice. The average contrast sensitivity of NW-implanted blind mice was 5 (or $20 \%$ contrast) and the contrast sensitivity peak was at $0.05 \mathrm{cpd}$. The visual acuity of NW -implanted blind mice was $0.313 \pm 0.015 \mathrm{cpd}$ (Fig.4b, c), with significant improvement from blind mice.

Previous studies found that sizes of receptive field are smaller where visual acuity is higher near the foveal region of the cortex in human ${ }^{38}$. To measure the size of the receptive field in V1 neurons of NW-implanted blind mice, we conducted two-photon calcium imaging in vivo (Fig.4d). It was previously known that the dorsal nasal retina (where we implanted NW arrays) retinotopically project to medial $\mathrm{V} 1{ }^{39,40}$. We first confirmed the retinotopic projection from the retina to $\mathrm{V} 1$ by injecting DiI in the dorsal nasal retina and CTB 488 in medial V1. Indeed, DiI and CTB 488 signals overlapped in the dorsal lateral geniculate nucleus (Extended Data Fig.4). GCaMP6s were largely expressed in V1 neurons (Fig.4e). Receptive fields of neurons in V1 were mapped using a flashing blue square on a black background and calculated based on calcium signals after Gaussian fitting

(Fig.4f-g). The average size of receptive fields in V1 neurons in normal mice was $233 \pm 20 \mathrm{deg}^{2}$, which was similar to previous studies ${ }^{41,42}$. The average size of receptive fields in V1 neurons was 
$403 \pm 86 \mathrm{deg}^{2}$ in blind mice with NW arrays implant (Fig.4h-i).

While drifting gratings used in the visual acuity experiment can be easily parameterized, natural scenes are ethologically more relevant. We measured the neuronal responses in V1 to natural scenes (Fig.4j-k). Fraction of natural-scene-responsive neurons was $72.36 \%$ and $16.69 \%$ in normal mice and blind mice, respectively. In NW arrays-implanted blind mice, fraction of natural-sceneresponsive neurons (56.71\%) was significantly larger than that in blind mice (Fig.41). The patterns in population response exhibited a similar pattern between normal mice and NW-implanted blind mice (Fig.4k). Previous studies found that natural scenes can be efficiently represented by sparse coding in V1 neurons ${ }^{43,44}$. Responsive selectivity to different stimulus conditions is quantified by lifetime sparseness ${ }^{43,45,46}$. Neurons in NW-implanted blind mice had an average lifetime sparseness of 0.54 , similar to that in normal mice $(0.61)$ (Fig.4m). Together with results from the visual acuity and contrast sensitivity test, features of receptive fields and responses to natural scenes in V1 neurons in NW-implanted blind mice collectively indicated that image-forming vision was largely restored in these mice.

\section{Long-term light-evoked responses in V1 neurons of NW-implanted blind mice}

Results from behavior experiments showed that mice implanted with NW were capable of conducting visual tasks for up to 9 months. Next, we aimed to investigate whether NW arrays elicited reliable light responses in V1 neurons over a long period of time. All mice used for twophoton recording were more than 4 months old. We conducted long-term two-photon recording via a glass cranial window (Extended Data Fig.5a) over V1 to continuously record activities from the same neuronal population $3,5,7,14,21,28,35,42,49,56,63,70,77$ and 84 days after NW arrays implantation (Fig.5b, Extended Data Fig.5c, e, Extended Movie 5). The total number of recorded neurons did not show significant difference over time (Extended Data Fig.5b). 4 representative neurons were recorded throughout the entire recording period, among which 2 neurons started to respond to light one month after implantation and remained responsive 84 days after implantation (Fig.5c), while 2 other neurons stopped to respond to light one month after implant (Fig.5d). Before NW arrays implantation, V1 neurons in blind mice rarely respond to light (in comparison to normal mice, Fig.5e). $26.13 \%$ and $30.24 \%$ of these neurons exhibited light-evoked responses 5 and 7 days after implant surgery (Fig.5e). The changes in fluorescence $\left(\Delta \mathrm{F} / \mathrm{F}_{0}\right)$ of 28 representative light- 
responsive neurons in two mice confirmed NW-array-mediated light responses (Extended Data Fig.5d, f). The fraction of light-responsive V1 neurons in NW arrays-implanted blind were significantly larger than that before implant surgery throughout 84 days of recording (Fig.5f). Note that the fraction of V1 neurons that responded to natural scenes (Fig. 41) was much larger than that responded to flashing light, consistent with previous report ${ }^{46}$.

Interestingly, the fraction of light-responsive neurons peaked around 1 week after NW arrays implantation (Fig.5f). The average amplitude of calcium signals gradually increased over time while the latency of light responses decreased over time (Fig. $5 \mathrm{~g}, \mathrm{~h}$ ), indicating that neurons in V1 exhibited improvement in reliable coding of visual stimulus. These observations were consistent with previous studies, showing that the visual system can retain considerable plasticity beyond critical periods after blindness ${ }^{47}$.

\section{NW exhibited good biocompatibility and stability in macaque monkey}

Long-term electrophysiological and behavioral experiments in NW-arrays implanted blind mice provided good prospects for translational study (Fig.1-5). Eyeballs of mice is much smaller than that of primates. More importantly, unlike primates, rodents have no fovea. We first conducted photocoagulation on the fovea and perifovea area in the right eye of a macaque monkey (named A) to induce focal photoreceptors degeneration (Fig.6a). Due to the COVID-19 pandemic, we were not able to conduct the implant surgery until 11 months after photocoagulation, when the presence of scar tissue in the photocoagulated area was not optimal for implant surgery. Instead of conducting surgery on the photocoagulated area, we identified an intact perifovea area to conduct implant surgery (indicated by the white arrow in Fig.6a).

Retinal prosthesis devices were implanted into a few mm sclerotomy following a 23 -gauge vitrectomy ${ }^{17}$. One advantage of our study is that the NW-arrays implants can be cut into small pieces of customized sizes and remain functioning, due to the fact that light spots as small as $50 \mu \mathrm{m}$ elicited responses in RGCs ${ }^{26}$. To minimize the surgical trauma on the sclera and retina, NW arrays were cut into $0.40 \mathrm{~mm} \times 1.80 \mathrm{~mm}$ pieces to be fit into the 23 -gauge trocars for vitrectomy. We anesthetized Monkey A, performed vitrectomy, and detached the retina by subretinal injection of balanced salt solution (Lactated Ringer's solution), and made a retinotomy $3 \mathrm{~mm}$ in diameter. We delivered NW arrays through 23-gauge trocars using forceps and 8 pieces of NW arrays were 
subretinally inserted. Finally, we injected perfluoro-decalin liquid over the NW arrays to stabilize the implant and injected silicone oil into the vitreous cavity to support retinal reattachment. Photocoagulations were conducted to seal the opening in the retina from retinotomy (indicated by green arrows in Fig.6a).

Color fundus photography taken 4 days, $3,4,6$, and 8 weeks after implant surgery showed that NW arrays stayed in place (Fig.6a). Optical coherence tomography showed that the retina and NW arrays were in close contact throughout 8 weeks after implantation (Fig.6b). There were no significant changes in RPE cells in autofluorescence images (Fig.6c). Red-free fundus photography indicated no vascular abnormality in the retina and surrounding tissue after NW arrays implant (Fig.6d). These data suggested that NW arrays were stable in subretinal space and had good biocompatibility in the macaque monkey.

\section{Visual stimulation elicited saccade behavior in macaque monkey with NW implant}

To examine whether NW arrays induced light-evoked responses in Monkey A, we conducted a monocular visually-guided saccade (VGS) behavioral test (Fig.7a). The non-surgical (left) eye was covered by eyeshade. Monkey A was trained to fixate at the central fixation point $\left(0.5^{\circ} \times 0.5^{\circ}\right)$ at the beginning of the task (Extended Data Fig.6a). A target point $\left(0.5^{\circ} \times 0.5^{\circ}\right)$ appeared $1 \mathrm{sec}$ later. When Monkey A shift its gaze from the central fixation into the target area (defined as a 15-degree circular region surrounding the target points, Extended Data Fig.6b) within 1 sec, the trial was defined as a correct trial.

Since NW arrays generate photocurrent upon UV, blue and green, but not red-light stimulation, we used red LED to map out the visual field as control. NW arrays were implanted at polar angle of 200 to 250 degrees with eccentricity of 19 and 21 degrees (Fig. 7b). The hit rate (number of correct trials divided by all trials) for red light decreased from $56.7 \% 5$ to 7 weeks after implant surgery to $35.7 \%$ in 10 to 12 weeks after implantation. In 14 to 15 weeks after implantation, the hit rate for red light was $12 \%$ (Extended Movie 6). A recent study indicated that subretinal implant of prosthetic device induced photoreceptor degeneration ${ }^{17}$, consistent with our results. To confirm that Monkey A was capable of conducting VGS task, the hit rate was more than $80 \%$ with red light stimuli (642/18 $\mathrm{nm}, 10 \mu \mathrm{W} \cdot \mathrm{mm}^{-2}$ ) in the normal region (Fig.7c, Fig.7e, Extended Data Fig.6c-i, Extended Data Table 2). 
To examine the NW-arrays-mediated light responses, we used blue and UV LED light to stimulate the NW-implanted area (Extended Movie 7). Note that the intensity of UV light we used was lower than that reported for solar light in the late summer afternoon in previous studies and also much lower than the known damaging thresholds of UV $\left(30 \mu \mathrm{W} \cdot \mathrm{mm}^{-2}\right)$ for the corneal endothelium, lens, and retina ${ }^{48}$. The hit rate for blue or UV light was much larger than that for red light $14 \sim 15$ weeks after implantation (Fig.7d, Extended Data Table 2). When using red light stimulation, 95.58\% of the endpoints were outside the target area, whereas when stimulating with ultraviolet or blue light, $80.28 \%$ of the endpoints located within the target area (Fig.7e-f). The mean hit rates elicited by blue and UV light were $72.5 \%$ and $74 \%$ respectively at $10.00 \mu \mathrm{W} \cdot \mathrm{mm}^{-2}$ (Fig. $7 \mathrm{~g}$ ). When the light intensity was $1.82 \mu \mathrm{W} \cdot \mathrm{mm}^{-2}$ for blue light or $0.45 \mu \mathrm{W} \cdot \mathrm{mm}^{-2}$ for UV light, the hit rate fell below $40 \%$. These results indicated that stimulating NW arrays by blue or UV light-induced saccade behavior in a nonhuman primate, rescuing light responses in photoreceptor-degenerated area.

\section{Discussion}

$\mathrm{TiO}_{2}$ is one of the most reported inorganic semiconductors, of which the synthesis method and the working principle have been well established. It possesses the advantages of non-toxic, high stability and low-cost. In addition, it can enable adsorption for wide-range wavelength light by tuning the bandgap via Au decoration and oxygen vacancy introduction. In this study, we demonstrated a NW-array based retinal prosthetic device with high sensitivity. After improving the fabrication process in the NW arrays from our previous study ${ }^{26}$, the light intensity threshold to elicit a perceptual response is $\sim \mu \mathrm{W} \cdot \mathrm{mm}^{-2}$ in both mice and macaque monkey. The intensity of UV light stimulation in our study was lower than that for solar light in the late summer afternoon and much lower than the known damage thresholds of UV $\left(30 \mu \mathrm{W} \cdot \mathrm{mm}^{-2}\right)$ for the corneal endothelium, lens, and retina ${ }^{48}$. Although a recent study reported activation of retinal and V1 cells in the order of $\mu \mathrm{W} \cdot \mathrm{mm}^{-2}$ using Channelrhodopsin variant, no behavioral evidence with low irradiance was presented ${ }^{50}$. Hence, to the best of our knowledge, our NW array is among the state-of-art retinal prosthetics with very high light sensitivity. Augmentation strategies such as video googles with light amplification function ${ }^{8,53}$ may further help enhance visual responses in dark environment. 
subretinal implant alpha-IMS, even though a grating acuity of $3 \mathrm{cpd}$ was reported in one patient, the majority of patients had low acuity and were not able to read ${ }^{31}$. In a photovoltaic Prima implant, the restored spatial resolution measured by visually evoked potentials (VEPs) in the visual cortex was $0.47 \mathrm{cpd}$ in rats ${ }^{18}$. In our study, the NW-array-implanted blind mice were capable of detecting moving light bars with a spatial resolution of $0.313 \mathrm{cpd}$. A high-density NW arrays ${ }^{22}$ could potentially pave the way for restored vision with better spatial resolution.

Due to the capacitance effect, $\mathrm{TiO}_{2}$ nanowires exhibit longer durations of photocurrents, consisted of transient Capacitive current and sustained Faradaic current, than conventional semiconductors such as silicon (see Extended Data Table 1). In our previous study, we reported both $\mathrm{ON}$-sustained and ON-transient responses in the RGCs recordings ${ }^{26}$, indicating that ON-sustained neurons may be responsible for static image perception while ON-transient neurons may be responsible for image changes (low frequency) and flicker fusion (20 Hz and above). In in vitro experiments in mice, we found that NW arrays elicited reliable responses at $3 \mathrm{~Hz}$ and below in ONtransient RGCs. In behavior experiments, NW-implanted blind mice also exhibited behavioral responses at $3 \mathrm{~Hz}$ and below. These results indicate that $\mathrm{NW}$-array-mediated image-forming vision enables the perception of slow images changes at $3 \mathrm{~Hz}$, with compensation in flicker fusion. with NW array implant, saccade experiments in macaque monkeys suggest that in-situ photoreceptors degenerate at the implant site, which is also observed in other subretinal prosthesis in primates ${ }^{53}$. For clinical applications, NW array and other subretinal implant are suitable for patients with complete loss of photoreceptors, including late-stage RP and geographic atrophy ${ }^{19}$. Moreover, subretinal implants are in principle compatible with optogenetic therapy and other restoration methods that delays the degeneration of photoreceptors.

One intriguing observation from our data is the transiently enhanced responses during the first week post implant together with continuously improving response reliability in the visual cortex of blind mice. Interestingly, in the blind patients with Alpha AMS subretinal implant, the performance in grating detection 3 months after the implant was better than that 2 months after implant ${ }^{16}$. Together, these results indicated that even in adults who are well beyond the age of the critical period, the sensory cortex retains certain levels of plasticity, which potentially leads to the functional rewiring of the visual cortex and improved visual function. 


\section{Synthesis of $\mathrm{TiO}_{2-\mathrm{x}} \mathrm{NW}$ and $\mathrm{Au} @ \mathrm{TiO}_{2-\mathrm{x}} \mathrm{NW}$ arrays}

In a typical synthesis, $0.5 \mathrm{~mL}$ tetrabutyl titanate (TBOT) was added into the mixture solution of $15 \mathrm{~mL}$ deionized water and $13 \mathrm{~mL}$ hydrochloric acid $(\mathrm{HCl})$. This stirred to form a transparent solution and fluorine-doped tin oxide (FTO) which coated with hydrophilic surface on glass subtrate were transferred into a 50-mL Teflon-lined stainless-steel autoclave, and heated to $150^{\circ} \mathrm{C}$ for 12 hours. Then it was annealed at $550^{\circ} \mathrm{C}$ for 3 hours with a heating rate of $5^{\circ} \mathrm{C}$ per minute in the air. This as-synthesized $\mathrm{TiO}_{2}$ was further annealed under $350{ }^{\circ} \mathrm{C}$ in $5 \% \mathrm{H}_{2} / \mathrm{Ar}$ atmosphere for 8 hours, with a flowing rate of $150 \sim 200$ standard cubic centimeters per minute $(\mathrm{sccm})$ to obtain the $\mathrm{TiO}_{2-\mathrm{x}} \mathrm{NW}$ arrays with oxygen vacancies. Afterwards, Au nanoparticles were coated on the $\mathrm{TiO}_{2} \mathrm{NW}$ arrays. In brief, the FTO substrate with $\mathrm{TiO}_{2-\mathrm{x}} \mathrm{NWs}$ was immersed into the $0.01 \mathrm{M} \mathrm{HAuCl}_{4}$ aqueous solution. In such solution, the $\mathrm{pH}$ value was tuned to $\sim 4.5$ by adding 0.2 $\mathrm{M} \mathrm{NaOH}$ aqueous solution. After incubating for 2 hours, the FTO substrate was taken out, dried and annealed under $300^{\circ} \mathrm{C}$ for 2 hours with a heating rate of $5{ }^{\circ} \mathrm{C}$ per minute in the $\mathrm{Ar}$ atmosphere . Finally, the FTO substrate was etched at $85^{\circ} \mathrm{C}$ in a mixed solution of $\mathrm{H}_{2} \mathrm{SO}_{4} / \mathrm{HF}(40 \mathrm{wt} \%)$ under the ratio of 13:2.

\section{Photocurrent measurement}

The photocurrent measurement was carried out using a setup consisting of a Zeiss upright DIC microscope (Examiner A1, Zeiss, Germany) and a 3-electrode system. The Au@ $@ \mathrm{TiO}_{2-\mathrm{x}} \mathrm{NW}$ arrays photoanode, a coiled $\mathrm{Pt}$ wire and $\mathrm{an} \mathrm{Ag} / \mathrm{AgCl}$ were used as working, counter and reference electrodes, respectively. A phosphate buffer saline (PBS, pH 7.4) was used as the electrolytes. A glass pipette (resistance within $4.8 \sim 5.2 \mathrm{M} \Omega$ ) filled with phosphate buffer saline was attached to the NW arrays and record its photocurrent. Near UV, blue and green light were generated from the mercury lamp (X-Cite 120, Lumen Dynamics, USA), filtered by fluorescence cubes (UV: 375/28 $\mathrm{nm}$; Blue: $470 / 20 \mathrm{~nm}$; Green: 546/12 nm, Zeiss Inc., Germany) and proved through the $\times 40$ waterimmersion objective. 
Mice were raised and bred at $23 \pm 2{ }^{\circ} \mathrm{C}$ room temperature, $60 \sim 65 \%$ relative humidity, and a $12 \mathrm{~h}$ light/12 h dark cycle. The wild-type (C57BL/6J) mice were purchased from the Slac Laboratory Animal Co. (Shanghai, China). Homozygous $r d 1^{-/}$and cone diphtheria toxin subunit-A (cone-DTA) positive mice ( $r d 1^{-/} / c D T A$ mice) were genotyped using protocols described in our previous work ${ }^{26}$. Details about age were reported in corresponding section of Results. The experimental procedures for mice was approved by the Animal Ethics Committee of School of Basic Medical Sciences at Fudan University.

One male rhesus monkey (Macaca mulatta) aging 12 years old and weighing 8 kilograms (in East China Normal University, Shanghai) was used in this study. The experimental procedures for macaque monkey was approved by the Institutional Animal Care and Use Committee at East China Normal University.

\section{Patch-clamp recording of retinal ganglion cells in mice retina}

Mice were anesthetized with isoflurane $(1 \sim 2 \%$ at $0.5 \sim 1.0 \mathrm{~L} / \mathrm{min})$. Enucleation was conducted on one eye, which was quickly placed in oxygenated Ranger's solution (in mM, $\mathrm{NaCl}$ 124, $\mathrm{KCl} 2.5, \mathrm{CaCl}_{2} 2, \mathrm{MgCl}_{2} 2, \mathrm{NaH}_{2} \mathrm{PO}_{4}$ 1.25, $\mathrm{NaHCO}_{3}$ 26, and glucose 22, pH 7.35; oxygenated with $95 \% \mathrm{O}_{2}$ and $5 \% \mathrm{CO}_{2}$ ). The retina was dissected and placed on a filter paper (Merck Millipore, Burlington, USA) in the recording chamber. Subsequently, NW arrays were attached to the inner nuclear layer of the blind retina. A Glass pipette (resistance: $5 \sim 10 \mathrm{M} \Omega$ ) was pulled by P-97 micropipette puller (Sutter Instruments, Novato, USA) and filled with internal solution (in mM, potassium gluconate $105, \mathrm{KCl} 5, \mathrm{CaCl}_{2}$ 0.5, $\mathrm{MgCl}_{2}$ 2, EGTA 5, HEPES 10, Mg-ATP 4, GTP-Na 0.5 , and sodium phosphocreatine $7, \mathrm{PH}=7.4)$. An in vitro patch clamp system was used to record action potentials of RGCs using MultiClamp 700B patch-clamp amplifier (Molecular Devices, San Jose, USA) and digitizer Digidata 1440 (Molecular Devices, San Jose, USA) under DIC microscope (Zeiss, Oberkochen, Germany) ${ }^{54}$.

Visual stimuli were provided by mercury lamp (X-Cite 120PC Q, LUMEN DYNAMICS, Ontario, Canada) and Digital Micromirror Device (DMD) (wavelength: $400 \mathrm{~nm}$ ). To investigate the response of RGCs to light with different wavelengths, UV, blue or green light was presented by mercury lamp and delivered via a $\times 40$ water-immersive objective. DMD was used to present 
times in $30 \mathrm{sec}$, while static light bar remained on for $30 \mathrm{sec}$. Different widths of the moving light $\operatorname{bar}(0.64,1.28,1.92,2.56,3.20$ and 3.84 degrees $)$ were used to examine the spatial resolution of the RGCs. Different temporal frequencies $(5.00,2.5,1.57,1.25,1.00$ and $0.5 \mathrm{~Hz})$ of flashing stimuli (area:5.76 $\times 5.76 \mathrm{deg}^{2}$ ) were used to examine the temporal resolution of the RGCs.

Clampfit (Axon, Scottsdale, USA) was used to analyze the action potentials of RGCs and Prism 6 (Graph pad, San Diego, USA) was used to analyze firing rates and fraction of responses. Firing rate was the number of action potentials during visual stimulation. Fraction of responses was the number of trials which elicited action potentials divided by 10 (visual stimuli).

\section{NW array implant surgery in mice}

The $r d 1^{-/ / c D T A}$ mice (blind mice) aged 8 to 10 weeks were anesthetized with isoflurane $(1 \sim$ $2 \%$ at $0.5 \sim 1.0 \mathrm{~L} / \mathrm{min}$ ). The eye-ball was fixed in a suitable position for implantation by suturing the upper and lower eyelids. A small incision was made on the dorsal sclera. $1 \sim 2 \mu \mathrm{L}$ of $0.9 \%$ sodium chloride solution was injected rapidly and carefully with NanoJectII (Drummond Scientific Company, USA) to induce retinal detachment. The incision was further expanded to make enough space for the NW array implant, which were inserted carefully into the incision. After the implant, the suture was removed and the eye-ball was washed with $0.9 \%$ saline solution, and applied with erythromycin eye ointment. The area of NW arrays was $0.5 \sim 1 \mathrm{~mm}^{2}$ and the NW arrays were sterilized with autoclave before implanted.

\section{Choice-box-based Behavioral Test}

The choice-box $(240 \mathrm{~mm} \times 240 \mathrm{~mm} \times 180 \mathrm{~mm})$ was customized using acrylic sheets, containing a water delivery system (Kamoer, Shanghai, China, composed of water pipe, water port, and water pump) and an audio signal system (a buzzer positioned in the middle of the choice-box lid). Visual stimuli were placed at two positions (12 cm apart). Light intensity of all visual stimuli in this behavioral task was measured at a distance of $6 \mathrm{~cm}$ away from the light source. Visual stimuli, water delivery system and the audio signal system were all controlled by Arduino.

Choice-box-based behavior test was divided into training trials and testing trials ${ }^{55}$. Mice were water restricted 3 days before the training trials. During the training trials, mice were allowed to explore the choice box freely for $5 \sim 10 \mathrm{~min}$ before the test starts. Trial started by cueing with audio 
signal (tone 1). After 2 to 3 seconds delay, the visual stimulus appeared randomly at one of the two visual stimulation locations. The stimulation duration and reaction time are both $20 \mathrm{sec}$. The mice were trained to touch the target area (defined by a circle centered at the LED with a diameter of 6 $\mathrm{cm}$ in light localization test) associated with the right visual stimuli either by their paws or noses. If the mice picked the right visual stimuli within the reaction time, another audio signal (tone 2) by the buzzer will be given and the mice were able to obtain water reward at the water port (defined as a correct trial). If the mice failed to touch the visual stimulation region within reaction time, the trial was defined as a miss trial and audio cue and water reward would also not be provided. If the mice touched area outside the right visual stimuli region on the screen within reaction time, the trial was defined as a wrong trial and audio cue and water reward would also not be provided. The next trial would start when the mice stayed away from the visual stimulation region. The interval of each trial was at least $10 \mathrm{sec}$, and 40 trials were carried out daily.

Testing phase would start when the correct rate of $r d 1^{-/ / c D T A}$ mice implanted with $\mathrm{Au} @ \mathrm{TiO}_{2-}$ ${ }_{\mathrm{x}} \mathrm{NW}$ arrays reached $70 \%$ and maintains stability for 3 days. The protocols used in testing phase was similar to that in the training phase, except that the stimulation duration and the reaction time were reduced to $10 \mathrm{sec}$, and the interval between each trial was at least $5 \mathrm{sec}$.

In the light localization test, LED light with different wavelengths and light intensities was used. LED visual stimuli appeared randomly at one of two visual stimulation locations. In the testing phase, UV LED light $\left(375 / 15 \mathrm{~nm}, 6.24 \mu \mathrm{W} \cdot \mathrm{mm}^{-2}\right)$, blue LED light $(465 / 25 \mathrm{~nm}$, light intensities: 6.75, 3.31, 2.93, 1.53 and $\left.0.64 \mu \mathrm{W} \cdot \mathrm{mm}^{-2}\right)$, and green LED light $(535 / 28 \mathrm{~nm}$, light intensities: 7.83 , $4.20,2.04$, and $1.15 \mu \mathrm{W} \cdot \mathrm{mm}^{-2}$ ) were used.

In the experiment of discriminating moving and static light bar, the visual stimulus was presented by the projector (CB-S41, EPSON, Suwa Japan). A moving light bar stimulus appeared randomly at one of the two visual stimulation locations, and a static light bar stimulus appeared at the other position simultaneously. Mice would be rewarded with water if they touched the target area associated with the moving light bar. In the testing phase, static or moving light bar stimulus with different widths (widths: 2.63, 3.94, 5.25, 6.57, and 7.88 degrees, velocity: 7.85 degrees/sec) and velocities (velocities: 5.23, 6.54, 7.85, 9.18, and 10.47 degrees/sec, width: 5.25 degrees) were used. 
In the experiment of discriminating flash stimulus and constantly bright stimulus, the visual stimulus was also presented by the projector (CB-S41, EPSON, Suwa, Japan). A flashing stimulus

$509(6 \mathrm{~cm} \times 6 \mathrm{~cm}$ square $)$ appeared at one of the two positions randomly in the visual stimulation region, and an ON stimulus appeared at the other position simultaneously. Mice would be rewarded with water if they touched the target area associated with the flashing stimulus. In the testing phase, temporal frequencies of $1,1.25,2,3.33$ and $5 \mathrm{~Hz}$ were used for the flash stimulus.

\section{Visual acuity and contrast sensitivity measurement}

To measure the visual acuity and contrast sensitivity, we designed a system with 4 LCD monitors arranged in a quadrangle with a camera installed above the system for video recording. Visual stimulus (drifting black and white gratings, 12 degree/sec) was generated by Python, using the Psychopy toolbox ${ }^{56}$. The direction of drifting gratings was switched between clockwise and counterclockwise. Each direction lasted for $10 \mathrm{sec}$ and repeated for 3 times. One day before testing, each mouse was habituated staying on the pedestal (height: $12 \mathrm{~cm}$, radius: $4 \mathrm{~cm}$ ) for several minutes. On the day of testing, each mouse was placed on the pedestal and allowed to move freely. If the mouse slipped or jumped off the pedestal, the testing was terminated and resumed.

Gray background was presented on the screen at the beginning of each session. When the mouse stopped moving, the gray background was replaced with drifting grating with the mean luminance at $100 \%$ contrast and the spatial frequency at 0.1 cycle/degree. After unambiguous tracking behavior was observed, the spatial frequency was increased 0.05 cycle/degree in the next successive trials until the mouse ceased to track the stimulus. The highest spatial frequency of drifting grating that the mouse could track was identified as the visual acuity.

In contrast sensitivity test, gray background was presented on the screen at the beginning of each session and was replaced with drifting grating when the mouse stopped moving. The test started with a grating of $100 \%$ contrast at a fixed spatial frequency, and the contrast was reduced by $10 \%$ in each step in the next successive trials until the mouse ceased to track the stimulus, and the contrast threshold was identified. The contrast threshold was identified at eight spatial frequencies between 
Mice were deeply anesthetized using overdose isoflurane for euthanasia and perfused transcardially with physiological saline, followed by $4 \%$ paraformaldehyde (PFA) using a perfusion pump. For immunohistochemistry of mic brain, they were kept in $4 \%$ PFA for fixation at $4{ }^{\circ} \mathrm{C}$ overnight and then dehydrated in 30\% sucrose. After being embedded and frozen, brains tissue was sectioned into 30- $\mu \mathrm{m}$ coronal slices in a cryostat (Leica CM 1950, Leica, Wetzlar, Germany). The slices were washed with Tris-buffered saline (TBS) 5 times (5 minutes each), covered with coverslips and mounted to be photograph by a fluorescence microscope (A1R, Nikon, Tokyo, Japan).

With regard to immunohistochemistry of mice retina, eyes was enucleated and the retina was dissected and fixed in $4 \%$ PFA for $4 \sim 7$ hours at $4^{\circ} \mathrm{C}$. Then the retina was dehydrated using $10 \%$, $20 \%$ and $30 \%$ sucrose solution respectively. After dehydration, the retina was embedded in optimal cutting temperature compound $(\mathrm{OCT})$ compound at $-80^{\circ} \mathrm{C}$ for more than 2 hours, and subsequently sectioned into $14 \mathrm{~mm}$ slices in a cryostat (Leica CM 1950, Leica, Wetzlar, Germany). After rinsed by TBS and immersed in $0.5 \%$ Triton-X-100 for 20 minutes, slices were incubated in a blocking solution consisting of 10\% Donkey serum (Jackson Immunoresearch, USA), 1\% bovine serum albumin (BSA), and $0.05 \%$ Triton-X-100 in 0.05 M TBS for 2 hours. Slices were then incubated by primary antibody (anti-Choline Acetyltransferase and anti-Brn3a, Millipore, Massachusetts, USA, 1:200) diluted in blocking solution overnight. In the following day, slices were washed 3 times (5 minutes each), and secondary antibody (Donkey anti-Goat conjugated to Alexa Flour 594, Jackson ImmunoResearch, West Grove, USA, 1:300) diluted in blocking solution was used to cover the slices for 2 hours in darkness. Slices were then stained with 1:3000 DAPI after rinsing, and finally rinsed, air-dried, and mounted. A fluorescence imaging microscope (A1R, Nikon, Tokyo, Japan) was used to obtain fluorescence images of the slices. The fluorescence image was then processed using Adobe Photoshop CC 2018.

\section{Intravitreal injection in mice}

The mice were anesthetized with isoflurane ( $1 \sim 2 \%$ at $0.5 \sim 1.0 \mathrm{~L} / \mathrm{min})$. Subsequently, $69 \mathrm{~nL}$ Dil Stain Perchlorate (1.5mg/mL, D282, Invitrogen, USA) was injected into the dorsal nasal retina 564 of $r d 1^{-/} / c D T A$ mice, in which the NW arrays were typically implanted, using a Nanoject II (Drummond scientific company, Broomall, USA). After surgery, mice were placed on a heating pad to recover and monitored for postoperative health. 


\section{Virus injection in mice}

The mice were first anesthetized with isoflurane $(1 \sim 2 \%$ at $0.5 \sim 1.0 \mathrm{~L} / \mathrm{min})$. Once the animals lost reflexes, the scalp was shaved and lidocaine applied on the ear bars. Body temperature was maintained using a heating pad. Sodium hyaluronate eye drops $(0.3 \%$, Santen Pharmaceutical Co., LTD, Shiga Plant, Japan) were applied to the eyes for protection during surgery. Skin was disinfected using alternating scrubs of $70 \%$ ethanol and betadine and removed to expose the skull. The skull was scraped to remove connective tissue and to allow adherence later in the procedure. Cranial drill was used to thin the skull at three injections site $(2.1 \mathrm{~mm}$ lateral and $3.2 \mathrm{~mm}$ posterior, $2.5 \mathrm{~mm}$ lateral and $3.2 \mathrm{~mm}$ posterior, $2.3 \mathrm{~mm}$ lateral and $3.6 \mathrm{~mm}$ posterior of bregma).

Glass pipette filled with AAV2/8-hSyn-GCaMP6s (Taitool Bioscience Co., LTD, Shanghai, China) was inserted to the injection sites using a Nanoject II injector (Drummond Scientific Company, USA). 40 pulses of $2.3 \mathrm{~nL}$ each ( $92 \mathrm{~nL}$ total volume), at 10 seconds intervals, were delivered to inject the AAV2/8-hSyn-GCaMP6s at the depth of $400 \mu \mathrm{m}$. The same procedure was repeated after retracting the pipette to the depth of 320 and $250 \mu \mathrm{m}$. The pipette was left in the tissue for 5 minutes before being slowly retracted. Procedures for the stereotaxic injection of the CTB-488 into V1 were the same as described previously.

\section{Cranial window implantation in mice}

Surgery for cranial window implantation was performed $6 \sim 8$ weeks after virus injections when the mice was over $3.5 \sim 4$ months old. Mice were anesthetized with isoflurane $(1 \sim 1.5 \%$ at 1 $\sim 1.5 \mathrm{~L} / \mathrm{min}$ ). Body temperature was maintained using a heating pad. Sodium hyaluronate eye drops $(0.3 \%)$ were applied to the eyes for protection during surgery. A $\sim 2.5 \mathrm{~mm}$ craniotomy was performed on the right hemisphere, starting at the $2.3 \mathrm{~mm}$ lateral and $1.3 \mathrm{~mm}$ anterior of lambda point. The skull was thinned and soaked in sterile saline solution. Gelfoam (Kang Sen Medical Equipment Co., LTD, Guilin, China) soaked in saline was used throughout the procedure to stop bleeding and to maintain osmosis once the brain was exposed. A custom-made glass window ( $0.1 \mathrm{~mm}$ thickness)

594 was embedded into the craniotomy and sealed with VetBond (3M Animal Care Products, St. Paul, USA). Dental cement (Super Bond C\&B, Japan) was applied to secured the window. A head bar was finally mounted on the skull using the same dental cement. 

Animal Pharmaceutical Co., LTD, Shanghai, China), dexamethasone sodium phosphate $(0.1 \mathrm{mg} / \mathrm{kg}$ body weight, Quanyu Biotechnology Animal Pharmaceutical Co., LTD, Shanghai, China), tolfedine acid injectable solution $(0.1 \mathrm{ml} / \mathrm{kg}$ body weight, Vetoquinol, French) and $0.5 \mathrm{ml}$ of sterile saline towards the end of surgery. Animals were placed in a heated chamber until ambulatory and then transferred back to their home cage. They were monitored daily for pain and wound health.

All mice recovered in home cage for two weeks. Cranial window was examined under a wide field fluorescence dissection microscope two weeks after cranial window implantation, and fluorescent labels near the cortical surface should be clearly visible through the wet skull.

\section{Procedure for two-photon calcium imaging in mice}

Recordings of GCaMP6 fluorescence signals were performed using Olympus FluoView FVMPE-RS upright two-photon laser-scanning system with an Olympus XL Plan N25 × /1.05 WMP $\infty / 0-0.23 / \mathrm{FN} / 18$ dipping objective (Olympus, Tokyo, Japan). Two-photon excitation was performed using 920 nm MAITAI eHPDS-OL laser (Mai Tai, Spectra-Physics, Santa Clara, USA), and emitted fluorescence was detected through a $495 \sim 540 \mathrm{~nm}$ bandpass filter. For the examination of GCaMP6s expression in V1, cranial window was imaged at a resolution of $512 \times 512$ pixels at $30 \mathrm{~Hz}$. Imaging sessions lasted $2 \sim 3$ hours including $1 \sim 2$ hours of effective imaging time.

In light-evoked responses experiments, mice were habituated to head-fixation and running on the cylindrical treadmill. Once the animals were comfortable with the setup, imaging was performed. The mice were kept awake during imaging. In receptive field mapping experiments and natural scenes stimulation experiments, the mice were anesthetized with isoflurane $(0.5 \sim 1.0 \%$ at $1 \sim 1.5$ $\mathrm{L} / \mathrm{min}$ ) and placed on a heating pad to monitor and maintain body temperature. Sodium hyaluronate eye drops $(0.3 \%)$ were applied to the eyes to prevent drying.

\section{Visual stimulus for two-photon Calcium imaging.}

Blue LED was used as light sources for the light-responsive experiments. LED was located 6 cm away from the animal's eye. Each trial started with a blank period for $20 \sim 25$ seconds randomly, and a LED stimulation was subsequently turned on for $1 \mathrm{sec}$ and repeated for 6 times. 
${ }^{56}$. The screen was adjusted to be 45 degrees from the anteroposterior axis, $12 \mathrm{~cm}$ from the animal's eye, subtending 96 and 80 degrees of the horizontal and vertical visual field, respectively. We used a sparse noise stimulus, consisting of blue squares presented on a black background along a grid of $6 \times 5$ squares to map RFs, each square is $\sim 16 \times 16$ degrees. The squares were presented for $1 \mathrm{sec}$ with a $10 \mathrm{sec}$ interval with 8 repetitions for anesthetized mice.

Stimuli of natural scenes were consisted of 30 natural images from the van Hateren Natural Image Dataset ${ }^{61}$ and the McGill Calibrated Colour Image Database ${ }^{62}$. The images of $800 \times 600$ pixels were presented in grayscale with normalized contrast. Each image was presented for $0.5 \mathrm{sec}$

\section{Analysis of in vivo calcium imaging data}

In vivo calcium movies were pre-processed in python using a custom-built pipeline based on CaImAn package ${ }^{63}$ for large-scale calcium imaging data analysis. Movies were motion-corrected using a rigid registration method to remove motion artifacts ${ }^{64}$. Fluorescence traces of individual neurons were extracted from the registered movie using a constrained non-negative matrix factorization (CNMF) framework ${ }^{65}$. Spatial correlation thresholds for ROI detection were set to 0.85 , and the signal to noise ratio for accepting a component was set to 2.50 . The automatic detection was manually screened to ensure correct segmentation of somatic calcium activity. This pipeline generated a set of spatial footprints and temporal traces for each animal on each day of recording. The changes in fluorescence $(\Delta \mathrm{F} / \mathrm{F})$ trace and $\mathrm{z}$-score were used in further analyses.

\section{Identification of light-responsive neurons}

To identify light-responsive neurons, we defined a pre-stimulus period as the 2-secwindow (60 frames) preceding the stimulus onset, and the baseline of the trial was the mean $\Delta \mathrm{F} / \mathrm{F}$ during the pre-stimulus period. We also defined a post-stimulus period as the 5-sec window (150 frames) following the stimulus onset. Post-stimulus window was $1 \mathrm{sec}$ in the natural scenes stimulus experiments. A neuron was considered responsive to the 1-sec light pulses if the maximum $\Delta \mathrm{F} / \mathrm{F}$ during the post-stimulus period was more than 5 times SD above the baseline and the time to decay half-peak must be over 10 frames in more than $50 \%$ of the trials. In the natural scenes test, the neuron which satisfied the above conditions would be identified as responsive cells for further 
analysis.

\section{Mean $\Delta F / F$ amplitude and latency in V1 neurons}

To estimate an ROI's $\Delta \mathrm{F} / \mathrm{F}$ mean amplitude in response to light stimuli, we segmented the $\Delta \mathrm{F} / \mathrm{F}$ traces during each light-evoked spiking and used the maximum $\Delta \mathrm{F} / \mathrm{F}$ value at each segment as a measurement of the $\Delta \mathrm{F} / \mathrm{F}$ amplitude for that particular segment. The time difference between the onset of the visual stimuli and the frame at which the $\Delta \mathrm{F} / \mathrm{F}$ trace first exceeded the threshold was defined as the latency. The average of these maximal values and latencies for light-responsive neurons were computed as the mean $\Delta \mathrm{F} / \mathrm{F}$ and latency, respectively. The latency was normalized by the average latency in normal mice. The mean $\Delta \mathrm{F} / \mathrm{F}$ was normalized by the $\Delta \mathrm{F} / \mathrm{F}$ amplitude at the 3rd day after implantation.

\section{Fitting spatial receptive fields in V1 neurons in mice}

The retinotopic organization of individual neurons was assessed by measuring the average $\Delta \mathrm{F} / \mathrm{F}$ response to each of the 30 stimulus positions $(6 \times 5$ grid $)$ with 8 repetitions. These data were interpolated by a 2D bilinear interpolation, and fit by least-squares regression with a twodimensional Gaussian Model. Neurons whose receptive field (center) was positioned 5 degrees from the edge of the screen (that provide visual stimuli) were chosen for further analysis.

\section{Lifetime sparseness.}

Lifetime sparseness was computed from the mean responses to natural scenes by using the definition in previous study ${ }^{43,46}$, as

$$
S_{L}=\frac{1-\frac{1}{N} \frac{\left(\sum_{i} r_{i}\right)^{2}}{\sum_{i} r_{i}^{2}}}{1-\frac{1}{N}}
$$

where $N$ is the number of stimulus conditions and $r_{i}$ is the mean response to stimulus condition $i$ across the test.

\section{Surgical procedures for NW arrays implantation in macaque monkey}

Macaque monkey was anesthetized with intramuscular tiletamine hydrochloride and 
zolazepam hydrochloride (Zoletil 50, $0.1 \mathrm{~mL} / \mathrm{kg}$ body weight, Virbac S.A., France) 20 minutes after intramuscular atropine $(0.5 \mathrm{mg} / \mathrm{mL}, 0.1 \mathrm{~mL} / \mathrm{kg}$ body weight, Healton Animal Pharmaceutical Co., LTD, Sichuan, China). Isoflurane inhalation maintained general anesthesia during retinal implant surgery. Mydriasis in the right eye was induced by tropicamide $(5 \mathrm{mg} / \mathrm{mL}$, Santen Pharmaceutical Co., LTD, Osaka, Japan). Lateral canthotomy was performed to allow 23-gauge trocars (Carl Zeiss Meditec AG, Jena, Germany) for vitrectomy and a retinal bleb was created by subretinal injection of balanced salt solution ${ }^{17}$. NW arrays were $1.8 \mathrm{~mm}$ in length and $0.4 \mathrm{~mm}$ in width, so as to be guided into the eyes through 23-gauge trocars for vitrectomy without an additional incision, reducing potential infections and post-surgery complications. 8 pieces of implantation in all were inserted subretinally through $3 \mathrm{~mm}$-wide sclerotomies in Monkey A (Constellation vision system, Fort Worth, USA). The detached retina was reattached by perfluorocarbon liquid (Bausch \& Lomb, Rochester, USA) and silicone oil (Arciolane3000, Arcadophta SARL, France). Retinal laser photocoagulation was operated at the border of the retinotomy ${ }^{66,67}$.

\section{Eyes Examinations for macaque monkey}

One to two drops of Compound Tropicamide Eye Drops (Santen Pharmaceutical Co., LTD, Shiga Plant, Japan) were instilled into Monkey A's eyes to dilute its pupil 3 times and 1 hour before the examination began. Monkey A was injected with atropine $(0.5 \mathrm{mg} / \mathrm{mL}, 0.1 \mathrm{~mL} / \mathrm{kg}$ body weight, Healton Animal Pharmaceutical Co., LTD, Sichuan, China) followed by intramuscular injection of tiletamine hydrochloride and zolazepam hydrochloride (Zoletil 50, $0.1 \mathrm{~mL} / \mathrm{kg}$ body weight, Virbac S.A., France). After anesthetization, Monkey A was placed prone in a supporting apparatus to receive eye examinations.

Color, Red-free, and autofluorescence fundus photography (TRC-50DX, TOPCON, Tokyo, Japan) of Monkey A's right eye were taken before photocoagulation, 11 months after photocoagulation, 4 days, 3, 4, 6 and 8 weeks after NW arrays implantation. Optic Coherence Tomography (OCT) (Cirrus HD-OCT 4000, Zeiss, Oberkochen Germany) was used to scan the retinal structure and the corresponding places of NW arrays. OCT images were taken at 4 days, 3 , 4, 6 and 8 weeks after implantation with NW arrays. Silt lamp (Oculus Optikgerate GmbH, Wetzlar, Germany) was used to examine Monkey A's lenses, cornea and anterior chamber by providing direct visualization. 


\section{Recording of eye position and visually-guided saccade task in macaque monkey}

Monkey A was seated in a chair which was placed on a platform in front of the screen (the distance between the monkey's eyes and the screen is $30 \mathrm{~cm}$ ) and looked flat at the central fixation point. A lightweight acrylic cap was implanted for head stabilization chronically. Monkey A's head was fixed by a custom-made head holder to keep the head stable during experiment. Pupil position was monitored and digitalized by an infrared eye system, including an eye-tracking camera (above the center of the screen), infrared illuminator, Eyelink plus 1000 (SR Research, USA) and Wise center software (Jisimingzhi Technology Co., Ltd. Beijing, China).

Visual stimuli were presented by red (642/18 nm), blue (465/25 nm) or UV (360/15 nm) LED, which were generated by TEMPO experiment control system (Reflective computing, Olympia, WA, USA), Neurotask software (SourceForge, San Diego, USA) and Arduino. Monkey A's eye in visually-guided saccade task was $30 \mathrm{~cm}$ away from the stimulus. The light intensity of the stimulus (red $(642 / 18 \mathrm{~nm})$, blue $(465 / 25 \mathrm{~nm})$ or UV $(360 / 15 \mathrm{~nm}) \mathrm{LED})$ was set to $\sim 10.00 \mu \mathrm{W} \cdot \mathrm{mm}^{-2}$ by an electric current source (DP3005B, MESTEK, Shenzhen, China) at a distance of $30 \mathrm{~cm}$ from the stimulus. We also measured the light intensity at a distance of $6 \mathrm{~cm}\left(\sim 107.00 \mu \mathrm{W} \cdot \mathrm{mm}^{-2}\right)$ from the same stimulus to ensure consistency with mice experiment.

The monkey was trained daily to perform a visually-guided saccade task and was rewarded for making saccadic eye movement from a central fixation point (equipped with an LED) to a peripheral target point (equipped with an LED). In each session, stimulations were presented in the implanted region and more than 4 normal regions in a random order. Up to ten sessions were recorded daily. Once Monkey A fixated at the fixation point for $1 \mathrm{sec}$, the LED at the target point was turned on for $1 \mathrm{sec}$ while the LED at the fixation point was turned off. The visual field was divided into 36 polar angles, with eccentricity from 17 to 21 degrees (interval 2 degrees).

To calculate the saccadic endpoint, we measured the velocity of eye movement trajectories using customized python code. The saccadic endpoint was the average position in the time window when the eye was first stationary for $50 \sim 100$ milliseconds after peak velocity ${ }^{21}$. The experiment animal was considered to have completed one correct saccade when the animal gaze reached a $15^{\circ}$ window surrounding the target point and maintained more than 50 milliseconds. The animal was rewarded when it made a correct saccadic eye movement. Each saccadic endpoint was normalized 
according to the relative position of the target point.

\section{Statistical analysis}

The differences and normality for multiple comparisons were tested by Prism (Graphpad, San Diego, CA). Comparisons between two distinct samples were made by two-tailed Student's unpaired t-test, and paired t-test were used for data with repeated measurements from the same sample. Comparisons between three or more distinct samples were made by one-way ANOVA followed by the Tukey post-hoc test. Results of the choice-box-based behavioral test were analyzed by two-way repeated-measures (RM) ANOVA followed by the Tukey post-hoc test. Results of patch-clamp recording and visually-guided saccade test were analyzed by one-way repeatedmeasures ANOVA followed by the Dunnett post-hoc test. With regards to the fitting model, we used $\log$-linear regression to fit the data. $\mathrm{P}<0.05$ was considered statistically significant. Data are presented as mean \pm SEM. Full statistical analyses corresponding to each figure can be found in Extended Data Table 3.

Data availability

Data used from this study are available from the corresponding author upon request.

\section{Code availability}

Custom-written codes used to analyze data from this study are available from the corresponding author upon request.

\section{References}

1 Maguire, A. M. et al. Safety and efficacy of gene transfer for Leber's congenital amaurosis. The New England journal of medicine 358, 2240-2248, doi:10.1056/NEJMoa0802315 (2008).

2 Cascella, R. et al. Towards the application of precision medicine in Age-Related Macular Degeneration. Progress in retinal and eye research 63, 132-146, doi:10.1016/j.preteyeres.2017.11.004 (2018).

3 Zhou, H. et al. Glia-to-Neuron Conversion by CRISPR-CasRx Alleviates Symptoms of

7774 Mahato, B. et al. Pharmacologic fibroblast reprogramming into photoreceptors restores 
vision. Nature 581, 83-88, doi:10.1038/s41586-020-2201-4 (2020).

Hoang, T. et al. Gene regulatory networks controlling vertebrate retinal regeneration. Science (New York, N.Y.) 370, doi:10.1126/science.abb8598 (2020).

Lu, Y. et al. Reprogramming to recover youthful epigenetic information and restore vision. Nature 588, 124-129, doi:10.1038/s41586-020-2975-4 (2020).

Maeder, M. L. et al. Development of a gene-editing approach to restore vision loss in Leber congenital amaurosis type 10. Nature medicine 25, 229-233, doi:10.1038/s41591018-0327-9 (2019).

8 Sahel, J. A. et al. Partial recovery of visual function in a blind patient after optogenetic therapy. Nature medicine 27, 1223-1229, doi:10.1038/s41591-021-01351-4 (2021).

9 Roska, B. \& Sahel, J. A. Restoring vision. Nature 557, 359-367, doi:10.1038/s41586-0180076-4 (2018).

10 Sahel, J. A., Bennett, J. \& Roska, B. Depicting brighter possibilities for treating blindness. Science translational medicine 11, doi:10.1126/scitransImed.aax2324 (2019).

11 Humayun, M. S. et al. Visual perception elicited by electrical stimulation of retina in blind humans. Archives of ophthalmology (Chicago, III. : 1960) 114, 40-46, doi:10.1001/archopht.1996.01100130038006 (1996).

12 da Cruz, L. et al. Five-Year Safety and Performance Results from the Argus II Retinal Prosthesis System Clinical Trial. Ophthalmology 123, 2248-2254, doi:10.1016/j.ophtha.2016.06.049 (2016).

13 Wilke, R. et al. Spatial resolution and perception of patterns mediated by a subretinal 16 electrode array in patients blinded by hereditary retinal dystrophies. Investigative ophthalmology \& visual science 52, 5995-6003, doi:10.1167/iovs.10-6946 (2011).

14 Mills, J. O., Jalil, A. \& Stanga, P. E. Electronic retinal implants and artificial vision: journey and present. Eye (London, England) 31, 1383-1398, doi:10.1038/eye.2017.65 (2017).

15 Stingl, K. et al. Interim Results of a Multicenter Trial with the New Electronic Subretinal Implant Alpha AMS in 15 Patients Blind from Inherited Retinal Degenerations. Frontiers in neuroscience 11, 445, doi:10.3389/fnins.2017.00445 (2017).

16 Edwards, T. L. et al. Assessment of the Electronic Retinal Implant Alpha AMS in Restoring Vision to Blind Patients with End-Stage Retinitis Pigmentosa. Ophthalmology 125, 432 443, doi:10.1016/j.ophtha.2017.09.019 (2018).

17 Prevot, P. H. et al. Behavioural responses to a photovoltaic subretinal prosthesis implanted in non-human primates. Nature biomedical engineering 4, 172-180, doi:10.1038/s41551019-0484-2 (2020).

18 Lorach, H. et al. Photovoltaic restoration of sight with high visual acuity. Nat Med 21, 476 482, doi:10.1038/nm.3851 (2015).

1 Palanker, D., Le Mer, Y., Mohand-Said, S., Muqit, M. \& Sahel, J. A. Photovoltaic Restoration of Central Vision in Atrophic Age-Related Macular Degeneration. Ophthalmology 127, 1097-1104, doi:10.1016/j.ophtha.2020.02.024 (2020).

20 Beauchamp, M. S. et al. Dynamic Stimulation of Visual Cortex Produces Form Vision in Sighted and Blind Humans. Cel/181, 774-783 e775, doi:10.1016/j.cell.2020.04.033 (2020).

21 Chen, X., Wang, F., Fernandez, E. \& Roelfsema, P. R. Shape perception via a high-channelcount neuroprosthesis in monkey visual cortex. Science 370, 1191-1196, doi:10.1126/science.abd7435 (2020). 
Gu, L. et al. A biomimetic eye with a hemispherical perovskite nanowire array retina. Nature 581, 278-282, doi:10.1038/s41586-020-2285-x (2020).

23 Nelidova, D. et al. Restoring light sensitivity using tunable near-infrared sensors. Science 368, 1108-1113, doi:10.1126/science.aaz5887 (2020).

24 Maya-Vetencourt, J. F. et al. Subretinally injected semiconducting polymer nanoparticles rescue vision in a rat model of retinal dystrophy. Nat Nanotechnol 15, 698-708, doi:10.1038/s41565-020-0696-3 (2020).

25 Acaron Ledesma, H. et al. An atlas of nano-enabled neural interfaces. Nat Nanotechnol 14, 645-657, doi:10.1038/s41565-019-0487-x (2019).

26 Tang, J. et al. Nanowire arrays restore vision in blind mice. Nat Commun 9, 786, doi:10.1038/s41467-018-03212-0 (2018).

27 Li, J. et al. Nanoscale stacking fault-assisted room temperature plasticity in flash-sintered TiO(2). Science advances 5, eaaw5519, doi:10.1126/sciadv.aaw5519 (2019).

28 Wang, G., Wang, H., Ling, Y., Tang, Y. \& Li, Y. Hydrogen-Treated TiO2 Nanowire Arrays for Photoelectrochemical Water Splitting. Nano letters 11, 3026-3033 (2011).

29 Jiang, Y. et al. Rational design of silicon structures for optically controlled multiscale biointerfaces. Nature biomedical engineering 2, 508-521, doi:10.1038/s41551-0180230-1 (2018).

30 Geruschat, D. R. et al. An analysis of observer-rated functional vision in patients implanted with the Argus II Retinal Prosthesis System at three years. Clinical \& experimental optometry 99, 227-232, doi:10.1111/cxo.12359 (2016).

31 Stingl, K. et al. Artificial vision with wirelessly powered subretinal electronic implant alphaIMS. Proceedings. Biological sciences 280, 20130077, doi:10.1098/rspb.2013.0077 (2013).

32 Spitschan, M. Melanopsin contributions to non-visual and visual function. Curr Opin 33 Stingl, K. et al. Subretinal Visual Implant Alpha IMS--Clinical trial interim report. Vision Res 111, 149-160, doi:10.1016/j.visres.2015.03.001 (2015).

34 Humayun, M. S. et al. Interim results from the international trial of Second Sight's visual prosthesis. Ophthalmology 119, 779-788, doi:10.1016/j.ophtha.2011.09.028 (2012).

35 Xiong, Y.-Z. et al. Relationship Between Acuity and Contrast Sensitivity: Differences Due to Eye Disease. Investigative ophthalmology \& visual science 61, 40-40, doi:10.1167/iovs.61.6.40 (2020).

36 Ganjawala, T. H., Lu, Q., Fenner, M. D., Abrams, G. W. \& Pan, Z. H. Improved CoChR Variants Restore Visual Acuity and Contrast Sensitivity in a Mouse Model of Blindness under Ambient Light Conditions. Mol Ther 27, 1195-1205, doi:10.1016/j.ymthe.2019.04.002 (2019).

37 Prusky, G. T., Alam, N. M., Beekman, S. \& Douglas, R. M. Rapid Quantification of Adult and Developing Mouse Spatial Vision Using a Virtual Optomotor System. Investigative ophthalmology \& visual science 45, 4611-4616, doi:10.1167/iovs.04-0541 (2004).

38 Harvey, B. M. \& Dumoulin, S. O. The relationship between cortical magnification factor and population receptive field size in human visual cortex: constancies in cortical architecture. The Journal of neuroscience : the official journal of the Society for Neuroscience 31, 13604-13612, doi:10.1523/JNEUROSCI.2572-11.2011 (2011). Wang, Q. \& Burkhalter, A. Area map of mouse visual cortex. The Journal of comparative 
neurology 502, 339-357, doi:10.1002/cne.21286 (2007).

40 Sterratt, D. C., Lyngholm, D., Willshaw, D. J. \& Thompson, I. D. Standard anatomical and visual space for the mouse retina: computational reconstruction and transformation of flattened retinae with the Retistruct package. PLoS computational biology 9, e1002921, doi:10.1371/journal.pcbi.1002921 (2013).

41 Roth, M. M. et al. Thalamic nuclei convey diverse contextual information to layer 1 of visual cortex. Nature neuroscience 19, 299-307, doi:10.1038/nn.4197 (2016).

42 Samonds, J. M., Feese, B. D., Lee, T. S. \& Kuhlman, S. J. Nonuniform surround suppression of visual responses in mouse V1. Journal of neurophysiology 118, 3282-3292, doi:10.1152/jn.00172.2017 (2017).

43 Vinje, W. E. \& Gallant, J. L. Sparse coding and decorrelation in primary visual cortex during natural vision. Science (New York, N.Y.) 287, 1273-1276, doi:10.1126/science.287.5456.1273 (2000).

44 Yoshida, T. \& Ohki, K. Natural images are reliably represented by sparse and variable populations of neurons in visual cortex. Nature communications 11, 872, doi:10.1038/s41467-020-14645-x (2020).

45 Rolls, E. T. \& Tovee, M. J. Sparseness of the neuronal representation of stimuli in the primate temporal visual cortex. Journal of neurophysiology 73, 713-726, doi:10.1152/jn.1995.73.2.713 (1995).

46 de Vries, S. E. J. et al. A large-scale standardized physiological survey reveals functional organization of the mouse visual cortex. Nature neuroscience 23, 138-151, doi:10.1038/s41593-019-0550-9 (2020).

$47 \quad$ Kalia, A. et al. Development of pattern vision following early and extended blindness. Proceedings of the National Academy of Sciences of the United States of America 111, 2035-2039, doi:10.1073/pnas.1311041111 (2014).

48 Spoerl, E., Mrochen, M., Sliney, D., Trokel, S. \& Seiler, T. Safety of UVA-riboflavin crosslinking of the cornea. Cornea 26, 385-389, doi:10.1097/ICO.0b013e3180334f78 (2007).

49 Marie, M. et al. Phototoxic damage to cone photoreceptors can be independent of the visual pigment: the porphyrin hypothesis. Cell Death Dis 11, 711, doi:10.1038/s41419020-02918-8 (2020).

50 Watanabe, Y. et al. Development of an optogenetic gene sensitive to daylight and its implications in vision restoration. NPJ Regen Med 6, 64, doi:10.1038/s41536-021-001775 (2021).

51 Markmann, S. et al. Biology of the Adrenal Gland Cortex Obviates Effective Use of AdenoAssociated Virus Vectors to Treat Hereditary Adrenal Disorders. Hum Gene Ther 29, 403412, doi:10.1089/hum.2017.203 (2018).

52 Keiser, M. S. et al. Toxicity after AAV delivery of RNAi expression constructs into nonhuman primate brain. Nature medicine 27, 1982-1989, doi:10.1038/s41591-021-01522-3 (2021).

53 Prévot, P. H. et al. Behavioural responses to a photovoltaic subretinal prosthesis implanted in non-human primates. Nature biomedical engineering 4, 172-180, doi:10.1038/s41551019-0484-2 (2020).

54 Boinagrov, D. et al. Upper threshold of extracellular neural stimulation. Journal of neurophysiology 108, 3233-3238, doi:10.1152/jn.01058.2011 (2012).

Li, X. et al. Serotonin receptor 2c-expressing cells in the ventral CA1 control attention via 
innervation of the Edinger-Westphal nucleus. Nature neuroscience 21, 1239-1250, doi:10.1038/s41593-018-0207-0 (2018).

56 Peirce, J. W. PsychoPy--Psychophysics software in Python. Journal of neuroscience methods 162, 8-13, doi:10.1016/j.jneumeth.2006.11.017 (2007).

57 Fang, Q. et al. A Differential Circuit via Retino-Colliculo-Pulvinar Pathway Enhances Feature Selectivity in Visual Cortex through Surround Suppression. Neuron 105, 355 369.e356, doi:10.1016/j.neuron.2019.10.027 (2020).

58 Carrillo-Reid, L., Han, S., Yang, W., Akrouh, A. \& Yuste, R. Controlling Visually Guided Behavior by Holographic Recalling of Cortical Ensembles. Cell 178, 447-457.e445, doi:10.1016/j.cell.2019.05.045 (2019).

59 Rossi, L. F., Harris, K. D. \& Carandini, M. Spatial connectivity matches direction selectivity in visual cortex. Nature 588, 648-652, doi:10.1038/s41586-020-2894-4 (2020).

60 Rasmussen, R., Matsumoto, A., Dahlstrup Sietam, M. \& Yonehara, K. A segregated cortical stream for retinal direction selectivity. Nature communications 11,831 , doi:10.1038/s41467-020-14643-z (2020).

61 van Hateren, J. H. \& van der Schaaf, A. Independent component filters of natural images compared with simple cells in primary visual cortex. Proceedings. Biological sciences 265, 359-366, doi:10.1098/rspb.1998.0303 (1998).

62 Olmos, A. \& Kingdom, F. A. A biologically inspired algorithm for the recovery of shading and reflectance images. Perception 33, 1463-1473, doi:10.1068/p5321 (2004).

63 Giovannucci, A. et al. CalmAn an open source tool for scalable calcium imaging data analysis. eLife 8, doi:10.7554/eLife.38173 (2019).

64 Pnevmatikakis, E. A. \& Giovannucci, A. NoRMCorre: An online algorithm for piecewise rigid motion correction of calcium imaging data. Journal of neuroscience methods 291 , 83-94, doi:10.1016/j.jneumeth.2017.07.031 (2017).

65 Pnevmatikakis, E. A. et al. Simultaneous Denoising, Deconvolution, and Demixing of Calcium Imaging Data. Neuron 89, 285-299, doi:10.1016/j.neuron.2015.11.037 (2016).

66 Matsuo, T. et al. Visual Evoked Potential Recovery by Subretinal Implantation of Photoelectric Dye-Coupled Thin Film Retinal Prosthesis in Monkey Eyes With Macular Degeneration. Artificial organs 42, E186-e203, doi:10.1111/aor.13120 (2018).

67 Tu, H. Y. et al. Medium- to long-term survival and functional examination of human iPSCderived retinas in rat and primate models of retinal degeneration. EBioMedicine 39, 562574, doi:10.1016/j.ebiom.2018.11.028 (2019).

68 Yang, Y., da Costa, R. C., Fuchter, M. J. \& Campbell, A. J. Circularly polarized light detection by a chiral organic semiconductor transistor. Nature photonics 7, 634-638, doi:10.1038/nphoton.2013.176 (2013).

69 van de Burgt, Y. et al. A non-volatile organic electrochemical device as a low-voltage artificial synapse for neuromorphic computing. Nature materials 16, 414-418, doi:10.1038/nmat4856 (2017).

$70 \mathrm{Hu}, \mathrm{Q}$. et al. Conjugation of haematopoietic stem cells and platelets decorated with antiPD-1 antibodies augments anti-leukaemia efficacy. Nature biomedical engineering $\mathbf{2}$, 831-840, doi:10.1038/s41551-018-0310-2 (2018).

Acknowledgments The authors thank the following funding agencies for supporting this work: the 

Science and Technology Major Project (2018SHZDZX01), ZJLab and Shanghai Center for Brain

956 Science and Brain-Inspired Technology, Key Scientific Technological Innovation Research Project of the Ministry of Education, Sanming Project of Medicine in Shenzhen (SZSM202011015),

958 Shanghai Hospital Development Center (SHDC2020CR4007), Shanghai Health and Family 959 Planning Commission (20164Y0096, 20184Y0184), Research and Development Fund of Zhongshan Hospital (2020ZSFZ19).

961

Author contributions J.Z., B.Y. and Y. Y. conceived the study. J.Z. and B.Y. wrote the paper. R.Y. 963 performed the behavioral experiments of mice and monkeys, refined the techniques, and analyzed the data, with help from P.Z., K.S., L.F., R.M.. T. Z., C.P. and G.Z. synthesized the $\mathrm{Au} @ \mathrm{TiO}_{2-\mathrm{x}} \mathrm{NW}$ arrays. P.Z., R.Y. and Y.C. developed two-photon microscope setups and chronic calcium imaging. Z.W., S.W. and G.W. performed in vitro patch clamp experiments. L.W., M.S., C.D., F.Y. and Y.Y. conducted the surgical procedures for NW arrays implantation in monkey. C.F., Y.Z., A.C., and F.Z. worked on monkeys' eyes examinations. S.J., W.X. and F.W. worked on choice-box-based behavioral device assembly. All authors discussed the results and commented on the manuscript.

\section{Competing interests}

972 The authors declare no competing interests.

\section{Additional information}

974 Correspondence and requests for materials should be addressed to J.Z., B.Y., or Y.Y. 

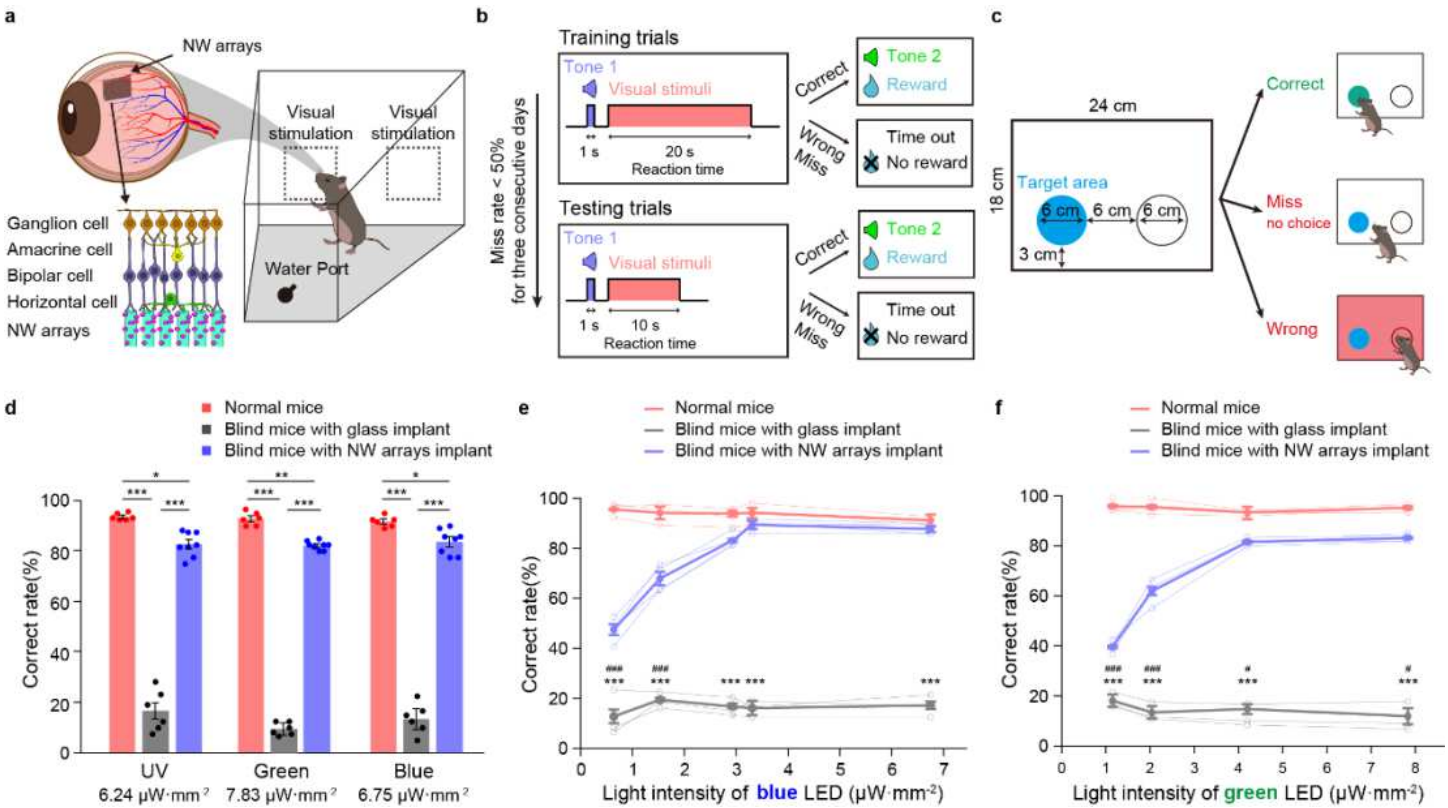

Fig. 1 | Choice-box-based behavioral paradigm and light localization test.

a, Schematics of $\mathrm{Au} @ \mathrm{TiO}_{2-\mathrm{x}} \mathrm{NW}$ arrays implanted blind mice in a choice-box-based behavioral system. b, Behavioral paradigm for the choice-box-based test. c, Schematics of light localization test. Two LEDs of the same color were presented. Target area was defined by a circle centered at the LED with a diameter of $6 \mathrm{~cm}$. $\mathbf{d}$, Correct rate of normal mice $(\mathrm{n}=6)$, blind mice with glass implant $(\mathrm{n}=6)$ and blind mice with NW arrays implant $(\mathrm{n}=8)$ with $\mathrm{UV}\left(375 / 15 \mathrm{~nm}, 6.24 \mu \mathrm{W} \cdot \mathrm{mm}^{-}\right.$ ${ }^{2}$ ), green $\left(535 / 28 \mathrm{~nm}, 7.83 \mu \mathrm{W} \cdot \mathrm{mm}^{-2}\right)$ and blue LEDs $\left(465 / 25 \mathrm{~nm}, 6.75 \mu \mathrm{W} \cdot \mathrm{mm}^{-2}\right)$. e-f, Correct rate of normal mice $(\mathrm{n}=3)$, blind mice with glass implant $(\mathrm{n}=3)$ and blind mice with $\mathrm{NW}$ arrays implant $(\mathrm{n}=4)$ using blue and green LEDs with different light intensities (blue LED intensities: $0.64 \sim 6.75$ $\mu \mathrm{W} \cdot \mathrm{mm}^{-2}$, green LED intensities: $1.15 \sim 7.83 \mu \mathrm{W} \cdot \mathrm{mm}^{-2}$ ). Light intensity of stimulus was measured at a distance of $6 \mathrm{~cm}$ from the screen. * indicates a significant difference between blind mice with NW arrays and blind mice with glass implant, \# indicates a significant difference between blind mice with NW arrays and normal mice (* and \#, $P<0.05$, *** and \#\#, $P<0.001$, one-way ANOVA for $\mathbf{d}$, two-way RM ANOVA for $\mathbf{e}$ and $\mathbf{f}$ ). Data are shown as mean \pm SEM. 

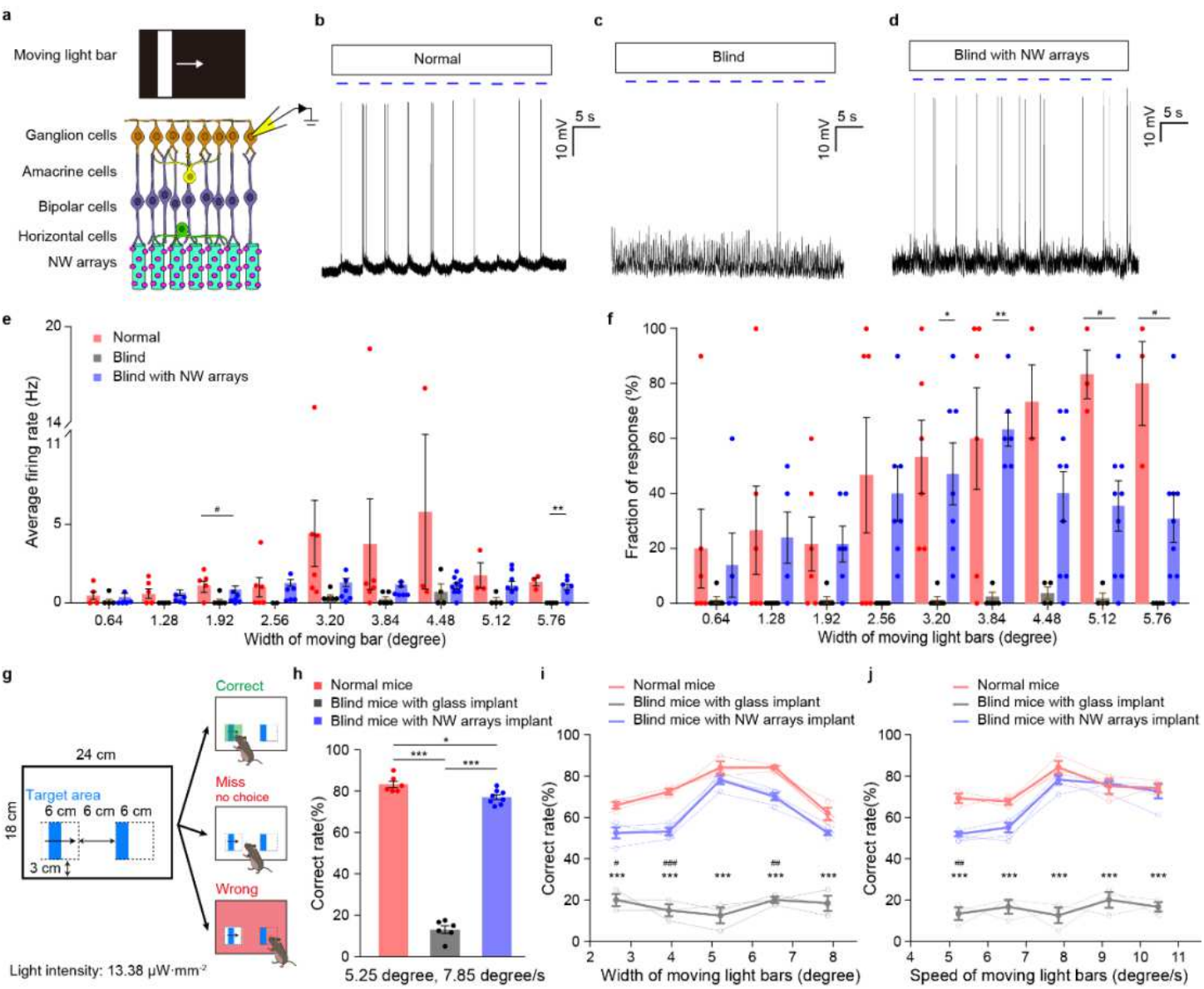

Fig. 2 | Responses of RGCs to moving light bars in NW arrays-attached blind retina In vitro and choice-box-based behavioral test using moving light bars.

a, Schematics of in vitro patch-clamp recording of the RGCs in NW arrays-attached blind mice retina. b-d, RGC responded to moving light bars stimulus (wavelength: $375 / 28 \mathrm{~nm}$, intensity: 10 $\mu \mathrm{W} \cdot \mathrm{mm}^{-2}$, width: 9.6 degrees, speed: 6.85 degrees $/ \mathrm{sec}$ ) in normal, blind and NW arrays-attached blind retinas. e-f, Average firing rates and fraction of responses of RGCs in a normal, glassattached and NW arrays-attached retinas using moving light bars with width ranging from 0.64 to 5.76 degrees. Normal mice: 9 RGCs from 6 retinas. Blind mice: 10 RGCs from 8 retinas. Blind mice with NW arrays attached: 16 RGCs from 10 retinas. $\mathbf{g}$, Schematics of the choice-box-based behavioral test using moving light bar and static light bar stimulus (wavelength: $470 \mathrm{~nm}$, intensity: $\left.13.38 \mu \mathrm{W} \cdot \mathrm{mm}^{-2}\right)$. $\mathbf{h}$, Correct rate of normal mice $(\mathrm{n}=6)$, blind mice with glass implant $(\mathrm{n}=6)$ and blind mice with NW arrays implant $(\mathrm{n}=8)$ in choice-box-based behavioral test using moving light bars (5.25 degrees in width at 7.85 degrees $/ \mathrm{sec})$. $\mathbf{i}-\mathbf{j}$, Correct rate of normal mice $(n=3)$, blind mice with glass implant $(n=3)$ and blind mice with NW arrays implant $(n=4)$ in choice-boxbased behavior test with moving light bars of different widths and speeds (width: $2.63 \sim 7.88$ degrees, speed: $5.23 \sim 10.47$ degrees/sec). All mice used in this test were over 6 months old and the blind mice in this test were implanted with NW arrays or glass for over 4 months. Light intensity of stimulus was tested at a distance of $6 \mathrm{~cm}$ from the screen. * indicates a significant difference between blind mice with NW arrays and blind mice with glass implant, \# indicates a significant difference between blind mice with $\mathrm{NW}$ arrays and normal mice (* and \#, $P<0.05$, ** and \#\#, $P<0.01$, *** and \#\#\#, $P<0.001$, one-way ANOVA for $\mathbf{e}$, $\mathbf{f}$ and $\mathbf{h}$, two-way RM ANOVA for $\mathbf{i}$ and $\mathbf{j}$ ). Data are shown as mean \pm SEM. 


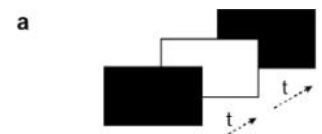

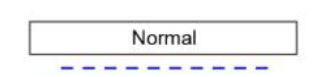

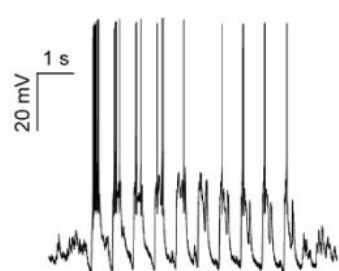

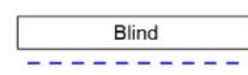

ㅊำ
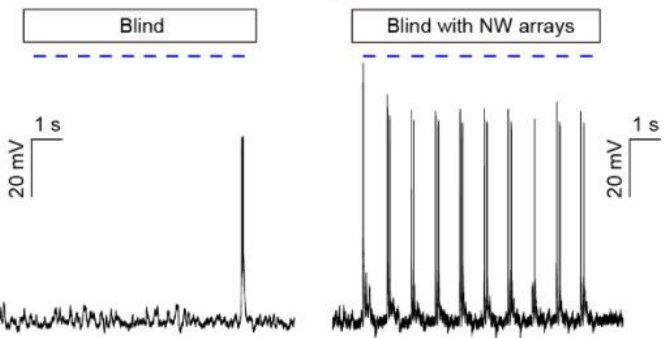

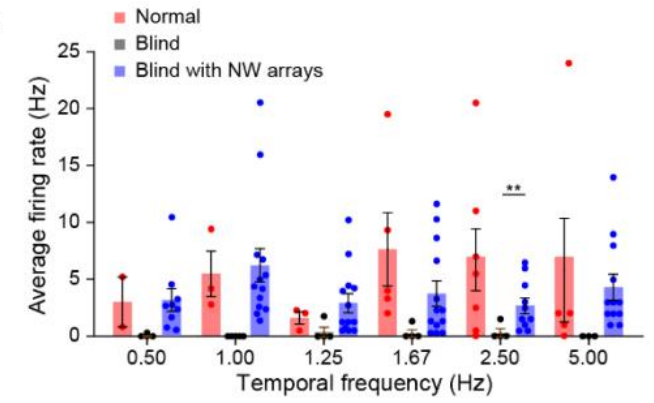

$$
\text { f }
$$

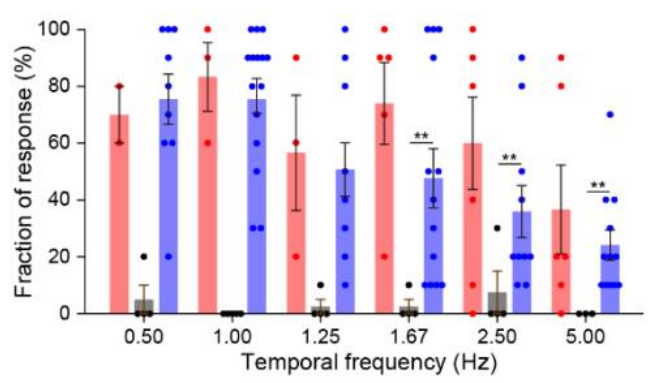

g

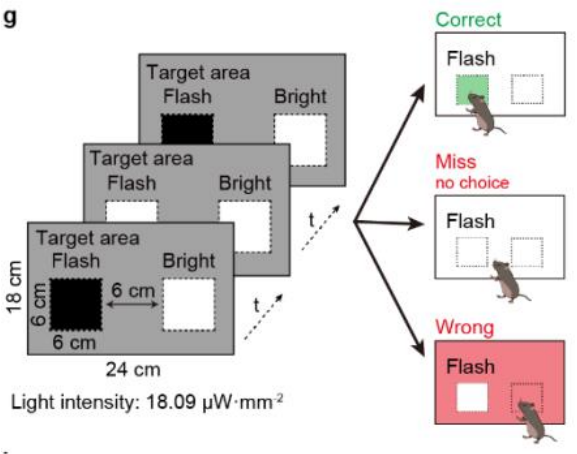

h $=$ Normal mice

- Blind mice with glass implant

- Blind mice with NW arrays implant

i - Normal mice
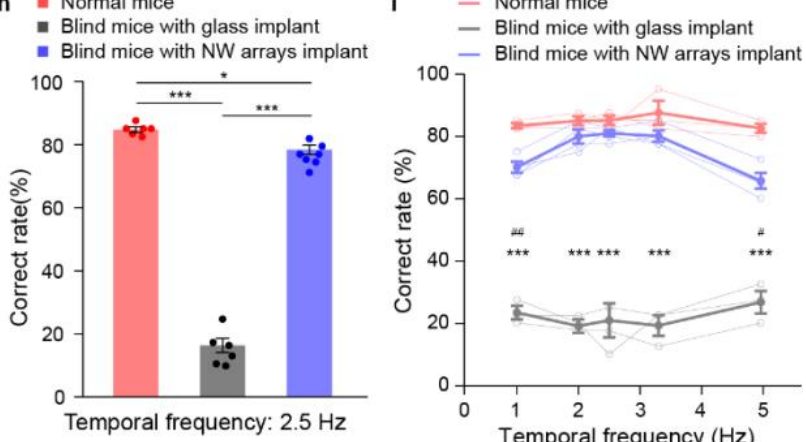

了
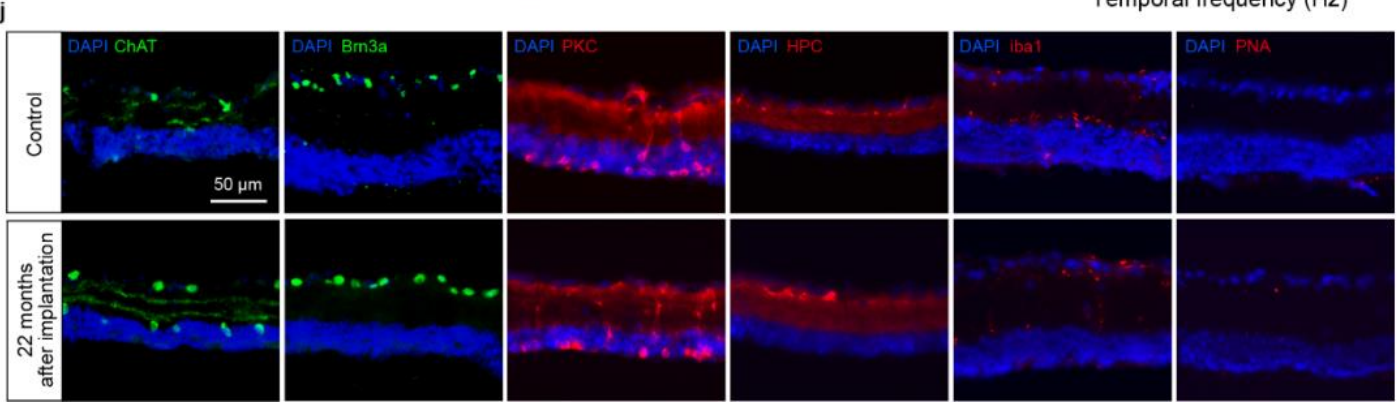

Fig. 3 | In vitro patch clamp recording of RGCs of NW arrays-attached blind retina and choicebox-based behavioral test using flashing light.

a, Schematics of in vitro patch clamp recording of the RGCs in NW arrays-attached blind mice retina. $t$ indicates the interval of stimuli, which was equal to the duration of stimuli. b-d, Flashing light (wavelength: $375 / 28 \mathrm{~nm}$, intensity: $10 \mu \mathrm{W} \cdot \mathrm{mm}^{-2}$, duration: $0.40 \mathrm{sec}, 1.25 \mathrm{~Hz}$ ) responses in normal, blind and NW arrays-attached blind retinas. e-f, Average firing rate and fraction of response of normal, glass-attached and NW arrays-attached retinas using flash visual stimulus with temporal frequency ranging from 0.50 to $5.00 \mathrm{~Hz}$. Temporal frequency was calculated as 1 divided by t. Normal mice: 7 RGCs from 6 retinas. Blind mice: 6 RGCs from 4 retinas. Blind mice with NW arrays attached: 15 RGCs from 8 retinas. $\mathbf{g}$, Schematics of choice-box-based behavioral test with flashing light (wavelength: $470 \mathrm{~nm}$, intensity: $18.09 \mu \mathrm{W} \cdot \mathrm{mm}^{-2}$ ). $\mathrm{t}$ indicates the duration of stimuli, which was equal to the interval of stimuli. $\mathbf{h}$, Correct rate of normal mice $(n=6)$, blind mice with glass implant $(\mathrm{n}=6)$ and blind mice with NW arrays implant $(\mathrm{n}=8)$ in choice-box-based behavior 
test with flashing light stimulus at temporal frequency of $2.5 \mathrm{~Hz}(\mathrm{t}=0.2 \mathrm{sec})$. $\mathbf{i}$, Correct rate of normal mice $(\mathrm{n}=3)$, blind mice with glass implant $(\mathrm{n}=3)$ and blind mice with NW arrays implant $(\mathrm{n}=4)$ in choice-box-based behavior test with flashing light stimulus of different temporal frequency $(1.0 \sim 5.0 \mathrm{~Hz})$. All mice used in this test were over 8 months old and the blind mice in this test were implanted with NW arrays or glass for over 6 months. Light intensity of stimulus was tested at a distance of $6 \mathrm{~cm}$ from the screen. $\mathbf{j}$, Representative immunofluorescence staining of blind mice retina with NW arrays implant for 22 months. Brn3a, RGCs. PKC-a, bipolar cells. HPC, amacrine cells. iba-1, microglia. PNA, cone cells, and cone domains of the interphotoreceptor matrix. * indicates a significant difference between blind mice with NW arrays and blind mice with glass implant, \# indicates a significant difference between blind mice with NW arrays and normal mice (** and \#\#, $P<0.01$, \#\#, $P<0.001$, one-way ANOVA for $\mathbf{e}$, $\mathbf{f}$ and $\mathbf{h}$, two-way RM ANOVA for i). Data are shown as mean \pm SEM. 

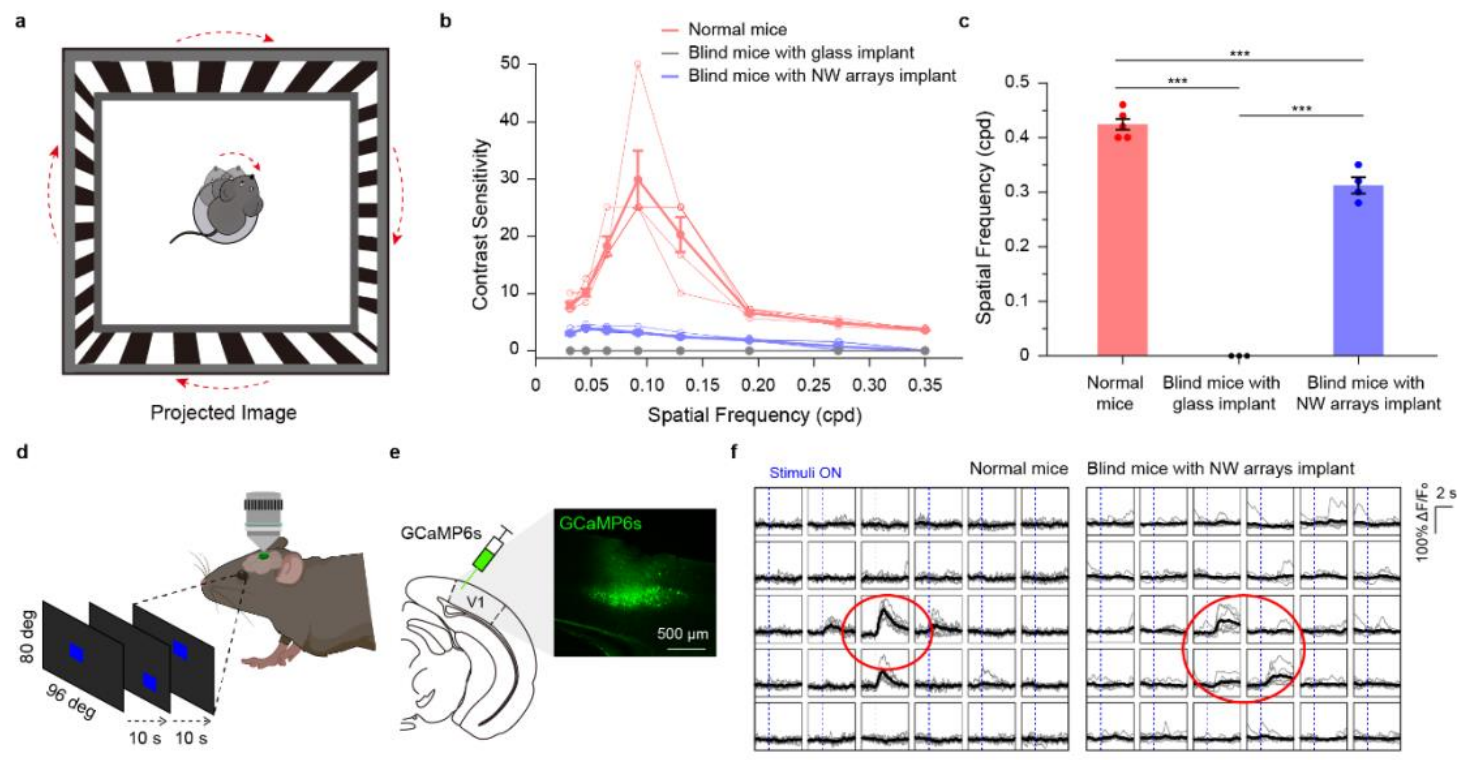

g

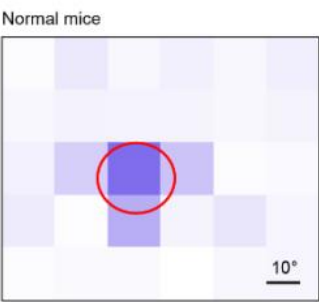

Normal mice

Blind mice with NW arrays implant
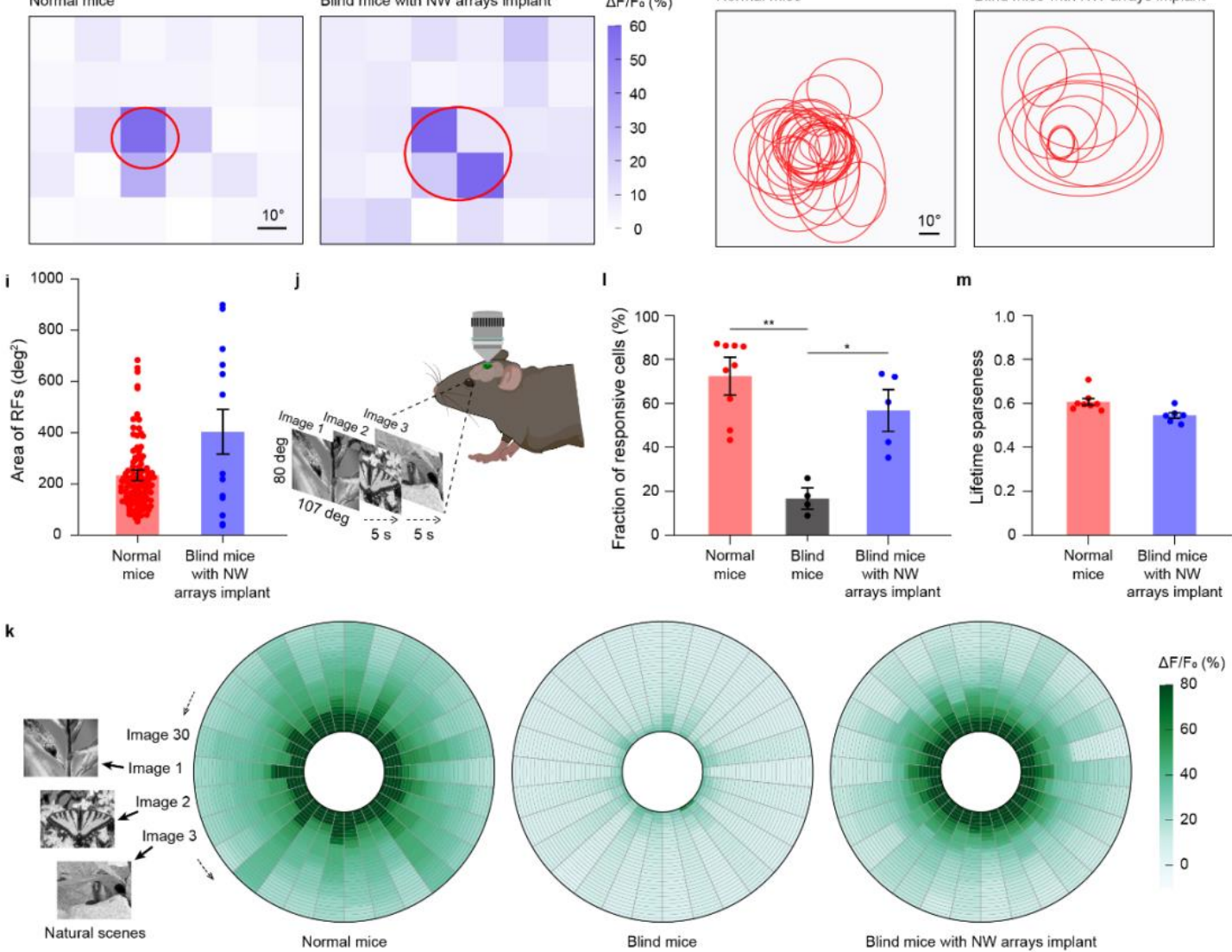

Fig. 4 Optomotor test, receptive fields and responses to natural scenes in V1 neurons of NWimplanted blind mice.

a, Schematics of the optomotor test. Mice were placed on a platform at the center of four screens displaying grating stimuli. A video camera is used to monitor the animal's behavior from above. $\mathbf{b}$, Contrast sensitivity of normal mice $(n=5)$, blind mice with glass implant $(n=3)$, and mice with NW arrays implant $(n=4)$ in optomotor test with different spatial frequencies of grating stimulus. c, Spatial frequency of normal mice $(\mathrm{n}=5)$, blind glass-implant mice $(\mathrm{n}=3)$, and $\mathrm{NW-implanted}$ mice $(n=4)$ in optomotor test. All mice used in optomotor test were over 11 months old and the 
blind mice were implanted with NW arrays for more than 9 months. d-e, Schematics of receptive field mapping using two-photon calcium imaging in V1. The cranial window was implanted to medial V1, which is retinotopically corresponding to naso-dorsal retina (with NW implant). Each blue square represented one visual stimulus consisted of $8.75 \mu \mathrm{W} \cdot \mathrm{mm}^{-2}, 16 \times 16$ degree $^{2} . \mathbf{f}$, GCaMP6 fluorescence signals from V1 neurons in normal mice (left) and blind mice with NW arrays implant (right) in response to one visual stimulus (individual trace in gray, average in black) ordered according to stimulus position. Red circles indicate the outline of calculated receptive field. $\mathbf{g}$, Average responses of neurons in Fig.4f . Each pixel was 16 degree by 16 degree. h, Distribution of receptive fields of normal mice and blind mice with $\mathrm{NW}$ arrays implant. i, Areas of V1 receptive field in normal mice (red, $233.19 \mathrm{deg}^{2}$, 111 cells from 4 mouse) and blind mice with NW arrays implant (purple, $402.74 \mathrm{deg}^{2}, 13$ cells from 3 mouse). $\mathbf{j}$, Schematics of two-photon calcium imaging with natural scenes, which were presented for $0.5 \mathrm{sec}$ followed by $5 \mathrm{sec}$ inter-image gray period. $\mathbf{k}$, Examples of natural scenes and heatmaps of cellular responses to the natural scenes in normal mice (left, $n=3$ ), blind mice (middle, $n=4$ ) and blind mice with NW arrays implant (right, $n=4$ ). Each axial column represented responses of 30 neurons to one natural scene, with the strongest response positioned at the core. l, Fraction of neurons that responded to at least one natural scene in normal mice $(72.36 \%, \mathrm{n}=3)$, blind mice $(16.69 \%, \mathrm{n}=4)$ and blind mice with $\mathrm{NW}$ arrays implant $(56.71 \%$, $\mathrm{n}=4)$. $\mathbf{m}$, Average lifetime sparseness of neurons in normal mice $(0.61, \mathrm{n}=3)$ and blind mice with NW arrays implant $(0.54, \mathrm{n}=4)$. ( $P<0.05, * * P<0.01$, *** $P<0.001$, one-way ANOVA for $\mathbf{c}$ and $\mathbf{l}$, and student's unpaired t-test for $\mathbf{i}$ and $\mathbf{m}$ ). Data are shown as mean \pm SEM. 

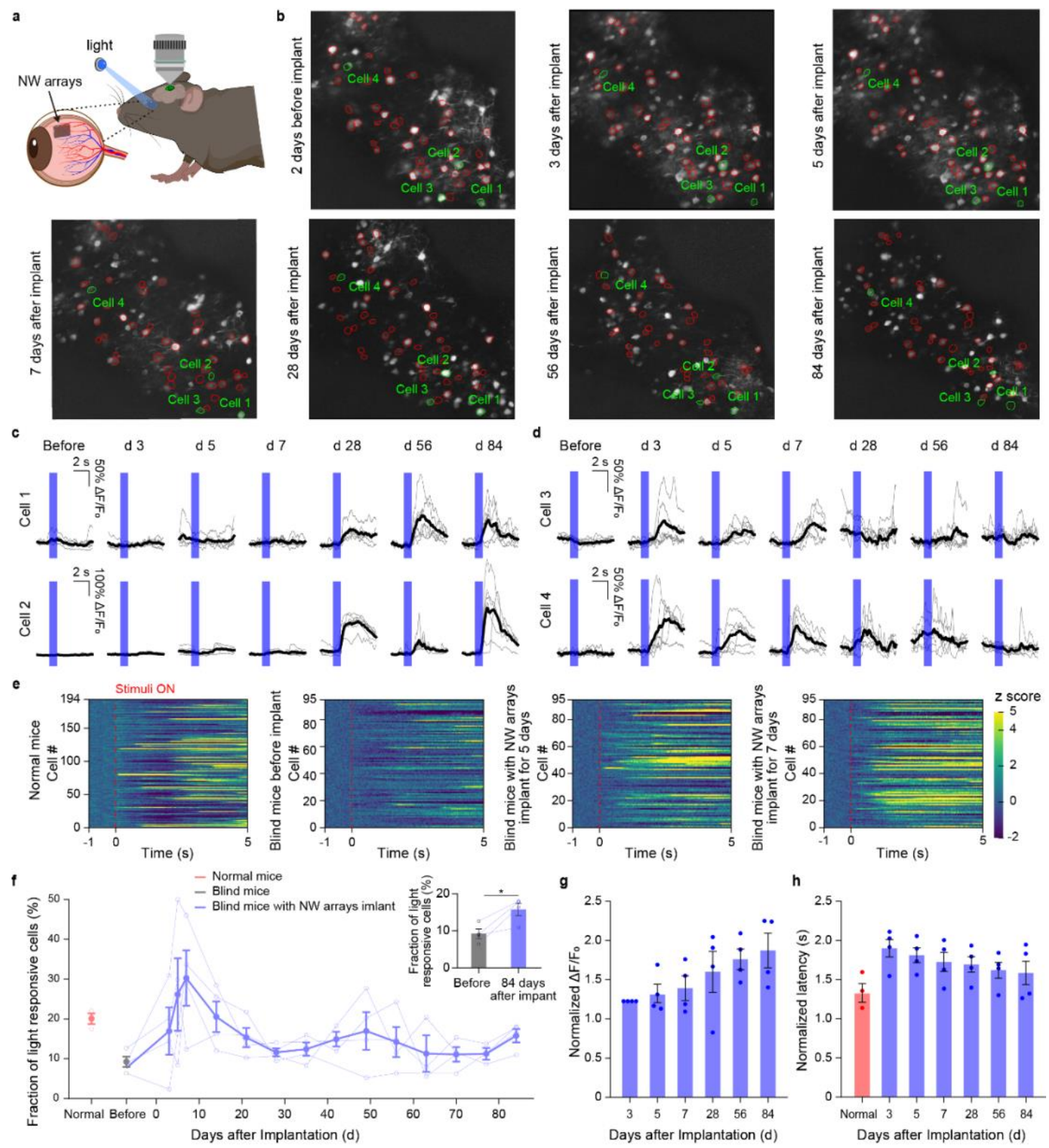

Fig. 5 | Long-term responses to light in V1 neurons of blind mice with NW arrays implant in vivo.

a, Schematics of two-photon calcium imaging in V1 neurons. b, Four example neurons (cell 1-4, indicated with green circles) 2 days before implant surgery and 3, 5, 7, 28, 56, 84 days after NW arrays implant surgery. c-d, The fluorescence trace of 4 example neurons (Cell 1-4 in Fig.5b). e, Change of GCaMP6 fluorescence (averaged over 6 trials) in response to blue LED stimulus (wavelength: $465 / 25 \mathrm{~nm}$, intensity: $6.75 \mu \mathrm{W} \cdot \mathrm{mm}^{-2}$, duration: $1 \mathrm{sec}$ ) in normal mice, blind mice before implant surgery as well as 5 and 7 days after NW implant surgery. The red dotted line indicates the onset of the blue LED stimulus. $\mathbf{f}-\mathbf{h}$, Fraction of light-responsive neurons, normalized $\triangle \mathrm{F} / \mathrm{F}$ and normalized latency of normal mice ( 3 imaging sites from 3 mice), blind mice before and after NW arrays implant (4 imaging sites from 3 mice) $(*, P<0.05$, paired t-test for $\mathbf{f})$. Light intensity of stimulus was tested at a distance of $6 \mathrm{~cm}$ from the stimulus. Data are shown as mean \pm SEM. 


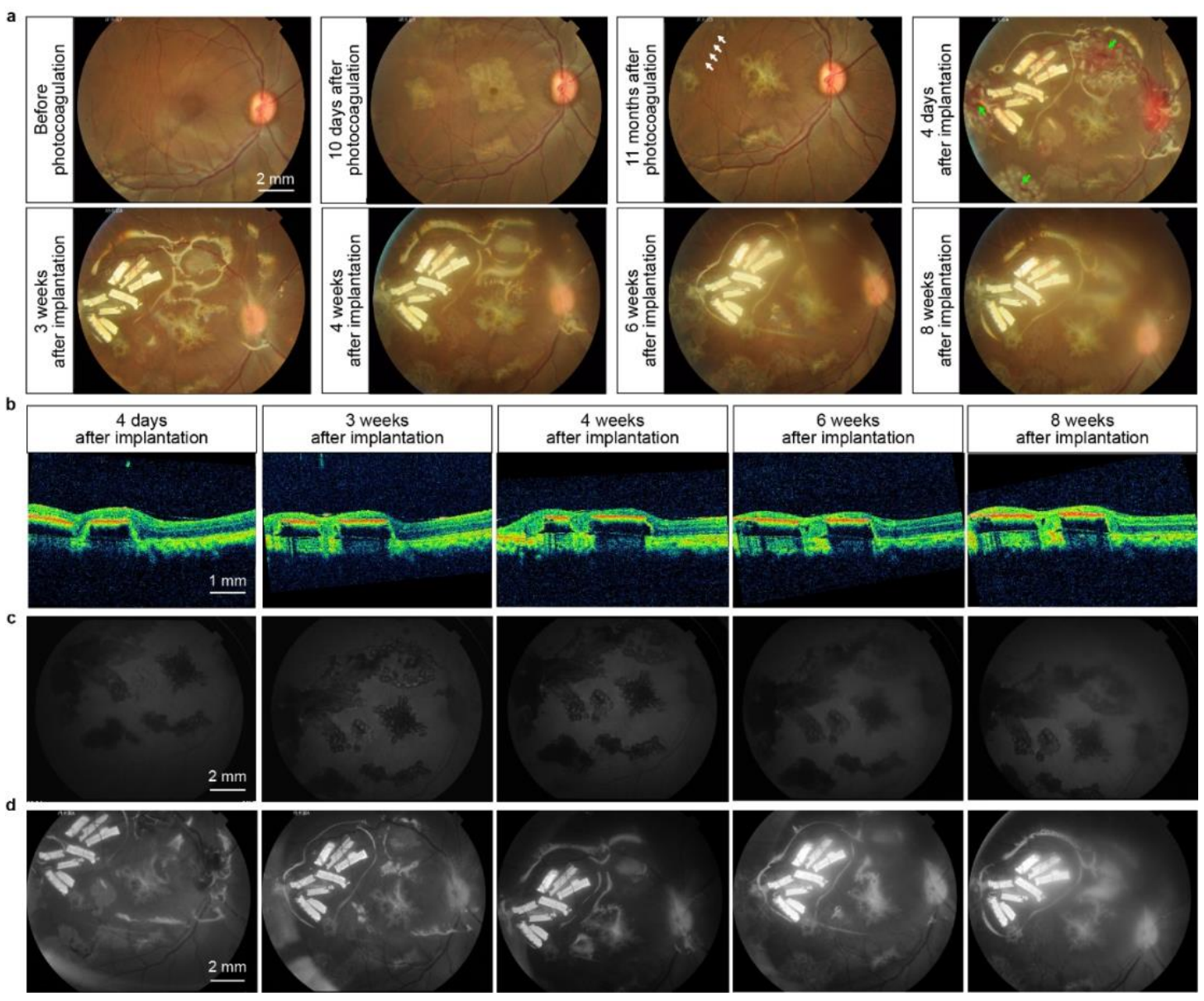

Fig. 6 | Ophthalmological characterization of Monkey A with NW arrays implant.

a, Color fundus photograph of the right eye of Monkey A with eight pieces of NW arrays implanted sub-retinally. The turbid places in the fundus photograph were mainly due to the silicon oil. The white arrows indicated the perifovea area for implant surgery. The green arrows indicated photocoagulation sites to seal the opening in the retina. $\mathbf{b}$. The retinal structure and the interface between the retina and NW arrays in OCT images of Monkey A's right eye. Red colored signals indicated the NW arrays. Dark signals indicated the glass substrate for the NW arrays. c, Fundus autofluorescence images of Monkey A's right eye. d, Red-free mode fundus photography of monkey's right eye. 


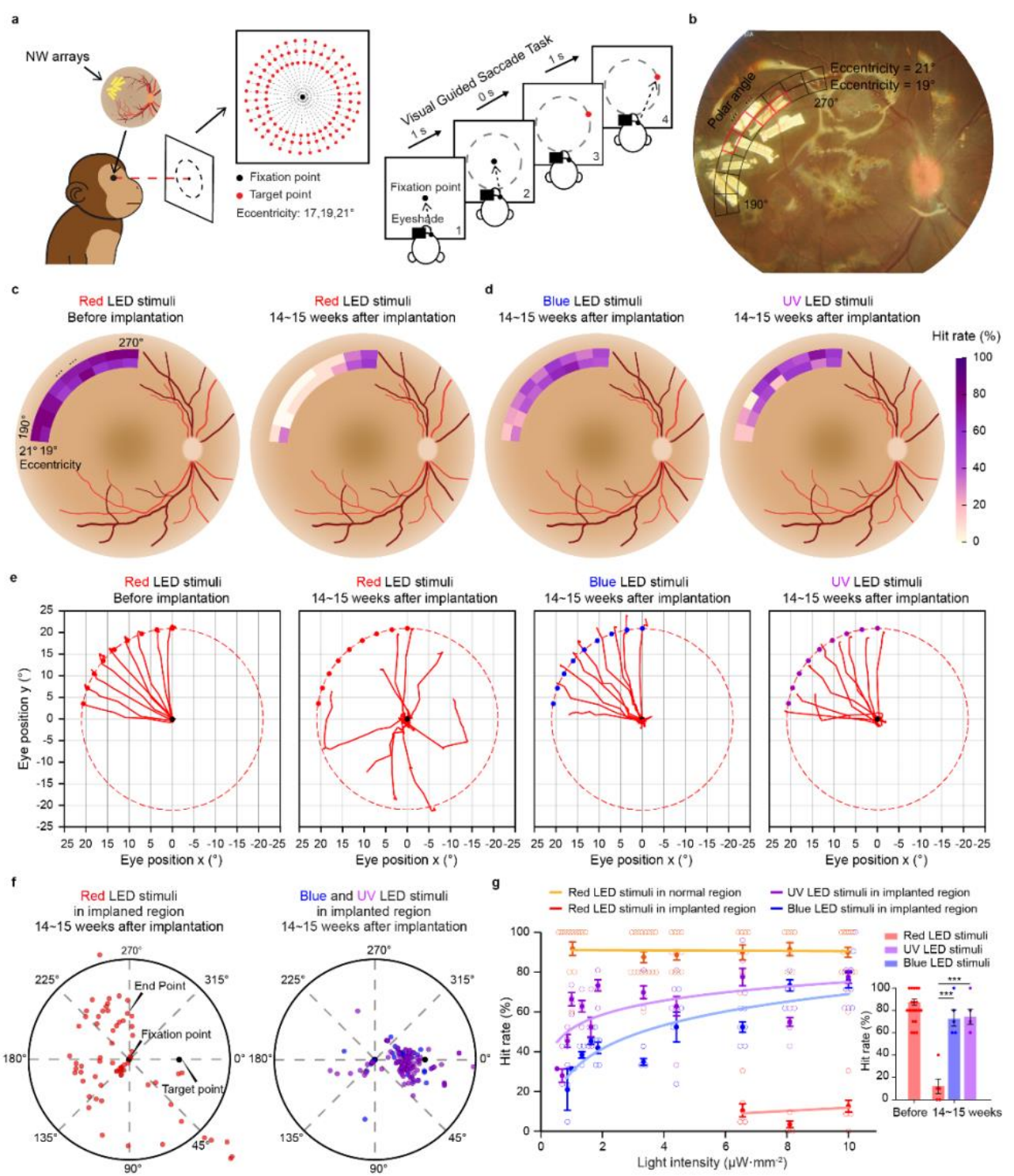

Fig. 7 | Visually-guided saccade behavior for Monkey A with NW arrays implant.

a, Schematics of visually-guided saccade (VGS) behavioral task for Monkey A with NW arrays implant (Red: $642 / 18 \mathrm{~nm}$, Blue: $465 / 25 \mathrm{~nm}$, UV: $360 / 15 \mathrm{~nm}$ ). Monkey A is required to gaze at the fixation point centered at the screen for $1 \mathrm{sec}$, and saccade towards the target point within $1 \mathrm{sec}$. Red LEDs were placed at the fixation point. Red, blue or UV LEDs were placed at the target point. Definition of target area was illustrated in Extended Data Fig.6b. b, NW arrays in the fundus photograph were overlayed onto the visual field (polar angle: 190 to 270-degrees; eccentricity: 19 and 21 degrees). c, Illustration of mean hit rates in VGS task with red LED stimuli $\left(0.5^{\circ}\right.$, polar angle: 190 to 270 degrees; eccentricity: 19 and 21 degrees) before implantation (left) and $14 \sim 15$ weeks after implantation (right). d, Illustration of mean hit rate in VGS task with blue LED (left) and UV LED stimuli (right) $14 \sim 15$ weeks after implantation. e, The saccadic traces in response to red, blue and UV stimuli in the target point (filled red, blue and purple circles, polar angle: 190 to 270 degrees; eccentricity 21 degrees). f, Distribution of normalized saccadic endpoint locations (the mean eye position in a time window when the eye position was stationary $50 \sim 100$ milliseconds after the peak velocity) using red (left), blue and UV (right) LED stimulus $14 \sim 15$ weeks after implantation. LED stimuli were presented at the regions defined by red rectangulars in Fig.7b. g, Left: Hit rates of VGS 
1113 task in normal regions (polar angle: 0 to 180 degrees and 280 to 350 degrees; eccentricity: 19 to 21 degrees) and NW arrays-implanted regions (eccentricity: 19 degrees or 21 degrees, polar angles: 220 to 250 degrees) for different light intensities $\left(0.60 \sim 10.00 \mu \mathrm{W} \cdot \mathrm{mm}^{-2}\right)$. Right: Mean hit rate of VGS task using red, blue and UV LED stimulus in NW arrays-implanted regions before implantation (red light intensity: $7.58 \mu \mathrm{W} \cdot \mathrm{mm}^{-2}, 20$ sessions) and $14 \sim 15$ weeks after implantation (light intensity: $10.00 \mu \mathrm{W} \cdot \mathrm{mm}^{-2}$ for both UV and blue LED, 5 sessions). Light intensity was measured $30 \mathrm{~cm}$ from the stimulus, where Monkey A conducted VGS tasks. ( ${ }^{* *}, P<0.001$, oneway ANOVA for g). Red LED, 642/18 nm. Blue LED, 465/25 nm. UV LED, 360/15 nm. Data are expressed as mean \pm SEM. 

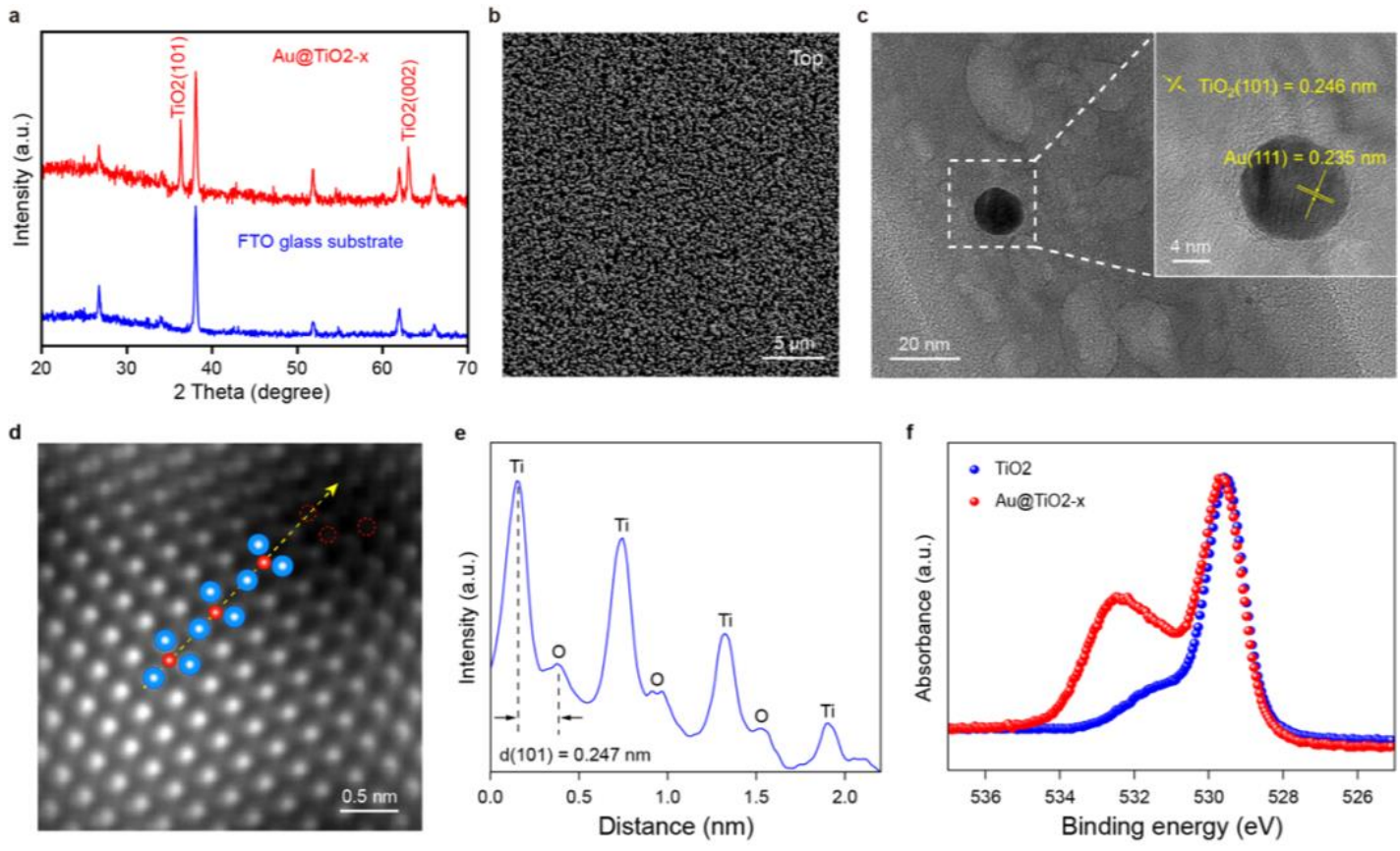

Extended Data Fig. 1 | Morphology and structure characterizations of Au@TiO 2-x.

a, XRD pattern of FTO-coated glass substrate and $\mathrm{Au} @ \mathrm{TiO}_{2-\mathrm{x}}$ grown on FTO-coated glass substrate.

b, Top view of $\mathrm{Au} @ \mathrm{TiO}_{2-\mathrm{x}} . \mathbf{c}$, TEM and the inserted HRTEM image of Au nanoparticles coated on $\mathrm{TiO}_{2}$-NW. d, Spherical aberration-corrected HAADF-STEM image of $\mathrm{Au} @ \mathrm{TiO}_{2-\mathrm{x}}$. e, The corresponding intensity profiles extracted from the dashed yellow line in $\mathrm{b}$. The blue and red balls represent the Ti and $\mathrm{O}$ atoms, respectively. The red dotted circles represent the oxygen vacancies. $\mathbf{f}$, $\mathrm{O} 1 \sec$ XPS spectra of original $\mathrm{TiO}_{2}$ and $\mathrm{Au} @ \mathrm{TiO}_{2-x}$. 


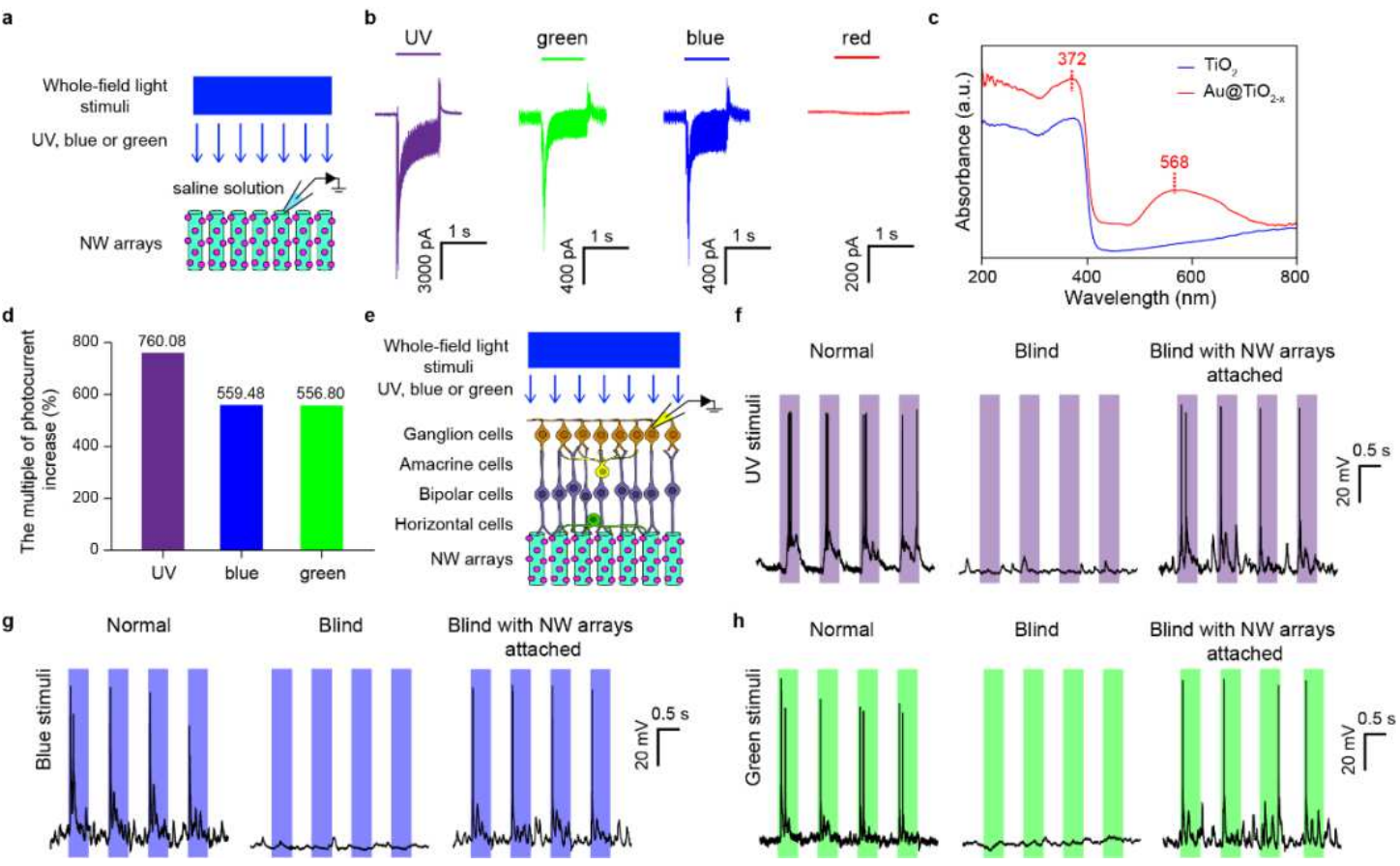

Extended Data Fig. 2 | Photocurrent of Au@TiO 2 -x NW arrays and light responses in NW arrays-attached RGCs in blind mice.

a, Schematic of $\mathrm{Au} @ \mathrm{TiO}_{2-\mathrm{x}} \mathrm{NW}$ arrays photocurrent measurement with UV (375/28 nm, 292.99 $\left.\mu \mathrm{W} \cdot \mathrm{mm}^{-2}\right)$, blue $\left(470 / 20 \mathrm{~nm}, 318.47 \mu \mathrm{W} \cdot \mathrm{mm}^{-2}\right)$ or green $\left(546 / 12 \mathrm{~nm}, 420.38 \mu \mathrm{W} \cdot \mathrm{mm}^{-2}\right)$. The photocurrents were measured by $\mathrm{Ag} / \mathrm{AgCl}$ electrodes attached to the surface of the $\mathrm{NW}$ arrays in normal saline solution. b, Photocurrents generated by illumination of UV, blue, green and red light, receptively by an $\mathrm{Au} @ \mathrm{TiO}_{2-\mathrm{x}} \mathrm{NW}$ arrays. c, UV-visible absorbance spectra of original $\mathrm{TiO}_{2}$ and $\mathrm{Au} @ \mathrm{TiO}_{2-\mathrm{x}}$. d, Compared with the published results ${ }^{26}$, the photocurrent of improved NW arrays increased by $760.08 \%, 559.48 \%$ and $556.80 \%$ under UV, blue and green light, receptively. e, Schematic of light responses recoding of NW arrays-attached RGCs in blind mice. f-h, Responses of RGCs in wild-type, blind and NW arrays-attached blind retinas with UV, blue and green light stimulation, respectively. Horizontal color bars represent the light stimulation color and duration (UV, $375 / 28 \mathrm{~nm}, 292.99 \mu \mathrm{W} \cdot \mathrm{mm}^{-2}$. Blue, $470 / 20 \mathrm{~nm}, 318.47 \mu \mathrm{W} \cdot \mathrm{mm}^{-2}$. Green, 546/12 nm, 420.38 $\mu \mathrm{W} \cdot \mathrm{mm}^{-2}$. Duration, $0.5 \mathrm{sec}$ ). 
a Choice-box-based behavioral test using UV LED light $\begin{array}{ll} & - \text { Normal mice } \\ \text { Group } 1 & - \text { Blind mice with glass implant (4 weeks) } \\ & - \text { Blind mice with NW arrays implant (4 weeks) }\end{array}$

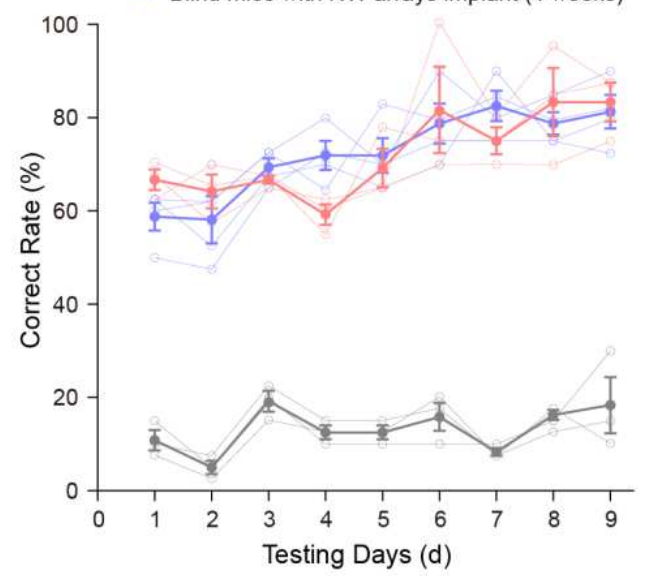

c

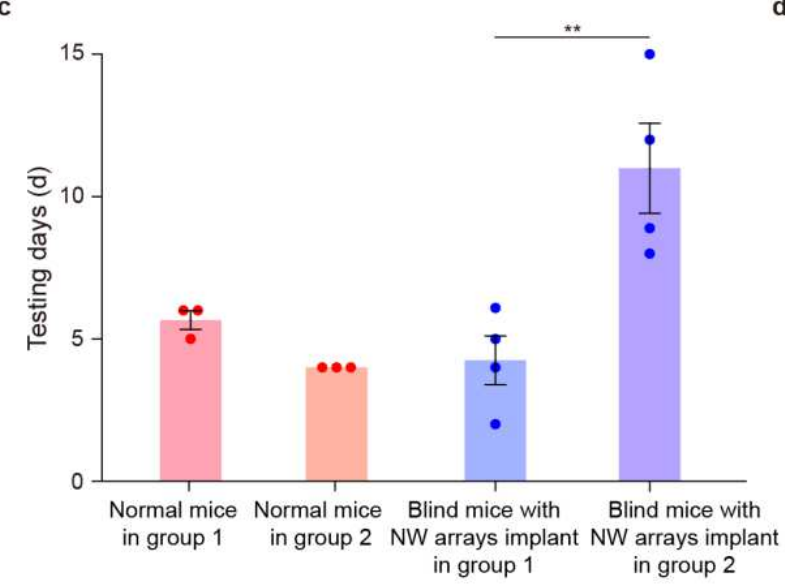

e

Choice-box-based behavioral test using moving light bars

- Normal mice

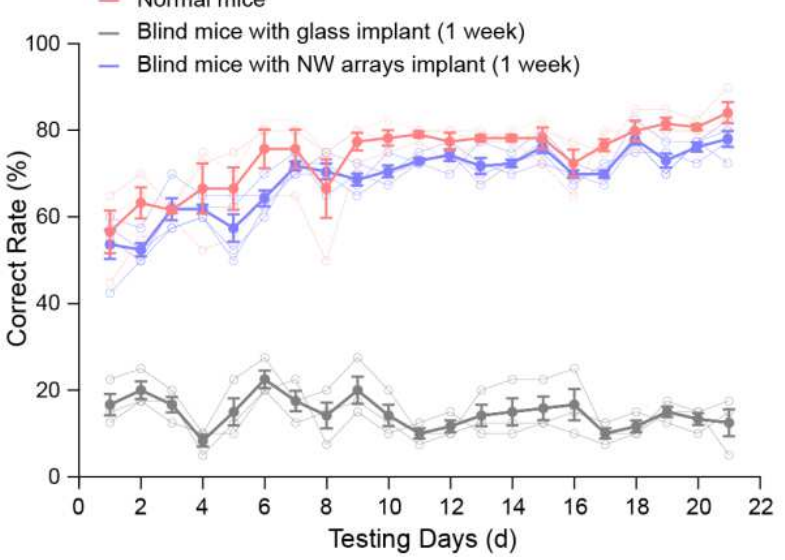

Choice-box-based behavioral test using UV LED light

- Normal mice

Group 2 - Blind mice with glass implant (1 week)

- Blind mice with NW arrays implant (1 week)

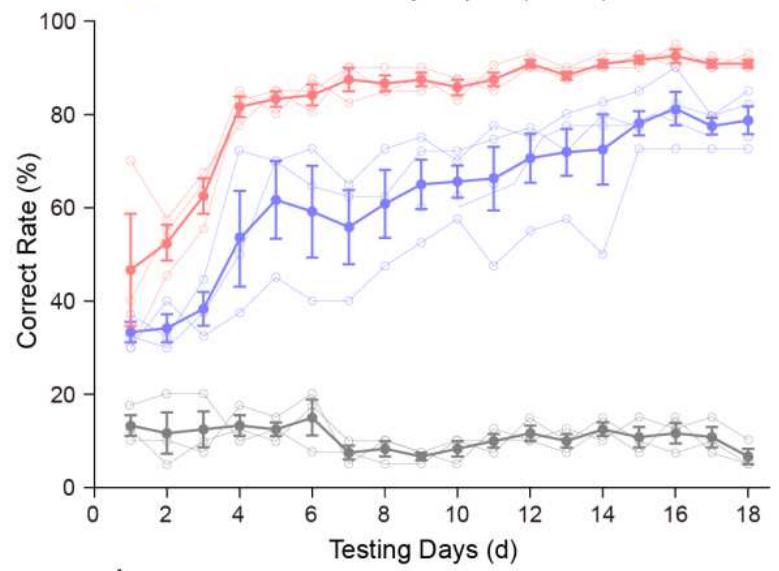

d

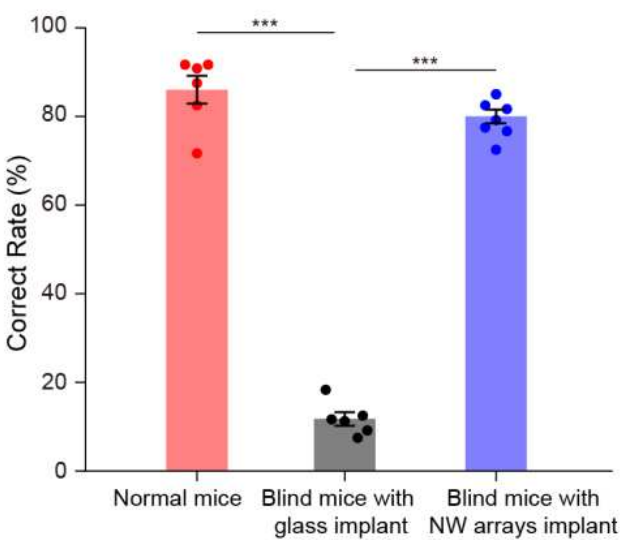

Extended Data Fig. 3 | Choice-box-based behavioral test using LED light, moving bars and flash stimuli at different days of $\mathrm{NW}$-array implant.

a, Correct rates of normal mice $(n=3)$, blind mice with glass implant $(n=3)$ and blind mice with NW arrays-implanted for 4 weeks $(n=4)$ in the choice-box-based behavior test using a UV LED $\left(375 / 15 \mathrm{~nm}, 6.24 \mu \mathrm{W} \cdot \mathrm{mm}^{-2}\right)$. b, Correct rates of normal mice $(\mathrm{n}=3)$, blind mice with glass implant $(\mathrm{n}=3)$ and blind mice with NW arrays-implanted for 1 week $(\mathrm{n}=4)$ in the choice-box-based behavior test using a UV LED $\left(375 / 15 \mathrm{~nm}, 6.24 \mu \mathrm{W} \cdot \mathrm{mm}^{-2}\right)$. c, Number of testing days when the correct rate reached $70 \%$ and maintained steady for 3 days in normal mice in two different groups 
(normal mice group 1 and group 2) and blind mice with NW arrays-implanted for 4 weeks or 1 week after implantation in the choice-box-based behavioral test. d, Correct rates of normal mice $(n=6)$, blind mice with glass implant $(n=6)$ and blind mice with NW arrays implant $(n=8)$ at the same time in c. e, Correct rates of normal mice $(n=3)$, blind mice with glass implant $(n=3)$ and blind mice with NW arrays-implanted for 1 week $(n=4)$ in the choice-box-based behavior test using moving light bars (5.25 degrees, 7.85 degrees $\left./ \mathrm{sec}, 13.38 \mu \mathrm{W} \cdot \mathrm{mm}^{-2}\right)$. f, Correct rates of normal mice $(\mathrm{n}=3)$, blind mice with glass implant $(\mathrm{n}=3)$ and blind mice with NW arrays-implanted for 1 week $(\mathrm{n}=4)$ in the choice-box-based behavior test using flashing light. * indicates a significant difference $(* *, P<0.01$. ***, $P<0.001$, one-way ANOVA for $\mathbf{c}$ and $\mathbf{d})$. Data are expressed as mean \pm SEM. 

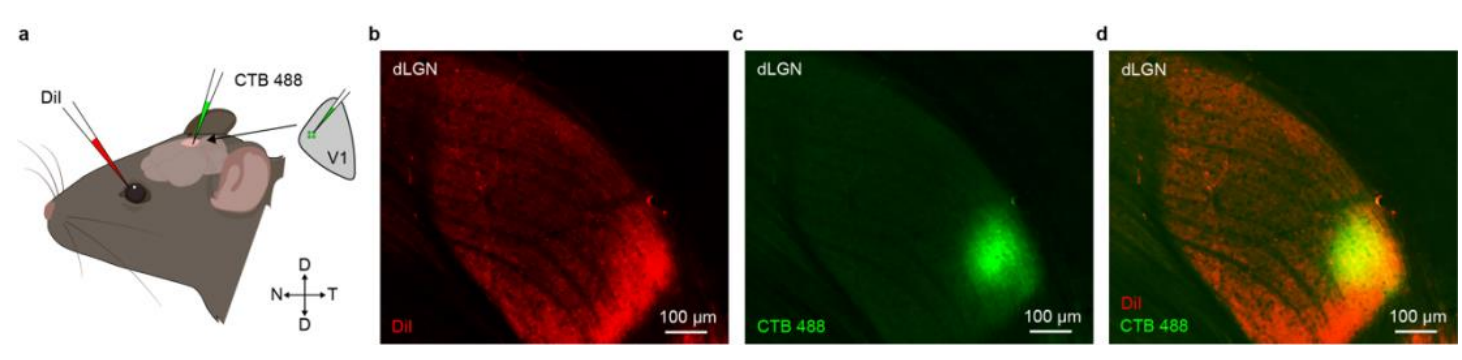

1170

Extended Data Fig. 4 | Position of NW-implant in the retina and its corresponding retinotopic

1172 position in the visual cortex in mice.

1173

a, Fluorescence dye (DiI) were injected introvitreally into mouse's dorsal retina (where NW was implanted). CTB-488 was injected into lateral V1. b-d, DiI (from the retina) and CTB-488 (from V1) signals in the dLGN. 

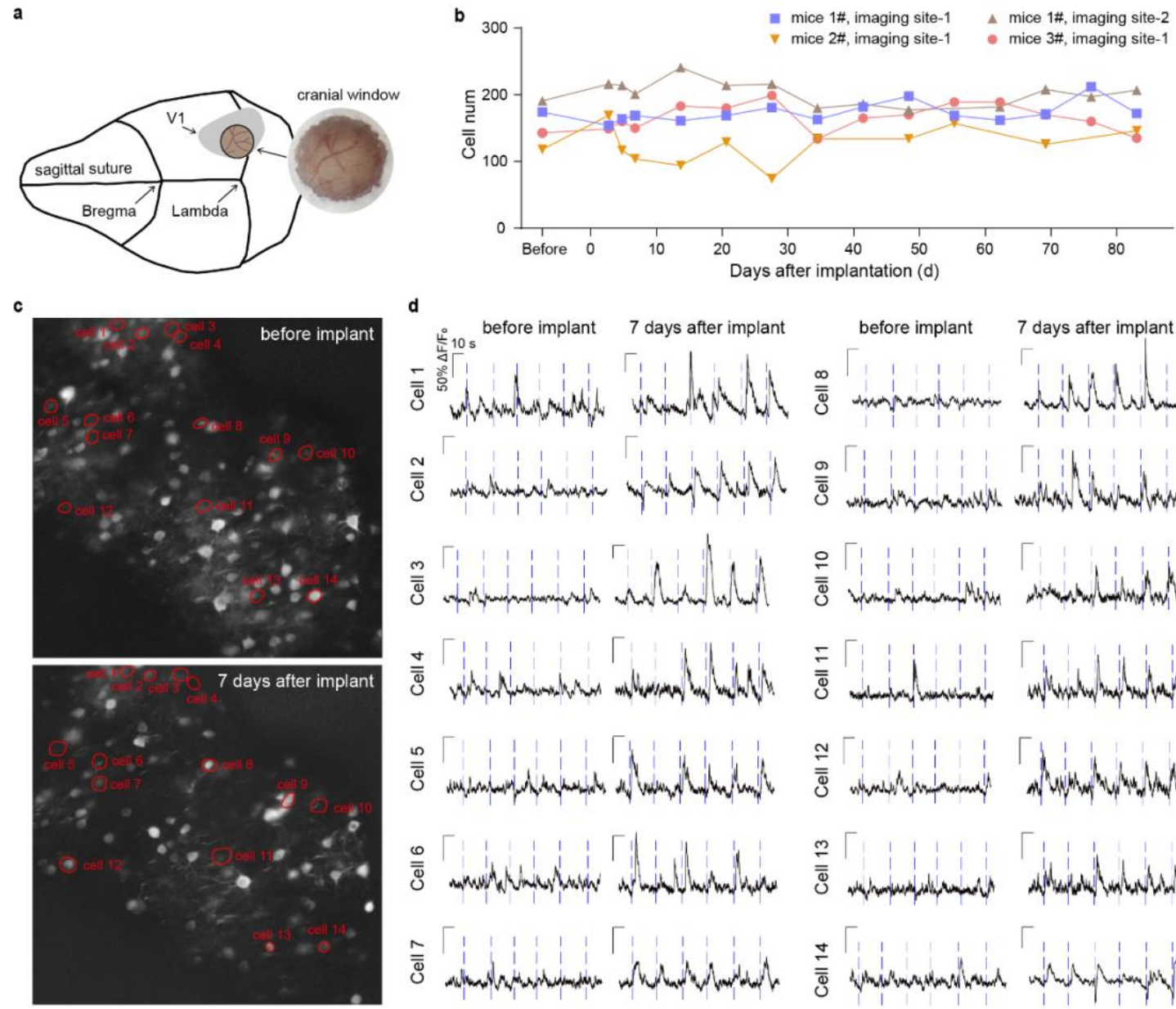

d

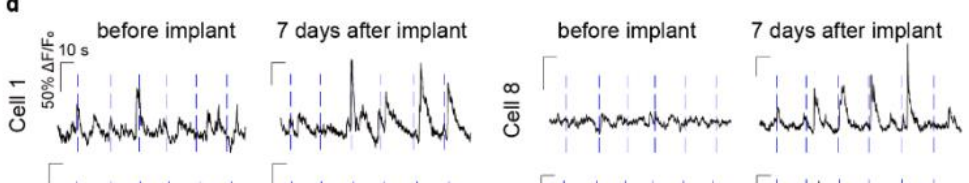

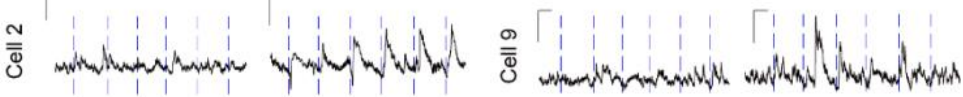

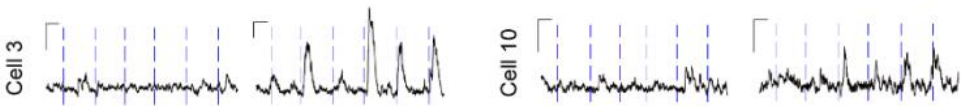

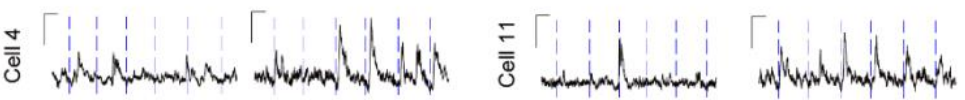
OD

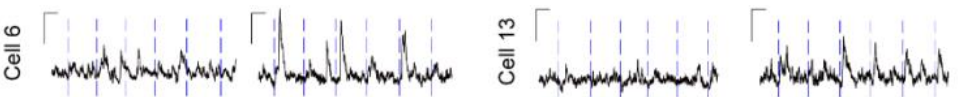

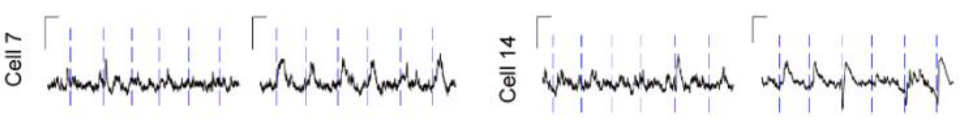
e
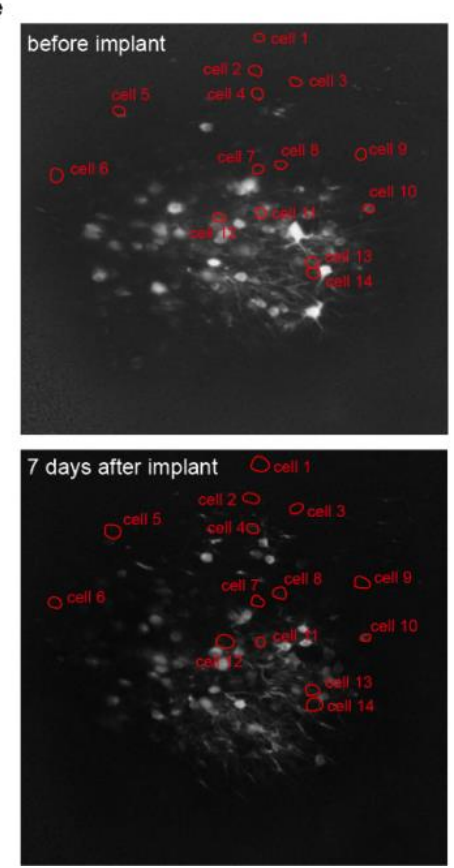

$f \quad-7$ days afterimplant

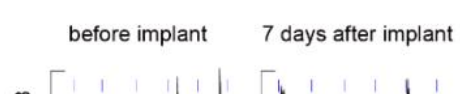

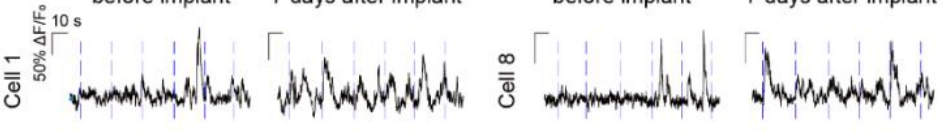

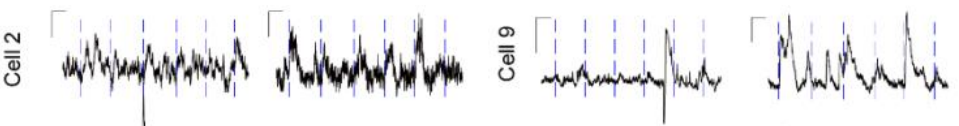

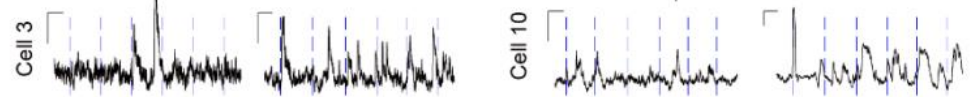

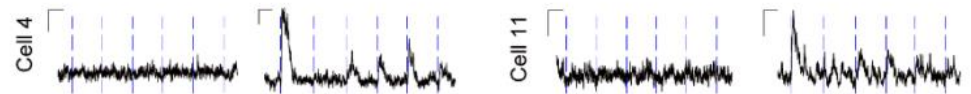

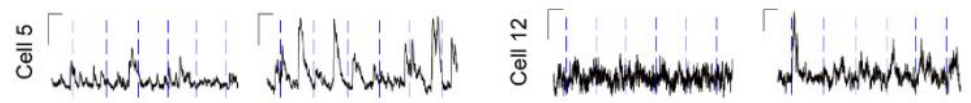

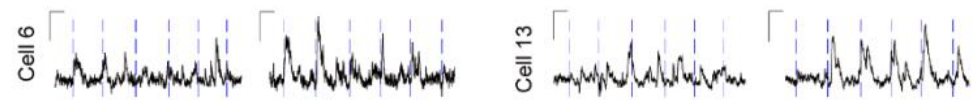

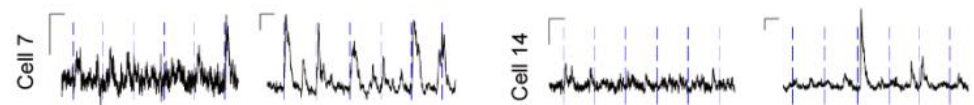

Extended Data Fig. 5 | Long-term light-evoked responses using two-photon calcium imaging in $\mathrm{V} 1$ of $\mathrm{NW}$-implanted blind mice in vivo.

1180 a, Schematic of the position of the cranial window in V1 and close-up of the completed cranial window on the day of surgery. $\mathbf{b}$, Number of neurons recorded at different time points throughout 
the experiment. $\mathbf{c}$ and e, Grayscale image of recording field of two blind mice before implant and 7 days after implant. 14 representative light-responsive neurons were marked by red contour. $\mathbf{d}$ and f, The fluorescence change of neurons in Extended Data Fig. 5 c, e in response to visual stimulation (Blue LED, $465 / 25 \mathrm{~nm}, 6.75 \mu \mathrm{W} \cdot \mathrm{mm}^{-2}$, duration: 1 second). Blue dotted lines indicate the onset time of the visual stimulation. 

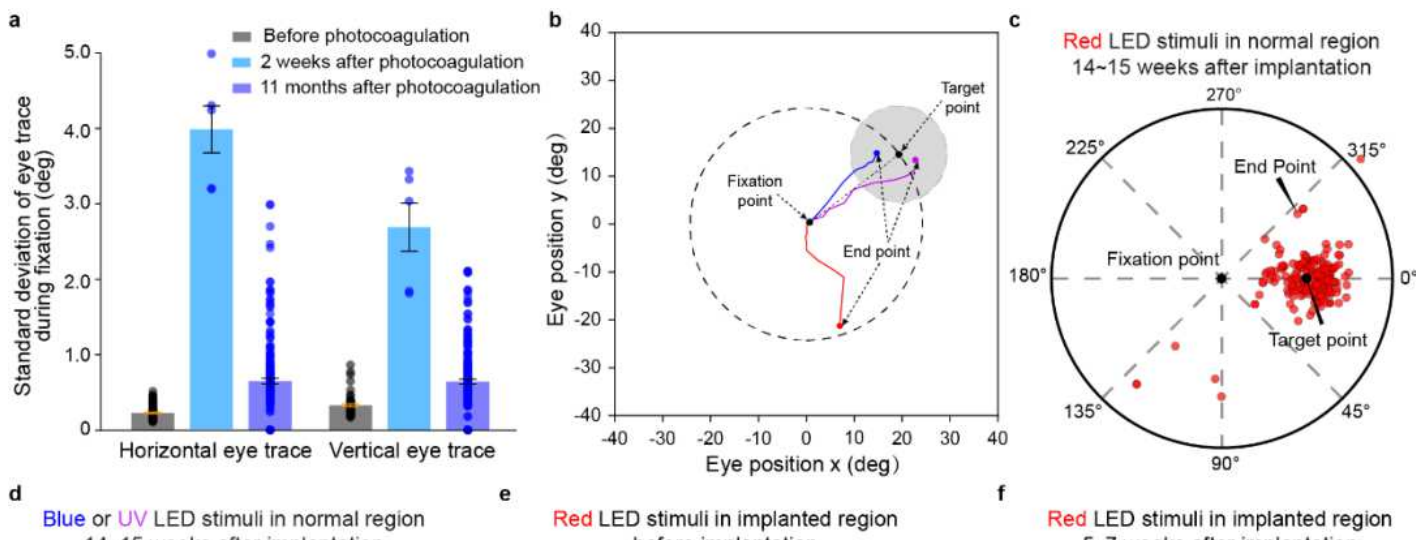

Blue or UV LED stimuli in normal region

Red LED stimuli in implanted region Red LED stimuli in implanted region
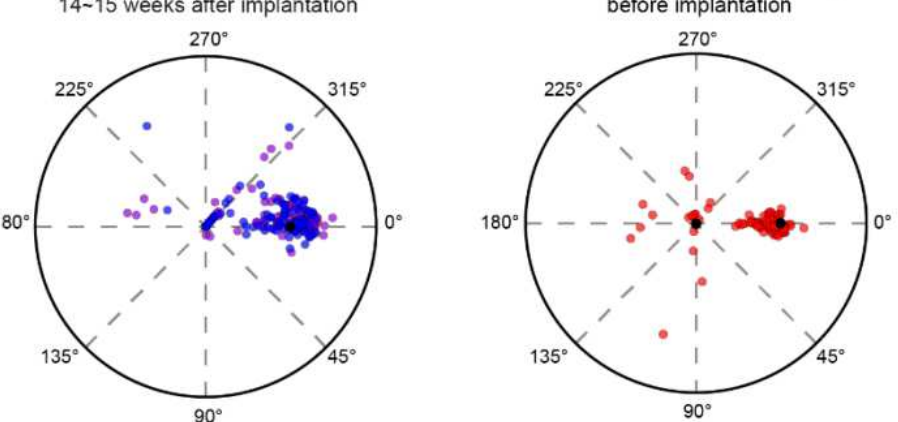

$5 \sim 7$ weeks after implantation

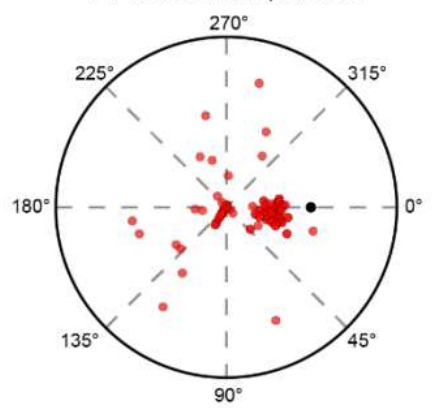

ed LED stimuli in implanted region 10 12 weeks after implantation
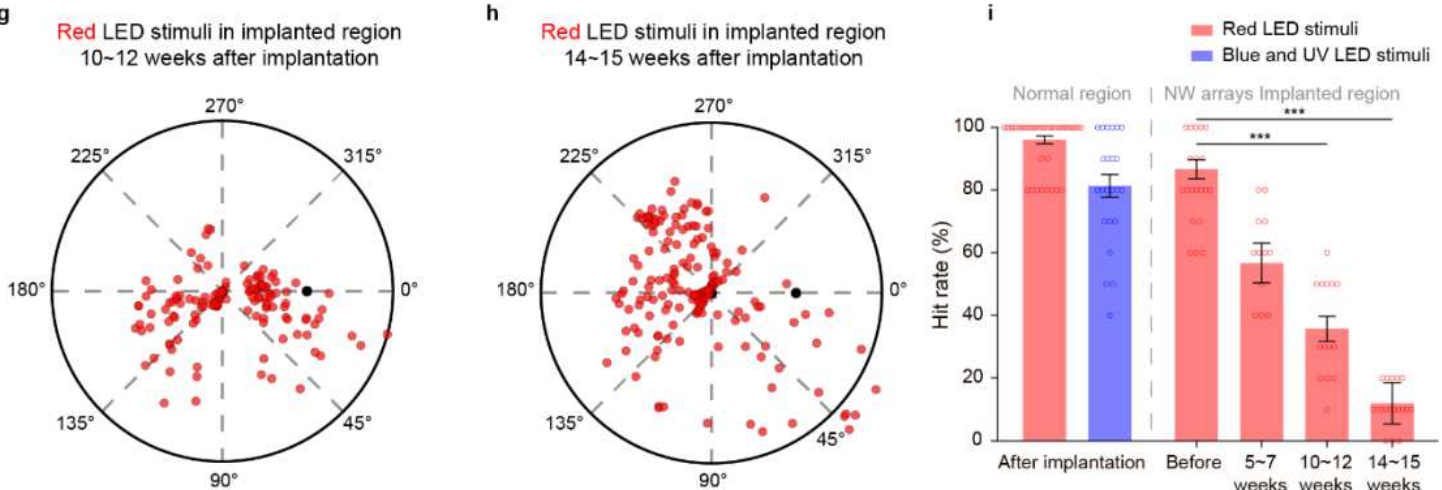

Extended Data Fig. 6 | VGS performance in Monkey A.

a, Standard deviation of Monkey A's horizontal and vertical eye trace during fixation before photocoagulation, 2 weeks and 11 months after photocoagulation. b, Schematic of VGS task. The gray area indicates a 15-degree circular region surrounding the target point (defined as target area, gray region in the figure). c-d, Distribution of normalized saccadic endpoints in normal retinal regions (eccentricities: 19 and 21 degrees, polar angles: 40, 50 and 130 degrees) with red (642/18 $\mathrm{nm})$, blue $(465 / 25 \mathrm{~nm})$ or UV (360/15 nm) LED stimuli. e-h, Distribution of normalized saccadic endpoints using red LED in NW-arrays implanted region (eccentricities: 19 and 21 degrees, polar angles: $200 \sim 250$ degrees) before implantation, $5 \sim 7$ weeks after implantation, $10 \sim 12$ weeks after implantation, and $14 \sim 15$ weeks after implantation. i, Mean hit rates of VGS task in Extended Data Fig.7 c-h. * indicates significant difference (***, $P<0.001$, one-way ANOVA for i). Red LED, $642 / 18 \mathrm{~nm}$. UV LED, 360/15 nm. Blue LED, 465/25 nm. Data are expressed as mean \pm SEM. 
Extended Data Table 1 | Summery of in-vitro photocurrent with the corresponding duration and in-vivo response with the corresponding duration using semiconductors as artificial photoreceptors.

\begin{tabular}{|c|c|c|c|c|c|c|}
\hline Semiconductors & Light source & $\begin{array}{l}\text { In-vitro } \\
\text { photocurr } \\
\text { ent (pA) }\end{array}$ & $\begin{array}{l}\text { In-vitro } \\
\text { duration } \\
\text { (second) }\end{array}$ & $\begin{array}{l}\text { In-vivo } \\
\text { response } \\
(\mathrm{mV})\end{array}$ & $\begin{array}{l}\text { In-vivo } \\
\text { duration } \\
\text { (second) }\end{array}$ & References \\
\hline \multirow{3}{*}{$\mathrm{Au} @ \mathrm{TiO}_{2-\mathrm{x}}$} & $\begin{array}{c}\text { UV } \\
\left(375 \mathrm{~nm}, 292.99 \mu \mathrm{W} \cdot \mathrm{mm}^{-2}\right)\end{array}$ & $\sim 13100$ & $\sim 1$ & $\sim 40$ & $\sim 0.1$ & \multirow{3}{*}{ This work } \\
\hline & $\begin{array}{c}\text { Blue } \\
\left(470 \mathrm{~nm}, 318.47 \mu \mathrm{W} \cdot \mathrm{mm}^{-2}\right)\end{array}$ & $\sim 1300$ & $\sim 1$ & $\sim 50$ & $\sim 0.1$ & \\
\hline & $\begin{array}{c}\text { Green } \\
\left(546 \mathrm{~nm}, 420.38 \mu \mathrm{W} \cdot \mathrm{mm}^{-2}\right)\end{array}$ & $\sim 1100$ & $\sim 1$ & $\sim 50$ & $\sim 0.1$ & \\
\hline \multirow{3}{*}{$\mathrm{Au} @ \mathrm{TiO}_{2}$} & $\begin{array}{c}\mathrm{UV} \\
\left(375 \mathrm{~nm}, 133 \mu \mathrm{W} \cdot \mathrm{mm}^{-2}\right)\end{array}$ & $\sim 1400$ & $\sim 1$ & $\sim 40$ & $\sim 0.05$ & \multirow{3}{*}{$\begin{array}{l}\text { Nat. Commun } \\
2018,9,786^{26}\end{array}$} \\
\hline & $\begin{array}{c}\text { Blue } \\
\left(470 \mathrm{~nm}, 691 \mu \mathrm{W} \cdot \mathrm{mm}^{-2}\right)\end{array}$ & $\sim 100$ & $\sim 1$ & $\sim 80$ & $\sim 0.05$ & \\
\hline & $\begin{array}{c}\text { Green } \\
\left(546 \mathrm{~nm}, 470 \mu \mathrm{W} \cdot \mathrm{mm}^{-2}\right)\end{array}$ & $\sim 100$ & $\sim 1$ & $\sim 60$ & $\sim 0.05$ & \\
\hline \multirow{2}{*}{$\begin{array}{l}\text { Poly(3- } \\
\text { hexylthiophene) }\end{array}$} & $\begin{array}{c}\text { Green } \\
\left(532 \mathrm{~nm}, 15000 \mu \mathrm{W} \cdot \mathrm{mm}^{-2}\right)\end{array}$ & $\sim 250$ & $\sim 0.02$ & I & l & \multirow{2}{*}{$\begin{array}{l}\text { Nat. Photonics } \\
2013,7,40068\end{array}$} \\
\hline & $\begin{array}{c}\text { Green } \\
\left(532 \mathrm{~nm}, 4000 \mu \mathrm{W} \cdot \mathrm{mm}^{-2}\right)\end{array}$ & I & I & $\sim 0.1$ & $\sim 0.01$ & \\
\hline PEDOT:PSS & $\begin{array}{c}\text { Green } \\
\left(530 \mathrm{~nm}, 2 * 10^{5} \mu \mathrm{W} \cdot \mathrm{mm}^{-2}\right)\end{array}$ & I & I & $\sim 0.167$ & $\sim 0.0004$ & $\begin{array}{c}\text { Nat. Mater. } \\
2017,7,40069\end{array}$ \\
\hline $\begin{array}{l}\text { Formamidinium } \\
\text { lead iodide }\end{array}$ & $\begin{array}{c}\text { Green } \\
\left(500 \mathrm{~nm}, 2000 \mu \mathrm{W} \cdot \mathrm{mm}^{-2}\right)\end{array}$ & $\sim 2 * 10^{6}$ & $\sim 0.3$ & I & / & $\begin{array}{c}\text { Nature } 2020, \\
581,278^{22}\end{array}$ \\
\hline \multirow{5}{*}{$\mathrm{Au} @ \mathrm{Si}^{*}$} & $\begin{array}{c}\text { Green } \\
\left(530 \mathrm{~nm}, \sim 4000 \mu \mathrm{W} \cdot \mathrm{mm}^{-2}\right)\end{array}$ & $\sim 10000$ & $\sim 0.01$ & l & l & \multirow{5}{*}{$\begin{array}{c}\text { Nat Biomed } \\
\text { Eng. 2018, 2, } \\
508^{29,70}\end{array}$} \\
\hline & $\begin{array}{c}\text { Green } \\
\left(530 \mathrm{~nm}, \sim 7000 \mu \mathrm{W} \cdot \mathrm{mm}^{-2}\right)\end{array}$ & $\sim 16000$ & $\sim 0.01$ & I & l & \\
\hline & $\begin{array}{c}\text { Green } \\
\left(530 \mathrm{~nm}, 60000 \mu \mathrm{W} \cdot \mathrm{mm}^{-2}\right)\end{array}$ & 85775 & $\sim 0.01$ & l & I & \\
\hline & $\begin{array}{c}\text { Green } \\
\left(532 \mathrm{~nm}, 1.9^{*} 10^{9} \mu \mathrm{W} \cdot \mathrm{mm}^{-2}\right)\end{array}$ & I & l & $\sim 50$ & $\sim 0.012$ & \\
\hline & $\begin{array}{c}\text { Blue } \\
\left(473 \mathrm{~nm}, 85000 \mu \mathrm{W} \cdot \mathrm{mm}^{-2}\right)\end{array}$ & l & I & $\sim 0.04$ & $\sim 0.0005$ & \\
\hline
\end{tabular}


Extended Data Table $2 \mid$ Hit rate of visually-guided saccade task.

\begin{tabular}{|c|c|c|c|c|c|}
\hline \multirow{2}{*}{\multicolumn{2}{|c|}{$\begin{array}{l}\text { Positions of saccadic } \\
\text { target point }\end{array}$}} & \multicolumn{4}{|c|}{ Hit Rate (\%) } \\
\hline & & \multirow{3}{*}{$\begin{array}{c}\begin{array}{c}\text { Before } \\
\text { implantation: }\end{array} \\
\text { Red } \\
\text { LED }\end{array}$} & \multicolumn{3}{|c|}{$\begin{array}{l}14 \sim 15 \text { weeks } \\
\text { after implantation: }\end{array}$} \\
\hline \multirow{2}{*}{$\begin{array}{l}\text { Eccentricity } \\
\text { (degree) }\end{array}$} & \multirow{2}{*}{$\begin{array}{l}\text { Polar angle } \\
\text { (degree) }\end{array}$} & & Red & Blue & UV \\
\hline & & & LED & LED & LED \\
\hline \multirow{9}{*}{19} & 190 & 86 & 40 & 40 & 20 \\
\hline & 200 & 100 & 0 & 26 & 40 \\
\hline & 210 & 93 & 10 & 50 & 50 \\
\hline & 220 & 66 & 10 & 46 & 60 \\
\hline & 230 & 80 & 10 & 60 & 20 \\
\hline & 240 & 100 & 10 & 80 & 70 \\
\hline & 250 & 73 & 30 & 85 & 70 \\
\hline & 260 & 80 & 50 & 55 & 40 \\
\hline & 270 & 73 & 70 & 50 & 60 \\
\hline \multirow{9}{*}{21} & 190 & 100 & 10 & 20 & 20 \\
\hline & 200 & 100 & 0 & 30 & 30 \\
\hline & 210 & 93 & 0 & 40 & 0 \\
\hline & 220 & 80 & 0 & 60 & 70 \\
\hline & 230 & 86 & 0 & 40 & 80 \\
\hline & 240 & 86 & 10 & 70 & 60 \\
\hline & 250 & 93 & 10 & 50 & 50 \\
\hline & 260 & 100 & 40 & 40 & 90 \\
\hline & 270 & 100 & 60 & 60 & 70 \\
\hline
\end{tabular}


Extended Data Table $3 \mid$ Statistical detail information for figures

\begin{tabular}{|c|c|c|c|c|}
\hline Fig. 1d UV & $\begin{array}{l}\text { Normal mice (Normal) VS Blind } \\
\text { mice with Glass implant (Glass) }\end{array}$ & Normal: $\mathrm{n}=3$, Glass: $\mathrm{n}=3$ & $\begin{array}{l}\text { One-way ANOVA with } \\
\text { Tukey post-hoc test. }\end{array}$ & $\mathrm{F}=1.977, \mathrm{P}<0.001$ \\
\hline Fig. 1d UV & $\begin{array}{l}\text { Normal VS Blind mice with NW } \\
\text { arrays implant (NW arrays) }\end{array}$ & Normal: $n=3, N W$ arrays: $n=4$ & $\begin{array}{l}\text { One-way ANOVA with } \\
\text { Tukey post-hoc test. }\end{array}$ & $\mathrm{F}=1.977, \mathrm{P}=0.0236$ \\
\hline Fig. 1d UV & Glass VS NW arrays & Glass: $n=3, N W$ arrays: $n=4$ & $\begin{array}{l}\text { One-way ANOVA with } \\
\text { Tukey post-hoc test. }\end{array}$ & $\mathrm{F}=1.977, \mathrm{P}<0.001$ \\
\hline Fig. 1d Green & Normal VS Glass & Normal: $\mathrm{n}=3$, Glass: $\mathrm{n}=3$ & $\begin{array}{l}\text { One-way ANOVA with } \\
\text { Tukey post-hoc test. }\end{array}$ & $\mathrm{F}=1.141, \mathrm{P}<0.001$ \\
\hline Fig. 1d Green & Glass VS NW arrays & Glass: $n=3, N W$ arrays: $n=4$ & $\begin{array}{l}\text { One-way ANOVA with } \\
\text { Tukey post-hoc test. }\end{array}$ & $\mathrm{F}=1.141, \mathrm{P}<0.001$ \\
\hline Fig. 1d Blue & Normal VS Glass & Normal: $n=3$, Glass: $n=3$ & $\begin{array}{l}\text { One-way ANOVA with } \\
\text { Tukey post-hoc test. }\end{array}$ & $\mathrm{F}=1.235, \mathrm{P}<0.001$ \\
\hline Fig. 1d Blue & Glass VS NW arrays & Glass: $n=3, N W$ arrays: $n=4$ & $\begin{array}{l}\text { One-way ANOVA with } \\
\text { Tukey post-hoc test. }\end{array}$ & $\mathrm{F}=1.235, \mathrm{P}<0.001$ \\
\hline Fig. 1e $0.64 \mu \mathrm{W} \cdot \mathrm{mm}^{-2}$ & Normal VS NW arrays & Normal: $n=3, N W$ arrays: $n=4$ & $\begin{array}{l}\text { One-way ANOVA with } \\
\text { Tukey post-hoc test. }\end{array}$ & $\mathrm{F}=0.3425, \mathrm{P}<0.001$ \\
\hline Fig. $1 \mathrm{e} 0.64 \mu \mathrm{W} \cdot \mathrm{mm}^{-2}$ & Glass VS NW arrays & Glass: $n=3, N W$ arrays: $n=4$ & $\begin{array}{l}\text { One-way ANOVA with } \\
\text { Tukey post-hoc test. }\end{array}$ & $\mathrm{F}=0.3425, \mathrm{P}<0.001$ \\
\hline Fig. $1 \mathrm{e} 1.53 \mu \mathrm{W} \cdot \mathrm{mm}^{-2}$ & Normal VS NW arrays & Normal: $n=3, N W$ arrays: $n=4$ & $\begin{array}{l}\text { One-way ANOVA with } \\
\text { Tukey post-hoc test. }\end{array}$ & $\mathrm{F}=0.3164, \mathrm{P}<0.001$ \\
\hline Fig. $1 \mathrm{e} 1.53 \mu \mathrm{W} \cdot \mathrm{mm}^{-2}$ & Glass VS NW arrays & Glass: $n=3, N W$ arrays: $n=4$ & $\begin{array}{l}\text { One-way ANOVA with } \\
\text { Tukey post-hoc test. }\end{array}$ & $\mathrm{F}=0.3164, \mathrm{P}<0.001$ \\
\hline Fig. $1 \mathrm{e} 2.93 \mu \mathrm{W} \cdot \mathrm{mm}^{-2}$ & Glass VS NW arrays & Glass: $n=3, N W$ arrays: $n=4$ & $\begin{array}{l}\text { One-way ANOVA with } \\
\text { Tukey post-hoc test. }\end{array}$ & $\mathrm{F}=0.4800, \mathrm{P}<0.001$ \\
\hline
\end{tabular}




\begin{tabular}{|c|c|c|c|c|}
\hline Fig. 1e $3.31 \mu \mathrm{W} \cdot \mathrm{mm}^{-2}$ & Glass VS NW arrays & Glass: $n=3, N W$ arrays: $n=4$ & $\begin{array}{l}\text { One-way ANOVA with } \\
\text { Tukey post-hoc test. }\end{array}$ & $\mathrm{F}=0.5706, \mathrm{P}<0.001$ \\
\hline Fig. 1e $6.75 \mu \mathrm{W} \cdot \mathrm{mm}^{-2}$ & Glass VS NW arrays & Glass: $n=3, N W$ arrays: $n=4$ & $\begin{array}{l}\text { One-way ANOVA with } \\
\text { Tukey post-hoc test. }\end{array}$ & $\mathrm{F}=1.236, \mathrm{P}<0.001$ \\
\hline Fig. $1 \mathrm{f} 1.15 \mu \mathrm{W} \cdot \mathrm{mm}^{-2}$ & Normal VS NW arrays & Normal: $n=3$, NW arrays: $n=4$ & $\begin{array}{l}\text { One-way ANOVA with } \\
\text { Tukey post-hoc test. }\end{array}$ & $\mathrm{F}=0.1522, \mathrm{P}<0.001$ \\
\hline Fig. 1f $1.15 \mu \mathrm{W} \cdot \mathrm{mm}^{-2}$ & Glass VS NW arrays & Glass: $n=3, N W$ arrays: $n=4$ & $\begin{array}{l}\text { One-way ANOVA with } \\
\text { Tukey post-hoc test. }\end{array}$ & $\mathrm{F}=0.1522, \mathrm{P}<0.001$ \\
\hline Fig. 1f $2.04 \mu \mathrm{W} \cdot \mathrm{mm}^{-2}$ & Normal VS NW arrays & Normal: $n=3$, NW arrays: $n=4$ & $\begin{array}{l}\text { One-way ANOVA with } \\
\text { Tukey post-hoc test. }\end{array}$ & $\mathrm{F}=0.1026, \mathrm{P}<0.001$ \\
\hline Fig. 1f $2.04 \mu \mathrm{W} \cdot \mathrm{mm}^{-2}$ & Glass VS NW arrays & Glass: $n=3, N W$ arrays: $n=4$ & $\begin{array}{l}\text { One-way ANOVA with } \\
\text { Tukey post-hoc test. }\end{array}$ & $\mathrm{F}=0.1026, \mathrm{P}<0.001$ \\
\hline Fig. $1 \mathrm{f} 4.20 \mu \mathrm{W} \cdot \mathrm{mm}^{-2}$ & Normal VS NW arrays & Normal: $n=3, N W$ arrays: $n=4$ & $\begin{array}{l}\text { One-way ANOVA with } \\
\text { Tukey post-hoc test. }\end{array}$ & $\mathrm{F}=1.141, \mathrm{P}<0.001$ \\
\hline Fig. 1f $4.20 \mu \mathrm{W} \cdot \mathrm{mm}^{-2}$ & Glass VS NW arrays & Glass: $n=3, N W$ arrays: $n=4$ & $\begin{array}{l}\text { One-way ANOVA with } \\
\text { Tukey post-hoc test. }\end{array}$ & $\mathrm{F}=1.141, \mathrm{P}<0.001$ \\
\hline Fig. $1 \mathrm{f} 7.83 \mu \mathrm{W} \cdot \mathrm{mm}^{-2}$ & Normal VS NW arrays & Normal: $n=3, N W$ arrays: $n=4$ & $\begin{array}{l}\text { One-way ANOVA with } \\
\text { Tukey post-hoc test. }\end{array}$ & $\mathrm{F}=0.3786, \mathrm{P}=0.004$ \\
\hline Fig. 1f $7.83 \mu \mathrm{W} \cdot \mathrm{mm}^{-2}$ & Glass VS NW arrays & Glass: $n=3, N W$ arrays: $n=4$ & $\begin{array}{l}\text { One-way ANOVA with } \\
\text { Tukey post-hoc test. }\end{array}$ & $\mathrm{F}=0.3786, \mathrm{P}<0.001$ \\
\hline Fig. 2e 1.92 degree & Normal VS Blind & Normal: $n=9$, Blind: $n=10$ & $\begin{array}{l}\text { One-way ANOVA with } \\
\text { Tukey post-hoc test. }\end{array}$ & $\mathrm{F}=3.013, \mathrm{P}=0.0419$ \\
\hline Fig. 2e 5.76 degree & Blind VS NW arrays & Blind: $n=10, N W$ arrays: $n=16$ & $\begin{array}{l}\text { One-way ANOVA with } \\
\text { Tukey post-hoc test. }\end{array}$ & $\mathrm{F}=2.110, \mathrm{P}=0.0043$ \\
\hline Fig. 2f 3.20 degree & Blind VS NW arrays & Blind: $n=10, N W$ arrays: $n=16$ & $\begin{array}{l}\text { One-way ANOVA with } \\
\text { Tukey post-hoc test. }\end{array}$ & $\mathrm{F}=6.679, \mathrm{P}=0.0161$ \\
\hline
\end{tabular}




\begin{tabular}{|c|c|c|c|c|}
\hline Fig. 2f 3.84 degree & Blind VS NW arrays & Blind: $n=10, N W$ arrays: $n=16$ & $\begin{array}{l}\text { One-way ANOVA with } \\
\text { Tukey post-hoc test. }\end{array}$ & $\mathrm{F}=6.640, \mathrm{P}=0.0077$ \\
\hline Fig. 2f 5.12 degree & Normal VS Blind & Normal: $\mathrm{n}=9$, Blind: $\mathrm{n}=10$ & $\begin{array}{l}\text { One-way ANOVA with } \\
\text { Tukey post-hoc test. }\end{array}$ & $\mathrm{F}=2.035, \mathrm{P}=0.0182$ \\
\hline Fig. 2f 5.76 degree & Normal VS Blind & Normal: $\mathrm{n}=9$, Blind: $\mathrm{n}=10$ & $\begin{array}{l}\text { One-way ANOVA with } \\
\text { Tukey post-hoc test. }\end{array}$ & $\mathrm{F}=1.975, \mathrm{P}=0.0199$ \\
\hline Fig. $2 \mathrm{~h} 2.63$ degree & Normal VS NW arrays & Normal: $n=3, N W$ arrays: $n=4$ & $\begin{array}{l}\text { Two-way RM ANOVA test } \\
\text { with Tukey post-hoc test. }\end{array}$ & $\mathrm{F}=0.3912, \mathrm{P}=0.0179$ \\
\hline Fig. $2 \mathrm{~h} 2.63$ degree & Glass VS NW arrays & Glass: $n=3, N W$ arrays: $n=4$ & $\begin{array}{l}\text { Two-way RM ANOVA test } \\
\text { with Tukey post-hoc test. }\end{array}$ & $\mathrm{F}=0.3912, \mathrm{P}<0.001$ \\
\hline Fig. 2h 3.94 degree & Glass VS NW arrays & Glass: $n=3, N W$ arrays: $n=4$ & $\begin{array}{l}\text { Two-way RM ANOVA test } \\
\text { with Tukey post-hoc test. }\end{array}$ & $\mathrm{F}=0.7000, \mathrm{P}<0.001$ \\
\hline Fig. $2 \mathrm{~h} 5.25$ degree & Glass VS NW arrays & Glass: $n=3, N W$ arrays: $n=4$ & $\begin{array}{l}\text { Two-way RM ANOVA test } \\
\text { with Tukey post-hoc test. }\end{array}$ & $\mathrm{F}=0.06891, \mathrm{P}<0.001$ \\
\hline Fig. 2h 6.57 degree & Glass VS NW arrays & Glass: $n=3, N W$ arrays: $n=4$ & $\begin{array}{l}\text { Two-way RM ANOVA test } \\
\text { with Tukey post-hoc test. }\end{array}$ & $\mathrm{F}=0.6192, \mathrm{P}<0.001$ \\
\hline Fig. 2h 7.88 degree & Glass VS NW arrays & Glass: $n=3, N W$ arrays: $n=4$ & $\begin{array}{l}\text { Two-way RM ANOVA test } \\
\text { with Tukey post-hoc test. }\end{array}$ & $\mathrm{F}=0.8694, \mathrm{P}<0.001$ \\
\hline Fig. 2i 5.23 degree/s & Glass VS NW arrays & Glass: $n=3, N W$ arrays: $n=4$ & $\begin{array}{l}\text { Two-way RM ANOVA test } \\
\text { with Tukey post-hoc test. }\end{array}$ & $\mathrm{F}=0.2753, \mathrm{P}<0.001$ \\
\hline Fig. 2i 6.54 degree/s & Glass VS NW arrays & Glass: $n=3, N W$ arrays: $n=4$ & $\begin{array}{l}\text { Two-way RM ANOVA test } \\
\text { with Tukey post-hoc test. }\end{array}$ & $\mathrm{F}=0.3595, \mathrm{P}<0.001$ \\
\hline Fig. $2 \mathrm{i} 7.85$ degree/s & Glass VS NW arrays & Glass: $n=3, N W$ arrays: $n=4$ & $\begin{array}{l}\text { Two-way RM ANOVA test } \\
\text { with Tukey post-hoc test. }\end{array}$ & $\mathrm{F}=0.6891, \mathrm{P}<0.001$ \\
\hline Fig. 2i 9.18 degree/s & Glass VS NW arrays & Glass: $n=3, N W$ arrays: $n=4$ & $\begin{array}{l}\text { Two-way RM ANOVA test } \\
\text { with Tukey post-hoc test. }\end{array}$ & $\mathrm{F}=0.5623, \mathrm{P}<0.001$ \\
\hline
\end{tabular}




\begin{tabular}{|c|c|c|c|c|}
\hline Fig. $2 \mathrm{i} 10.47$ degree/s & Glass VS NW arrays & Glass: $n=3, N W$ arrays: $n=4$ & $\begin{array}{l}\text { Two-way RM ANOVA test } \\
\text { with Tukey post-hoc test. }\end{array}$ & $\mathrm{F}=0.1000, \mathrm{P}<0.001$ \\
\hline Fig. $3 \mathrm{e} 2.5 \mathrm{~Hz}$ & Blind VS NW arrays & Blind: $n=6, N W$ arrays: $n=15$ & $\begin{array}{l}\text { One-way ANOVA with } \\
\text { Tukey post-hoc test. }\end{array}$ & $\mathrm{F}=3.864, \mathrm{P}=0.0086$ \\
\hline Fig. 3f $1.67 \mathrm{~Hz}$ & Blind VS NW arrays & Blind: $n=6, N W$ arrays: $n=15$ & $\begin{array}{l}\text { One-way ANOVA with } \\
\text { Tukey post-hoc test. }\end{array}$ & $\mathrm{F}=2.720, \mathrm{P}=0.00824$ \\
\hline Fig. 3f $2.50 \mathrm{~Hz}$ & Blind VS NW arrays & Blind: $n=6, N W$ arrays: $n=15$ & $\begin{array}{l}\text { One-way ANOVA with } \\
\text { Tukey post-hoc test. }\end{array}$ & $\mathrm{F}=1.422, \mathrm{P}=0.00482$ \\
\hline Fig. 3f $5.00 \mathrm{~Hz}$ & Blind VS NW arrays & Blind: $n=6, N W$ arrays: $n=15$ & $\begin{array}{l}\text { One-way ANOVA with } \\
\text { Tukey post-hoc test. }\end{array}$ & $\mathrm{F}=2.085, \mathrm{P}=0.00308$ \\
\hline Fig. $3 \mathrm{~h} 1 \mathrm{~Hz}$ & Normal VS NW arrays & Normal: $n=3, N W$ arrays: $n=4$ & $\begin{array}{l}\text { Two-way RM ANOVA test } \\
\text { with Tukey post-hoc test. }\end{array}$ & $\mathrm{F}=0.5765, \mathrm{P}=0.0023$ \\
\hline Fig. $3 \mathrm{~h} 1 \mathrm{~Hz}$ & Glass VS NW arrays & Glass: $n=3, N W$ arrays: $n=4$ & $\begin{array}{l}\text { Two-way RM ANOVA test } \\
\text { with Tukey post-hoc test. }\end{array}$ & $\mathrm{F}=0.5765, \mathrm{P}<0.001$ \\
\hline Fig. $3 \mathrm{~h} 2 \mathrm{~Hz}$ & Glass VS NW arrays & Glass: $n=3, N W$ arrays: $n=4$ & $\begin{array}{l}\text { Two-way RM ANOVA test } \\
\text { with Tukey post-hoc test. }\end{array}$ & $\mathrm{F}=0.09172, \mathrm{P}<0.001$ \\
\hline Fig. $3 \mathrm{~h} 2.5 \mathrm{~Hz}$ & Glass VS NW arrays & Glass: $n=3, N W$ arrays: $n=4$ & $\begin{array}{l}\text { Two-way RM ANOVA test } \\
\text { with Tukey post-hoc test. }\end{array}$ & $\mathrm{F}=1.644, \mathrm{P}<0.001$ \\
\hline Fig. $3 \mathrm{~h} 3.3 \mathrm{~Hz}$ & Glass VS NW arrays & Glass: $n=3, N W$ arrays: $n=4$ & $\begin{array}{l}\text { Two-way RM ANOVA test } \\
\text { with Tukey post-hoc test. }\end{array}$ & $\mathrm{F}=0.1201, \mathrm{P}<0.001$ \\
\hline Fig. $3 \mathrm{~h} 5 \mathrm{~Hz}$ & Normal VS NW arrays & Normal: $n=3, N W$ arrays: $n=4$ & $\begin{array}{l}\text { Two-way RM ANOVA test } \\
\text { with Tukey post-hoc test. }\end{array}$ & $\mathrm{F}=0.4393, \mathrm{P}=0.0071$ \\
\hline Fig. $3 \mathrm{~h} 5 \mathrm{~Hz}$ & Glass VS NW arrays & Glass: $n=3, N W$ arrays: $n=4$ & $\begin{array}{l}\text { Two-way RM ANOVA test } \\
\text { with Tukey post-hoc test. }\end{array}$ & $\mathrm{F}=0.4393, \mathrm{P}<0.001$ \\
\hline Fig. $4 \mathrm{c}$ & Normal VS Glass & Normal: $n=5$, Glass: $n=3$ & $\begin{array}{l}\text { One-way ANOVA with } \\
\text { Tukey post-hoc test. }\end{array}$ & $\mathrm{F}=3.102, \mathrm{P}<0.001$ \\
\hline
\end{tabular}




\begin{tabular}{|c|c|c|c|c|}
\hline Fig. $4 \mathrm{c}$ & Normal VS NW arrays & Normal: $n=5, N W$ arrays: $n=4$ & $\begin{array}{l}\text { One-way ANOVA with } \\
\text { Tukey post-hoc test. }\end{array}$ & $\mathrm{F}=3.102, \mathrm{P}=0.002$ \\
\hline Fig. $4 \mathrm{c}$ & Glass VS NW arrays & Glass: $n=3, N W$ arrays: $n=4$ & $\begin{array}{l}\text { One-way ANOVA with } \\
\text { Tukey post-hoc test. }\end{array}$ & $\mathrm{F}=3.102, \mathrm{P}<0.001$ \\
\hline Fig. $4 \mathrm{i}$ & Normal VS NW arrays & Normal: $n=111, N W$ arrays: $n=13$ & Unpaired t-test & $\mathrm{t}=4.098, \mathrm{P}=0.072$ \\
\hline Fig. 41 & Normal VS Blind & Normal: $n=3$, Blind: $n=4$ & $\begin{array}{l}\text { One-way ANOVA with } \\
\text { Tukey post-hoc test. }\end{array}$ & $\mathrm{F}=1.010, \mathrm{P}=0.0047$ \\
\hline Fig. 41 & Blind VS NW arrays & Blind: $n=4, N W$ arrays: $n=4$ & $\begin{array}{l}\text { One-way ANOVA with } \\
\text { Tukey post-hoc test. }\end{array}$ & $\mathrm{F}=1.010, \mathrm{P}=0.0207$ \\
\hline Fig. $4 \mathrm{~m}$ & Normal VS NW arrays & Normal: $n=8, N W$ arrays: $n=6$ & Unpaired t-test & $\mathrm{t}=1.632, \mathrm{P}=0.1287$ \\
\hline Fig. $5 d$ & Before VS 84 days after implant & $\begin{array}{l}\text { Before: } n=3,84 \text { days after implant: } \\
n=3\end{array}$ & Paired t-test & $\mathrm{t}=3.112, \mathrm{P}=0.0358$ \\
\hline Fig. 7f & 14 15 weeks: Red VS Blue & Red: $n=5$, Blue: 4 & $\begin{array}{l}\text { One-way ANOVA with } \\
\text { Tukey post-hoc test. }\end{array}$ & $\mathrm{F}=0.06668, \mathrm{P}=0.006$ \\
\hline Fig. $7 f$ & 14 15 weeks: Red VS UV & Red: $n=5, U V: n=5$ & $\begin{array}{l}\text { One-way ANOVA with } \\
\text { Tukey post-hoc test. }\end{array}$ & $\mathrm{F}=0.06668, \mathrm{P}=0.003$ \\
\hline Extended Data Fig. 3c & $\begin{array}{l}\text { Blind mice with NW arrays implant } \\
\text { in group } 1 \text { VS group } 2\end{array}$ & Group 1: $n=4$, Group 2: $n=4$ & $\begin{array}{l}\text { One-way ANOVA with } \\
\text { Tukey post-hoc test. }\end{array}$ & $\mathrm{F}=4.707, \mathrm{p}=0.0094$ \\
\hline Extended Data Fig. 3d & Normal VS NW arrays & Normal: $n=6, N W$ arrays: $n=6$ & $\begin{array}{l}\text { One-way ANOVA with } \\
\text { Tukey post-hoc test. }\end{array}$ & $\mathrm{F}=8.001, \mathrm{P}<0.001$ \\
\hline Extended Data Fig. 3d & Glass VS NW arrays & Glass: $n=6, N W$ arrays: $n=6$ & $\begin{array}{l}\text { One-way ANOVA with } \\
\text { Tukey post-hoc test. }\end{array}$ & $\mathrm{F}=8.001, \mathrm{P}<0.001$ \\
\hline Extended Data Fig. 6i & Before VS 10 12 weeks & Before: $n=20,10 \sim 12$ weeks: $n=14$ & $\begin{array}{l}\text { One-way RM ANOVA with } \\
\text { Dunnett post-hoc test }\end{array}$ & $\mathrm{F}=3.197, \mathrm{P}<0.001$ \\
\hline Extended Data Fig. 6i & Before VS 14 15 weeks & Before: $n=20,14 \sim 15$ weeks: $n=18$ & $\begin{array}{l}\text { One-way RM ANOVA with } \\
\text { Dunnett post-hoc test }\end{array}$ & $\mathrm{F}=3.197, \mathrm{P}<0.001$ \\
\hline
\end{tabular}


Extended Data Movie 1 | Choice-box-based behavioral test of normal mice, blind mice with glass implant and blind mice with NW arrays implant using green LED stimulus.

Extended Data Movie 2 | Choice-box-based behavioral test of normal mice, blind mice with glass implant and blind mice with NW arrays implant using moving visual stimulus.

Extended Data Movie 3 | Choice-box-based behavioral test of normal mice, blind mice with glass implant and blind mice with NW arrays implant using flash visual stimulus.

Extended Data Movie 4 | Visual acuity and contrast sensitivity test of normal mice, blind mice with glass implant and blind mice with NW arrays implant.

Extended Data Movie 5 | Light-evoked responses in V1 neurons through two-photon calcium imaging recording of normal mice, blind mice before implantation and 7 days after implantation.

Extended Data Movie 6 | Visually-guided saccade task of monkey A with red LED stimulus in region of implantation and control.

Extended Data Movie 7 | Visually-guided saccade task of monkey A with blue LED stimulus in region of implantation and control. 


\section{Supplementary Files}

This is a list of supplementary files associated with this preprint. Click to download.

- ExtendedDataMovie1.ChoiceboxbasedbehavioraltestwithgreenLEDlightstimulus.mp4

- ExtendedDataMovie2.Choiceboxbasedbehavioraltestwithmovingvisualstimulus.mp4

- ExtendedDataMovie3.Choiceboxbasedbehavioraltestwithflashvisualstimulus.mp4

- ExtendedDataMovie4.Visualacuityandcontrastsensitivitytest.mp4

- ExtendedDataMovie5.LightevokedresponsesinV1neuronsthroughtwophotoncalciumimagingrecording.mp4

- ExtendedDataMovie6.VisualguidedsaccadetaskwithRedLedstimulus.mp4

- ExtendedDataMovie7.VisualguidedsaccadetaskwithBlueLedstimulus.mp4 